\title{
Waste-To-Energy in the United States: Socioeconomic Factors and the Decision-Making Process
}

T. Randall Curlee

Susan M. Schexnayder

David P. Vogt

Amy K. Wolfe

Michael P. Kelsay

David L. Feldman

Oak Ridge National Laboratory

Oak Ridge, Tennessee

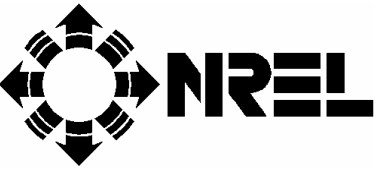

National Renewable Energy Laboratory 1617 Cole Boulevard Golden, Colorado 80401-3393

A national laboratory of the U.S. Department of Energy Managed by Midwest Research Institute for the U.S. Department of Energy under contract No. DE-AC02-83CH10093 


\section{Waste-To-Energy in the}

United States: Socioeconomic

Factors and the Decision-Making

\section{Process}

T. Randall Curlee

Susan M. Schexnayder

David P. Vogt

Amy K. Wolfe

Michael P. Kelsay

David L. Feldman

Oak Ridge National Laboratory

Oak Ridge, Tennessee

NREL technical monitor: Philip B. Shepherd

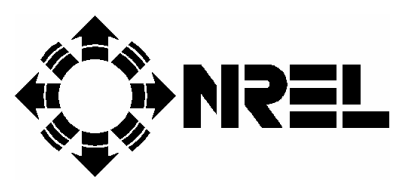

National Renewable Energy Laboratory 1617 Cole Boulevard Golden, Colorado 80401-3393

A national laboratory of the U.S. Department of Energy Managed by Midwest Research Institute for the U.S. Department of Energy under contract No. DE-AC02-83CH10093

Prepared under Subcontract No. DA-1-11246-1

October 1993 


\section{NOTICE}

NOTICE; This report was prepared as an account of work sponsored by an agency of the United States government. Neither the United States government nor any agency thereof, nor any of their employees, makes any waranty, express or implied, or assumes any legal liability or responsibility for the accuracy. completeness, or usefulness of any information, apparatus, product, or process disclosed, or represents that its use would not infringe privately owned rights. Reference herein to any specific commercial product, process, or service by trade name, trademark, manufacturer, or athenwise does not necessarily constitute or imply its endorsement, recommendation, or favoring by the United States government or any agency thereot. The views and opinions of authors expressed herein do not necessarily state or reflect those of the United States govemment or any agency thereof.

Printed in the United States of America

Available from:

National Technical Information Service

U.S. Department of Commerce

5285 Port Royal Road

Spring field, VA 22161

Price: Microfiche A01

Printed Copy A08

Codes are used for pricing all publications. The code is determined by the number of pages in the publication. Intormation pertaining to the pricing codes can be found in the current issue of the following publications which are generally available in most libranies: Energy Research Abstracts (ERA); Government Reports Announcements and Index (GRA and I); Scientific and Technical Abstract Reports (STAR); and publication NTIS-PR-360 available from NTIS at the above address. 


\section{ACKNOWLEDGEMENTS}

The authors would like to acknowledge and thank the numerous individuals who made significant contributions in the research and preparation of this report. Mr. Scott Rickard, an economics graduate student at the University of Tennessee, contributed excellent data and graphics support. Mss. Cynthia Moody, Kathy Ballew, Judy Burns, and Mariann Huskey industrious and timely secretarial support and helped in meeting an ambitious delivery schedule.

We would like to thank our sponsors from the National Renewable Energy Laboratory, Messrs. Philip Shepherd and Bimleshwar Gupta, and the U.S. Department of Energy contact for this work, Mr. Simon Friedrich. Our conversations over the course of this study were invaluable in terms of identifying contacts and data sources and in establishing a general project direction.

Particular thanks go to all the individuals who made the case-study segment of this work possible. We greatly appreciate their time and valued insights into how the decision-making process works. Our thanks also go to those individuals who provided background data and information, in particular Mr. Jonathan Kiser of the Integrated Waste Services Association, Mr. Jim Glenn of BioCycle magazine, Mr. Steve Brown of the Council of State Governments, Mr. Dwight Conner of the National Conference of State Legislators, Mr. Steve Teslik of the Partnership for Plastics Progress, and Dr. Booker Morey of the Stanford Research Institute. 


\section{TABLE OF CONTENTS}

LIST OF FIGURES $\ldots \ldots \ldots \ldots \ldots \ldots \ldots \ldots \ldots \ldots \ldots \ldots \ldots \ldots \ldots \ldots \ldots \ldots$

LIST OF TABLES $\ldots \ldots \ldots \ldots \ldots \ldots \ldots \ldots \ldots \ldots \ldots \ldots \ldots \ldots \ldots \ldots$

EXECUTTVE SUMMARY $\ldots \ldots \ldots \ldots \ldots \ldots \ldots \ldots \ldots \ldots \ldots \ldots \ldots \ldots$ viii

CHAPTER 1. INTRODUCTION $\ldots \ldots \ldots \ldots \ldots \ldots \ldots \ldots \ldots \ldots \ldots \ldots \ldots \ldots \ldots$

1.1 THE MOTIVATION FOR THIS STUDY $\ldots \ldots \ldots \ldots \ldots \ldots \ldots$

1.2 THE STUDY'S GENERAL APPROACH $\ldots \ldots \ldots \ldots \ldots \ldots \ldots \ldots$

CHAPTER 2. WASTE-TO-ENERGY IN THE UNITED STATES AND KEY

SOCIOECONOMIC FACTORS $\ldots \ldots \ldots \ldots \ldots \ldots \ldots \ldots \ldots \ldots \ldots$

2.1 INTRODUCTION ....................... 4

2.2 ANALYSIS OF COMMUNITIES WITH WASTE-TO-ENERGY

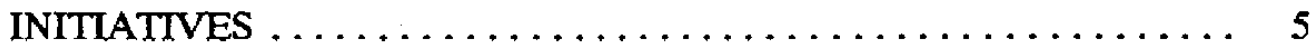

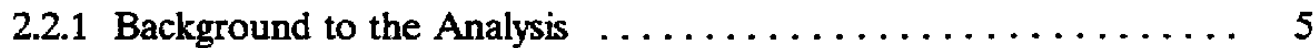

2.2.2 Demographic Settlement Patterns . . . . . . . . . . . . 12

2.2.3 County Population Socioeconomic Characteristics . . . . . . . . 18

2.2.4 Availability of Waste Management Alternatives $\ldots \ldots \ldots \ldots 21$

2.2.5 The Local Climate for Environmental Concern . . . . . . . . . . . 26

2.2 .6 Multiple Factor Analysis . . . . . . . . . . . . . . 30

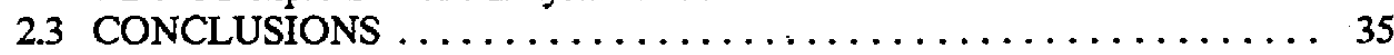

CHAPTER 3. WTE AND FINANCIAL ISSUES $\ldots \ldots \ldots \ldots \ldots \ldots \ldots \ldots \ldots \ldots$

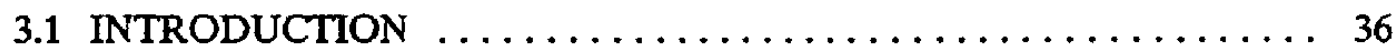

3.2 THE INCREASING COSTS OF WTE FACILITIES . . . . . . . 37

3.3 FEDERAL TAX POLICX ....................... 39

3.4 OTHER FINANCLAL CONSTRAINTS ON LOCAL

JURISDICTIONS ...................... 42

3.5 ADJUSTMENTS IN THE FINANCING OF WTE PROJECTS . . . . . 42

3.5.1 Advanced-Planned and Operational Facilities . . . . . . . . 43

3.5 .2 Cancelled Facilities . . . . . . . . . . . . . . . . . . . 47

3.6 SUMMARY AND FUTURE OUTLOOK $\ldots \ldots \ldots \ldots \ldots \ldots \ldots \ldots$

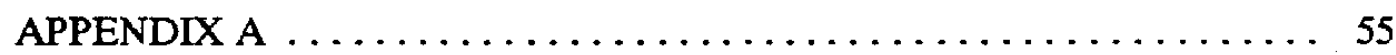

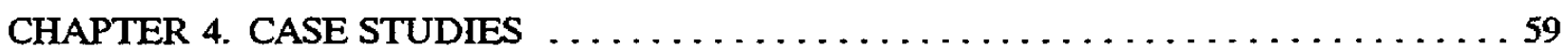

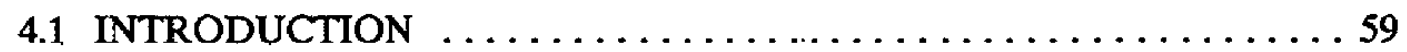

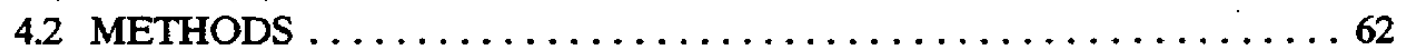

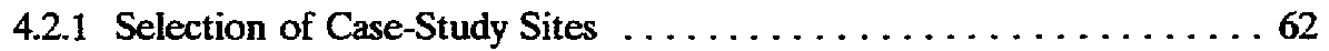

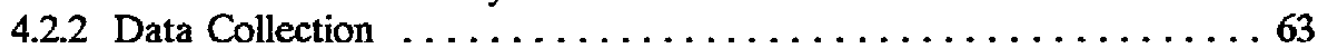

4.2.2.1 Selection of Respondents . . . . . . . . . . . 63

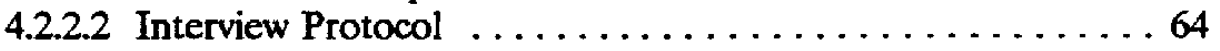

4.2 .3 Analytical Methods .................... 64 
4.3 BROWARD COUNTY, FLORIDA $\ldots \ldots \ldots \ldots \ldots \ldots \ldots \ldots \ldots \ldots$

4.3.1 Waste Management Context . . . . . . . . . . . . . . 66

43.2 Previous Siting Controversies $\ldots \ldots \ldots \ldots \ldots \ldots \ldots \ldots \ldots \ldots 6 \ldots \ldots 6$

4.3.3 Decision-Making Process . . . . . . . . . . . . . . . 66

4.3.3.1 Events ......................66

4.3.3.2 Participation ..................... 69

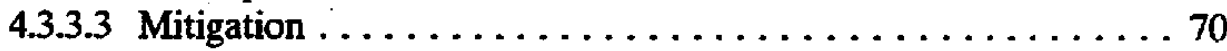

4.3.3.4 Regulations and Laws $\ldots \ldots \ldots \ldots \ldots \ldots \ldots \ldots \ldots$

4.3 .4 Decision-Making Issues $\ldots \ldots \ldots \ldots \ldots \ldots \ldots \ldots \ldots \ldots$

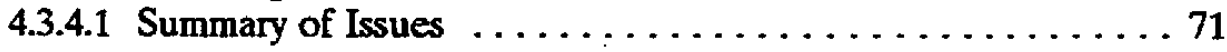

4.3.4.2 Public Attitudes and Participants' Relations . . . . . . 72

4.3.5 Improving the Decision-Making Process $\ldots \ldots \ldots \ldots \ldots \ldots 73$

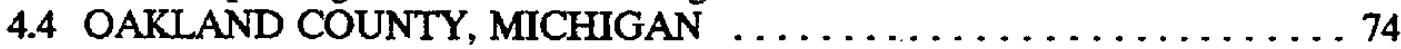

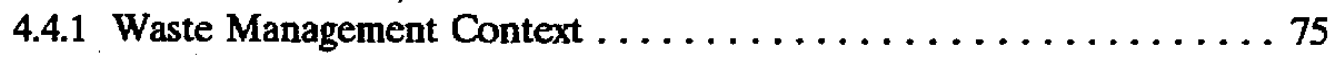

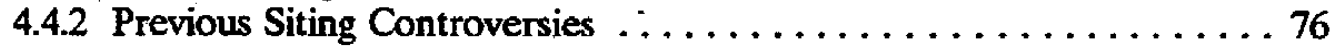

4.4.3 Decision-Making Process $\ldots \ldots \ldots \ldots \ldots \ldots \ldots \ldots \ldots 77$

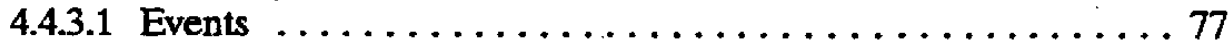

4.4.3.2 Participation $\ldots \ldots \ldots \ldots \ldots \ldots \ldots \ldots \ldots \ldots \ldots \ldots \ldots$

4.4.3.3 Mitigation ...................... 82

4.4.3.4 Regulations and Laws $\ldots \ldots \ldots \ldots \ldots \ldots \ldots \ldots \ldots \ldots$

4.4.4 Decision-Making Issues $\ldots \ldots \ldots \ldots \ldots \ldots \ldots \ldots \ldots \ldots$

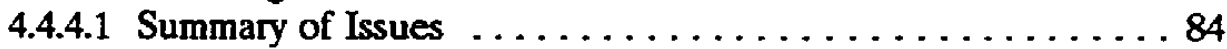

4.4.4.2 Public Attitudes and Participants' Relations . . . . . . . . 84

4.4.5 Improving the Decision-Making Process . . . . . . . . . . 85

4.5 KNOX COUNTY, TENNESSEE $\ldots \ldots \ldots \ldots \ldots \ldots \ldots \ldots \ldots \ldots$

4.5.1 Waste Management Context . . . . . . . . . . . . . . 87

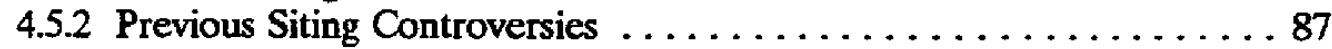

4.5.3 Decision-Making Process $\ldots \ldots \ldots \ldots \ldots \ldots \ldots \ldots \ldots \ldots$

4.5.3.1 Events $\ldots \ldots \ldots \ldots \ldots \ldots \ldots \ldots \ldots \ldots \ldots \ldots \ldots \ldots$

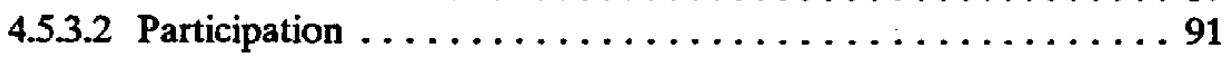

4.5.3.3 Mitigation ....................... 93

4.5.3.4 Regulations and Laws . . . . . . . . . . . . 93

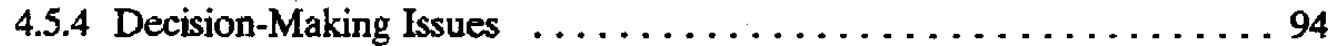

4.5.4.1 Summary of Issues . . . . . . . . . . . . . . 94

4.5.4.2 Public Attitudes and Participants' Relations . . . . . . . . . 95

4.5.5 Improving the Decision-Making Process . . . . . . . . . . . 95

4.6 MONMOUTH COUNTY, NEW JERSEY . . . . . . . . . . . . 96

4.6.1 Waste Management Context . . . . . . . . . . . . . . . 96

4.6.2 Previous Siting Controversies . . . . . . . . . . . . . . 97

4.6.3 Decision-Making Process . . . . . . . . . . . . . . . 97

4.6.3.1 Events $\ldots \ldots \ldots \ldots \ldots \ldots \ldots \ldots \ldots \ldots \ldots \ldots \ldots \ldots \ldots \ldots$

4.6.3.2 Participation . . . . . . . . . . . . . . . 100

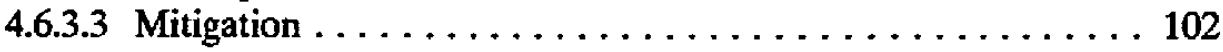

4.6.3.4 Regulations and Laws . . . . . . . . . . . . 102

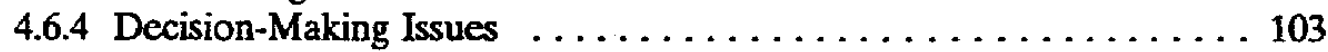

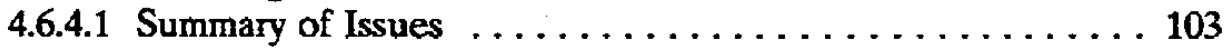

4.6.4.2 Public Attitudes and Participants' Relations . . . . . . . 104

4.6.5 Improving the Decision-Making Process . . . . . . . . . . . 105 


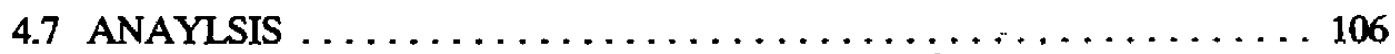

4.7.1 Decision-Making Process $\ldots \ldots \ldots \ldots \ldots \ldots \ldots \ldots \ldots \ldots \ldots \ldots \ldots \ldots$

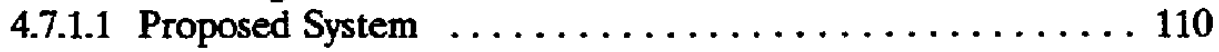

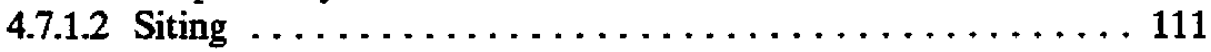

4.7.1.3 Interaction Among Parties $\ldots \ldots \ldots \ldots \ldots \ldots \ldots \ldots \ldots \ldots \ldots \ldots$

4.7.1.4 Public Participation ...................... 115

4.7.1.5 Catalysts Driving the Project . . . . . . . . . . . 116

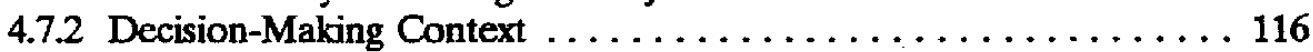

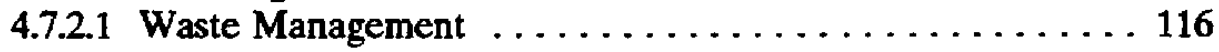

4.7.2.2 Key Demographic Variables . . . . . . . . . . . . 117

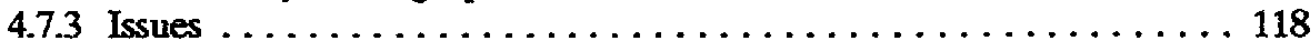

4.8 SUMMARY AND FUTURE OUTLOOK $\ldots \ldots \ldots \ldots \ldots \ldots \ldots \ldots$

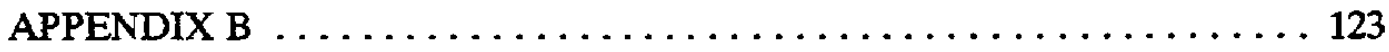

CHAPTER 5. CONCLUSIONS $\ldots \ldots \ldots \ldots \ldots \ldots \ldots \ldots \ldots \ldots \ldots \ldots \ldots \ldots \ldots \ldots \ldots \ldots \ldots \ldots \ldots$

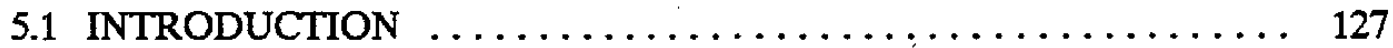

5.2 FINDINGS FROM AN AGGREGATE PERSPECTIVE $\ldots \ldots \ldots \ldots 127$

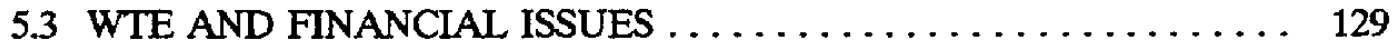

5.4 CASE STUDY RESULTS $\ldots \ldots \ldots \ldots \ldots \ldots \ldots \ldots \ldots \ldots \ldots \ldots$

5.5 SUMMARY CONCLUSIONS $\ldots \ldots \ldots \ldots \ldots \ldots \ldots \ldots \ldots \ldots \ldots \ldots$

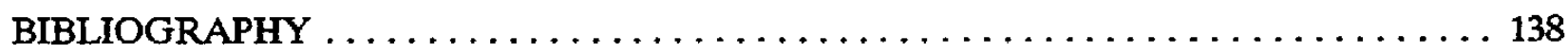




\section{LIST OF FIGURES}

Figure

$2.1 \quad$ WTE Initiatives by County Size $\ldots \ldots \ldots \ldots \ldots \ldots \ldots \ldots \ldots \ldots \ldots \ldots \ldots$

2.2 Counties with Existing and Planned WTE Facilities $\ldots \ldots \ldots \ldots \ldots \ldots \ldots \ldots \ldots \ldots$

2.3 Counties with Existing and Planned Facilities or Cancelled Initiatives $\ldots \ldots \ldots \ldots . .9$ 


\section{LIST OF TABLES}

$2.1 \quad$ Distribution of WTE Counties by WTE Involvement $\ldots \ldots \ldots \ldots \ldots \ldots \ldots \ldots \ldots$

2.2 Distribution of WTE Initiative Counties by Status of Initiatives $\ldots \ldots \ldots \ldots \ldots \ldots \ldots$

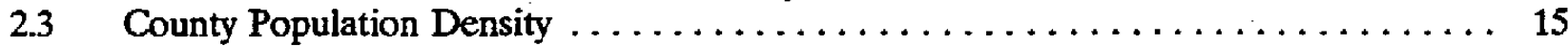

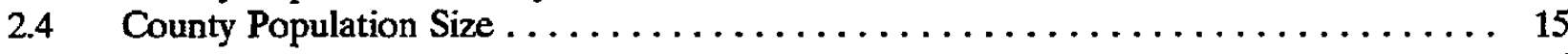

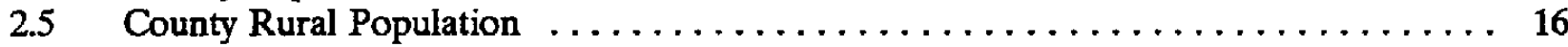

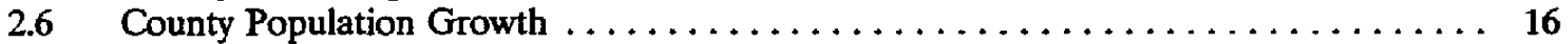

2.7 County Population with High School Degrees $\ldots \ldots \ldots \ldots \ldots \ldots \ldots \ldots \ldots \ldots$

2.8 County Per-Capita Income $\ldots \ldots \ldots \ldots \ldots \ldots \ldots \ldots \ldots \ldots \ldots \ldots \ldots \ldots \ldots \ldots$

2.9 County Population at Family Formation Age $\ldots \ldots \ldots \ldots \ldots \ldots \ldots \ldots \ldots$

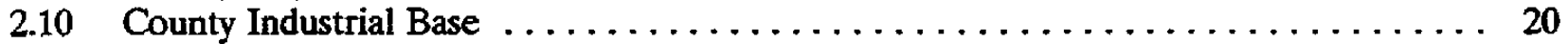

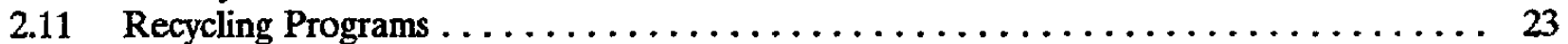

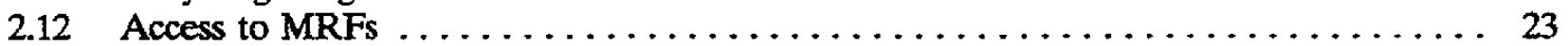

2.13 Access to Landfills ................................. 25

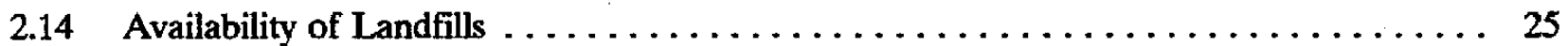

2.15 County Municipal Solid Waste Disposal Expenditures $\ldots \ldots \ldots \ldots \ldots \ldots \ldots \ldots$

2.16 Membership in Conservation Groups $\ldots \ldots \ldots \ldots \ldots \ldots \ldots \ldots \ldots \ldots \ldots$

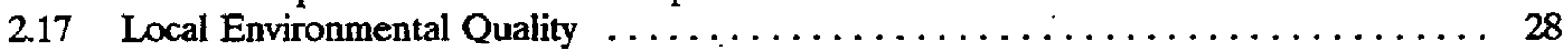

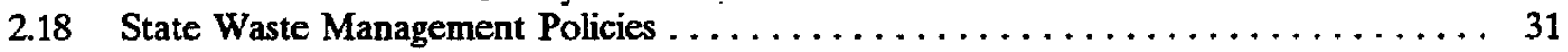

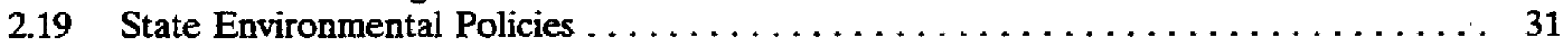

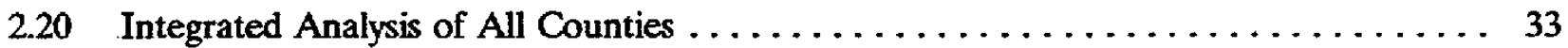

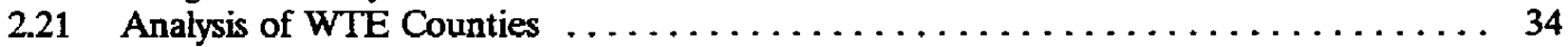

3.1 Waste-to-Energy Facility Adjusted Capital Costs: 1982-1990 . . . . . . . . . . . . 38

3.2 WTE Facility Design Capacities: $1990 \ldots \ldots \ldots \ldots \ldots \ldots \ldots \ldots \ldots \ldots$

3.3 WTE Design Capacity by Region: Advanced-Planned and Existing Facilities (1990) .. 40

3.4 WTE Capital Finance: Historical Trends of Finance $\ldots \ldots \ldots \ldots \ldots \ldots \ldots \ldots \ldots$

3.5 Alternative Methods of Finance: Advanced-Planned and Existing WTE Facilities

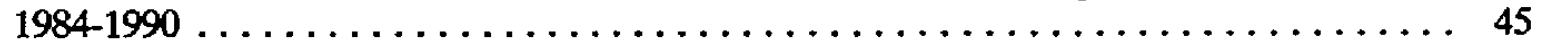

3.6 WTE Capital Finance Mechanisms: $1990 \ldots \ldots \ldots \ldots \ldots \ldots \ldots \ldots \ldots \ldots$

3.7 WTE Capital Finance Mechanisms at Cancelled Facilities by Type:

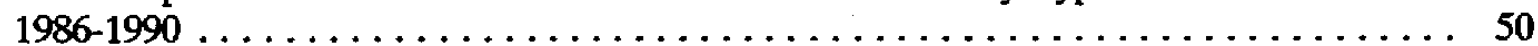

3.8 WTE Capital Finance Mechanisms at Cancelled Facilities by Finance Amount: $1986-1990 \ldots \ldots \ldots \ldots \ldots \ldots \ldots \ldots \ldots \ldots \ldots \ldots \ldots$

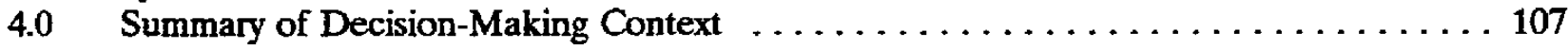

$4.1 \quad$ Summary of Decision-Making Process $\ldots \ldots \ldots \ldots \ldots \ldots \ldots \ldots \ldots \ldots \ldots \ldots$ 


\title{
WASTE-TO-ENERGY IN THE UNITED STATES: SOCIOECONOMIC FACTORS AND THE DECISION-MAKING PROCESS
}

\author{
EXECUTIVE SUMMARY
}

\section{INTRODUCTION}

Municipal solid waste (MSW) combustion with energy recovery, commonly called waste-toenergy (WTE), was adopted by many U.S. communities during the 1980 s to manage their growing quantities of MSW. Although less than one percent of all U.S. MSW was burned to retrieve its heat energy in 1970, WTE grew to account for 16 percent of MSW in 1990, and many experts forecasted that WTE would be used to manage as much as half of all garbage by the turn of the century.

However, the growth of WTE has been reduced in recent years by project cancellations. This study takes an in-depth look at the socioeconomic factors that have played a role in the decisions of communities that have considered WTE as a component of their solid waste management strategies. More specifically, a three-pronged approach is adopted to investigate (1) the relationships between a municipality's decision to consider and accept/reject WTE and key socioeconomic parameters, (2) the potential impacts of recent changes in financial markets on the viability of WTE, and (3) the WTE decision-making process and the socioeconomic parameters that are most important in the municipality's decision. The first two objectives are met by the collection and analysis of aggregate data on all U.S. WTE initiatives during the 1982 to 1990 time frame. The latter objective is met by way of four in-depth case studies-two directed at communities that have accepted WTE and two that have cancelled WTE projects.

\section{THE SOCIOECONOMICS OF WTE FROM AN AGGREGATE PERSPECTIVE}

Chapters 2 and 3 of this report present the results of an intensive data collection and analysis exercise in which information about each existing, planned, and cancelled WTE project was collected and studied. Numerous potential relationships between decisions about WTE and local socioeconomic characteristics are examined.

This work has identified a total with 354 counties WTE initiatives. Almost two-thirds of all WTE initiatives have occurred in metropolitan counties-with 54 percent of the total in metro counties with populations in excess of 100,000 . Non-metropolitan counties account for 30 percent of initiatives.

The study concludes that non-metro counties have scratched relatively more facilities than metro counties-41 percent of all initiatives in non-metro counties and 37 percent in metro counties. Counties with WTE initiatives are generally wealthier, more educated (i.e., percent completing high school), less blue collar (i.e., percent of workers in manufacturing, mining, and construction), less rural (i.e., percent of population in a rural environment), and have a higher percentage of individuals in what is called the "builder" stage (i.e., 22 to 39 years old). Counties that have WTE initiatives are more likely to have existing recycling programs and material recovery facilities (MRFs). There is no 
identifiable relationship between the availability of landfills (measured in terms of number of landfills per capita) and the decision to consider WTE; and there is no significant difference between WTE and non-WTE counties in terms of population growth. Communities in states with stronger environmental regulations and incentives and goals for recycling are also more likely to have considered WTE. Communities that have considered WTE facilities have average populations of about 385,000 , as compared to communities that have not had WTE initiatives with average populations of only 41,000 . Within those metropolitan counties that have actively considered WTE, larger and less rural populations appear to be key characteristics. The same conclusions are generally true for WTE initiatives in non-metro counties.

Therefore, the results suggest numerous differences between counties that have formally considered a WTE initiative and those counties that have not. Possibly more important, however, is the finding that there are virtually no differences between counties with existing WTE facilities and counties that have cancelled WTE projects. In other words, when only those counties that have had a WTE initiative are considered, there are no significant differences between communities that see those initiatives through to completion and those communities that cancel their projects at some point in the planning process. If there are particular socioeconomic factors that have contributed to the cancellations of WTE projects during recent years, they are factors other than those considered in this segment of this study.

\section{FINANCIAL ISSUES}

Chapter 3 of this report focuses specifically on the financial trends that occurred during the 1980 s and early 1990 s that may have contributed to WTE project cancellation and altered the relative attractiveness of WTE. Three major trends are assessed. First, the costs of WTE facilities escalated during this period, as many communities moved toward large mass-burn and refuse-derived-fuel facilities. Second, federal tax policy took a major turn in 1986 with the enactment of the Tax Reform Act (TRA86), which placed limits on the local government's ability to finance WTE and other projects with federally tax-exempt financing. Third, trends, such as increased demands for other environmental infrastructure, local and state tax and expenditure limitations, and difficulties in accessing national capital markets, hindered some financial packages.

During the 1980s, the federal government imposed new restrictions on the types of local debt that could qualify for federal tax-exempt status and placed unified volume caps on each state's allotment of tax-exempt, private-activity bonds. In order to qualify as tax-exempt bonds under TRA86, the bonds must be classified as (1) governmental bonds (on which there are no limits), or (2) private-activity bonds that are also "qualified bonds" for solid and hazardous waste facilities (which are subject to unified volume caps). Governmental bonds have their down side in that the municipality must retain an almost proprietary interest in the facility, forego its share of the tax benefits, and observe the restrictions on private use of facilities imposed by TRA86. And in order to be classified as "qualified bonds," a host of restrictions must be met. To the extent that tax-exempt bonds cannot be used to finance WTE facilities, the total cost of project financing will be higher.

Although financial problems exist, this study finds that, in general, municipalities are successfully adjusting to altered financial conditions by taking a four-pronged approach to finance WTE projects. First, local jurisdictions are using a combination of several financing mechanisms in their financial packages. Second, jurisdictions are increasingly using local-sector resources for 
financing (e.g., city and county revenues and taxable revenue bonds). Third, as traditional debt options become less viable because of restrictions imposed by, for example TRA86, innovative and new methods of finance are being used. Fourth, private-sector participation is being used more extensively. Private-sector participation allows local-sector resources to be reallocated elsewhere for other public good consumption.

In terms of the impacts of financial changes on WTE project cancellations, the results are somewhat mixed. Study findings show that most successful WTE projects utilize multiple and innovative forms of finance. Innovative methods of finance were not present in any of the financial packages put together or considered for facilities that were eventually cancelled. It is unclear, however, if the absence of multiple and innovative financing mechanisms was a contributor to the failure of the projects, or if these projects simply did not get far enough down the development path to consider these innovate and possibly less obvious financing strategies.

The unified volume caps may have hindered WTE project development, but the magnitude of the problems those caps imposed is not clear. For example, six of the nine states that contributed more than $\mathbf{4 5}$ percent of all WTE project cancellations came close to fully using their caps; and more than $\$ 750$ million in solid-waste financing requests were denied in 1991 as a result of the unified volume caps. However, some states that had several cancellations did not use a high percentage of their allowed caps.

There is little doubt that the restrictions imposed by TRA86 played a significant role in escalating the rate at which WTE projects were introduced in the mid to latter 1980 s. Some projects that might have developed at a more leisurely pace were no doubt "moved along" to avoid the impending financing restrictions of TRA86. If TRA86, in fact, resulted in an upward surge in the number of WTE projects being considered in the mid to latter $1980 \mathrm{~s}$, a follow-on argument is that the number of cancellations also increased even if the probability of a project making it through to operation remained unchanged.

The fundamentals of the long-term bond market are generally positive over the next decade, and, therefore, capital markets should show little strain in funding future expenditures for local environmental projects, such as WTE. The problem is whether local jurisdictions will have the financial ability and, in some cases, the political will to take on higher levels of debt burden. Large, capital-intensive WTE facilities can crowd out other local investments, and some small communities may face obstacles in accessing capital markets.

On the positive side, innovative financial instruments are increasingly available that overcome to some extent the financial obstacles imposed during the 1980s. Adjustments on the parts of capital markets and communities to new financial realities are likely to improve the financial viability of capital-intensive projects, such as WTE facilities. Although financing constraints will continue to be problematic, especially for those communities with questionable credit ratings, financial constraints are not expected to be a "major obstacle" as the overall viability of WTE is determined in the 1990 s. 


\section{THE DECISION-MAKING PROCESS}

Our aggregate analyses of socioeconomic and financial conditions do not draw strong conclusions about differences between communities that begin a WTE project and follow that project through to completion and communities that abandon a project somewhere in the planning process. Socioeconomic parameters do not differ markedly between the two groups; and while certain financial trends do seem to be partially responsible for the increased rate of project cancellation in the late 1980 s, financial constraints do not appear to be the primary force motivating project cancellations. The major challenge faced by proponents, as well as opponents, of WTE may be obstacles in the decision-making process itself.

To better understand the process by which communities make decisions about WTE and identify factors that may contribute to project cancellation, this study undertook four in-depth case studies. At two sites-Oakland County, Michigan and Broward County, Florida-a WTE project was approved, and in the case of Broward County two WTE facilities are now operational. At the two other sites-Monmouth County, New Jersey and Knox County, Tennessee-planned WTE facilities were cancelled. Questions of particular interest in the case studies included the sequence of decision events; the participation of different groups in different steps of the decision process; the degree of agreement at each decision step; the effects of mitigation and compensation at different stages of implementation; the effectiveness of different siting procedures; public attitudes about WTE technologies, costs, and environmental impacts; and any difficulties that may have arisen when several governmental jurisdictions were forced to cooperate or form compacts to site a facility. Chapter 4 of this study provides a detailed discussion of case-study results.

Several general findings result from the study. In general terms, the decision to accept or reject a project does not fall neatly into simple "acceptance" or "rejection" categories. There are degrees of acceptance and rejection. At one extreme is Broward County, where WTE was clearly accepted and two facilities are now operational. Oakland County's mandate to proceed with WTE implementation is less clear. Although a public referendum narrowly approved WTE use, municipalities have failed to sign intergovernmental agreements committing their waste to the county's system. Further, the county currently has no construction and service vendor due to the recent withdrawal of Westinghouse. Monmouth and Knox Counties rejected WTE, but at different stages and in different ways. In Monmouth County, voters rejected a WTE proposal by a very small margin-about the same as the margin by which Oakland Country accepted their project. The Knox County project ended when Knoxville's mayor withdrew his support shortly before bond issuance.

Although comparisons between case studies are made largely in the context of the outcome of the decision-i.e., whether or not to proceed with the project-attention is also paid to the decisionmaking process itself. Examining the decision-making process does not presuppose that either WTE acceptance or rejection is the more desired outcome. It does, however, provide insights into process factors that influence the final WTE decision, even though any one factor affecting the decisionmaking process may not lead to consistent outcomes.

While our small sample size does not support strong conclusions about the WTE population as a whole, the following preliminary findings do stand out. First, selecting among ownership options and negotiating with vendors to provide services were arduous and some of the most time-consuming aspects of decision making at each of the case-study sites. However, facility ownership apparently was not a strong factor affecting the outcome of the decision-making process. 
Second, the size of the proposed facility relative to the size of the waste stream was a significant decision-making factor. Sizing decisions have implications not only for facility costs; they also have important implications for public acceptance of WTE because of resultant opportunities for waste importation and actual or perceived effects on other waste management methods, especially recycling. Study findings do suggest that the timing of WTE implementation relative to other waste reduction and recycling programs are factors affecting WTE decision making.

Third, case study comparisons indicate that there is no clear link between siting activities or site characteristics and the outcome of WTE decision making. For example, systematic site identification processes were undertaken by Broward County, where WTE was accepted, and by Knox County, where WTE was rejected. Both Oakland County and Monmouth County offered considerable financial compensation to the host communities, yet WTE was rejected at Monmouth. Further, though siting literature suggests that a technically correct, systematic, and comparative siting process is essential to siting a WTE facility, case-study siting activities suggest that a participant can be satisfied that a proposed site is technically and environmentally suitable in the absence of multi-site comparisons.

Fourth, there are clear differences between Broward and the other case-study sites in terms of the types of interaction that occurred and the level of agreement among participants. Broward's negotiations with its member municipalities occurred against a backdrop of generally satisfactory past relations with its municipalities and a tradition of interaction with the Broward League of Cities. In contrast, for example, Knox County and Knoxville have had a troubled relationship. None of the case-study counties' member municipalities were completely supportive of the WTE project, and patterns of mistrust that resulted from unrelated matters were found to affect WTE planning.

Fifth, having state-level support for WTE apparently influences WTE decisions. WTE planners and decision makers attempt to follow state guidelines for solid waste management whether or not the guidelines are encoded as law. As a result, state positions supporting WTE (often expressed as goals) facilitate WTE adoption at the local level. Complete or partial withdrawal of state support for WTE slows the decision-making process when permits are delayed or moratoria are enacted. Also, and as is concluded from the case studies, the public may be swayed by the positions of state governments because the public may perceive state staff to be better trained and more qualified than local government staff. Likewise, having constant and near unanimous support from county officials significantly influences the decision-making outcome.

Sixth, perception of need for waste management capacity is likely to have contributed to agreement in Broward County. Closure of the county landfill and projections of continuing population growth may have made Broward's decision makers and the public perceive a dire need for a WTE facility. At the other sites the public perceived no such urgency and urged decision makers to delay action.

Seventh, case-study respondents uniformly agreed that the public must be informed about solid waste management issues and activities early in the planning process. There were strong, though not unanimous, recommendations for improving the decision-making process by involving the public, but few concrete suggestions about how this might be accomplished. Facilitating public participation in the decision-making process will not produce uniform decisions to adopt WTE, a point acknowledged by all respondents. However, dissatisfaction with decision-making that generally excludes or makes public participation difficult, exacerbates opposition to the decision. 
Finally, the general solid waste management experience of sites where WTE has been accepted differs from that where WTE was rejected. It may be that alone none of the contextual factors at sites where WTE was accepted-e.g., contaminated landfills, experience with waste combustion, and limited opportunities for waste exportation-are significant enough to affect WTE decisions. In concert, however, the occurrence of these factors at case-study sites where WTE has been accepted suggests that such experience positively influences acceptance of WTE.

\section{SUMMARY CONCLUSIONS}

Although the conclusions of this study are numerous and varied, several summary findings are particularly significant in the assessment of WTE project cancellations. First, on the basis of our aggregate socioeconomic analysis, there are marked differences between communities that initiate a WTE project and those communities that have not yet considered WTE. Socioeconomic differences do not, however, correlate with the decision to either proceed with or cancel a WTE project. Second, the study's financial analysis identifies several trends that made WTE financing more difficult in the latter 1980s; but that analysis does not conclude that financial barriers were the predominant reason for WTE project cancellations, nor are those financial constraints likely to seriously restrict the further development of WTE in the coming decade. Third, the case studies identify numerous complexities that community leaders and decision-makers must address when making a decision about WTE or most other methods to manage municipal waste. Once a WTE project has been initiated, the decision to proceed with or abandon that project appears to depend largely on the dynamics of the decision-making process and the interactions of concerned parties. 


\section{CHAPTER 1. INTRODUCTION}

\subsection{THE MOTIVATION FOR THIS STUDY}

This report documents the findings of a study sponsored by the National Renewable Energy Laboratory (NREL) for the U.S. Department of Energy and conducted by the Oak Ridge National Laboratory (ORNL) to investigate the socioeconomic factors that have contributed to waste-to-energy (WTE) project cancellations in recent years. More specifically, the study investigated (1) the relationships between a municipality's decision to consider and accept/reject WTE and key socioeconomic parameters, (2) the potential impacts of recent changes in financial markets on the viability of WTE, and (3) the WTE decision-making process and the socioeconomic parameters that are most important in the municipality's decision. The first two objectives were met by the collection and analysis of aggregate data on all U.S. WTE initiatives during the 1982 to 1990 time frame. The latter objective was met by way of four in-depth case studies-two directed at communities that have accepted WTE and two that have cancelled WTE projects.

\subsection{THE STUDY'S GENERAL APPROACH}

The approach used in this work was to first collect and assess publicly-available information and data on WTE in the United States and the various socioeconomic factors that may have played a role in recent project cancellations. Given that current information and data are better in some areas of concern than in others, a three-pronged approach was selected to utilize available information most effectively and cover the widest range of socioeconomic factors.

The first prong of the study's three-pronged approach is referred to as an "aggregate socioeconomic analysis." The basic question in this part of the study was whether communities that complete WTE projects differ significantly from communities that cancel projects based on state and local socioeconomic and other conditions. To some extent we also explored how communities that 
complete or plan a WTE facility differ from communities that have not yet actively considered WTE. Factors considered within this part of the study included per-capita income, population density, metropolitan versus non-metropolitan areas, population age, education level, and type of industrial/commercial base. This part of the work addressed these issues in the aggregate, or, in other words, relevant information was obtained for the entire population of WTE projects-both those that were completed and those that were cancelled at some stage of the planning process.

The second part of the study focused specifically on financial issues. More specifically, the study investigated whether altered financial conditions have played a major role in recent decisions to abandon WTE projects. This work looked in particular at recent increases in WTE capital costs, the effects of the Tax Reform Act of 1986, and the development and adoption of innovative financing methods that overcome, to some extent, the financial hurdles placed in the way of communities attempting to finance what is likely to be their most expensive public-works project. As with the first part of this study, the financial analysis examined information from the entire population of WTE facilities either built or planned.

The last part of this study took a case-study approach that examines how the decision-making process itself contributes to the community's decision about WTE. The case-study approach also allows an investigation of issues that are not amenable to study at the aggregate level because of data or other limitations. Case studies were done at four sites. At two sites-Oakland County, Michigan and Broward County, Florida-a WTE project was approved, and in the case of Broward County two WTE facilities are now operational. At the two other sites-Monmouth County, New Jersey and Knox County, Tennessee-planned WTE facilities were abandoned. Questions of particular interest in the case studies include the sequence of decision events; the participation of different groups in different steps of the decision process; the effects of mitigation and compensation at different stages of implementation; the effectiveness of different siting procedures; public attitudes about WTE 
technologies, costs, and environmental impacts; and any difficulties that may arise when several governmental jurisdictions are forced to cooperate or form compacts to site a facility successfully.

A note about the scope of this study is appropriate at this point. It was not the purpose of this study to assess technology or environmental considerations attendant to the siting of facilities. Other efforts at NREL and the U.S. Department of Energy are targeted at technology issues. The focus of this study is on socioeconomic factors that have an impact on the selection and viability of WTE as a management option. While technology and environmental issues entered this analysis, they did so only to the extent that those technology and environmental issues were found to alter actual or perceived socioeconomic conditions.

The following chapter presents the resuits of the study's aggregate socioeconomic analysis. Chapter 3 details the findings of this study's financial analysis. Case-study results are summarized in Chapter 4. Summary conclusions are presented in the final chapter. 


\section{CHAPTER 2 WASTE-TO-ENERGY IN THE UNITED STATES AND KEY SOCIOECONOMIC FACTORS}

\section{INTRODUCTION}

This chapter examines a variety of potential relationships between local decisions about WTE and socioeconomic characteristics at an aggregate level. In other words, whereas the case studies examined conditions at four specific sites, this part of the study takes a more global perspective in that data were collected and analyzed for all existing and most cancelled facilities, as well as the states and communities in which those projects were considered. Numerous questions were addressed. For example, does the decision to adopt or abandon a WTE project correlate with socioeconomic characteristics such as per-capita income, population density, population age, educational level, and type of commercial/industrial base? Is there a relationship between population growth and WTE? Are communities with relatively high-cost waste-disposal systems more likely to consider and adopt WTE? Is there a relationship between the existence of an active recycling program and the decision about WTE? Do state legislative mandates to recycle and reduce the quantity of MSW correlate with the adoption or rejection of WTE? Is the consideration and adoption of WTE more likely to occur in states with high-cost and limited landfill capacity? Is a community's ambient air quality related to its decision about WTE? These and other questions are addressed in this chapter.

Before examining how socioeconomic characterics may contribute to decisions to consider and possibly abandon a WTE project, a word of warning is appropriate. Specifically, the emphasis of this work is on identifying relationships, not establishing causality. Because of data limitations and other reasons, this work cannot establish that specific decisions about WTE are "caused" by particular socioeconomic conditions. While relationships can be established, the stronger conclusion of "causality" must await future work. 


\section{ANALYSIS OF COMMUNITIES WIH WASTE-TO-ENERGY INITIATIVES}

\section{Background to the Anabysis}

Government Advisory Associates (GAA) has maintained a detailed database on all planned, operational, and shutdown WTE facilities in the U.S. since the early 1980s. In more recent issues of their publication Resource Recovery Yearbook, GAA has also reported on cancelled WTE projects. Examination of the initiatives listed in the GAA databases from the years 1982, 1984, 1986$87,1988-89$, and 1991 allowed the identification of 351 counties in the contiguous U.S. that have had WTE initiatives.

The GAA data do not allow the development of a comprehensive longitudinal data base containing information about the annual status of each facility since 1980 , and such a data base was not constructed for this work. Rather, a single temporal cross-section of WTE initiatives and facilities was prepared that indicates the status of each initiative as of 1990 . For the purpose of this chapter's analysis we defined four status categories of WTE initiatives. A "planning" status refers to any WTE initiative that is in the conceptually planned, advanced-planned, under construction, or shakedown phase. Operating facilities include all currently built and operating facilities, as well as facilities temporarily shutdown. Cancelled facilities are either projects that never matured beyond the planning stage or facilities that were under construction but never became operational. For those years prior to the time that GAA kept records on cancelled projects, a close examination of planned and existing facilities from one issue to the next allows the identification of cancelled projects. Facilities that became operational, but then were permanently shutdown, are categorized as such.

To assess the relationships between WTE decisions and local socioeconomic characteristics, the WTE facilities were located by county and matched with local socioeconomic data. Organizing the data by counties provided the simplest and most consistent regional unit of analysis for this study. In many regions, local waste management services are a function of county governments; and in those 
cases the county is the appropriate spatial unit of analysis. In those cases where a large city or township provides the bulk of the service in the county, it is expected that the demographic and economic characteristics of the city will also dominate the county statistics. The independent cities of Virginia are an exception, in that their statistics are often reported separately. The approach used for the independent cities in this study was to incorporate the city data with an associated county. ${ }^{1}$

Summary results of this identification process with respect to distribution counties and there type of WTE involvement are summarized in Tables 2.1 and 2.2. Note that some initiatives and counties were deleted from this analysis because of methodological concerns. Specifically, initiatives in Hawaii and Alaska were omitted from the analysis because the county basis of analysis was inappropriate for these states. Several facilities serving military installations also were dropped from the analysis. The WTE initiatives examined are distributed among 351 counties. Some counties have more than one WTE initiative.

For reasons presented later in this discussion, initiatives are disaggregated by metropolitan and non-metropolitan counties. The spatial dispension of the counties that are and have been involved in WTE initiatives are presented in Figures 2.1, 2.2, and 2.3. The U.S. maps are shaded to indicate the counties that have had a WTE initiative of various types during the time period covered in the GAA data bases.

Relatively few of the initiatives have been sponsored by multi-county units, although many WTE initiatives appeared to be dependent on obtaining waste from a wide catchment area. In these cases, the initiative was associated with what appeared to be the county that would most closely reflect the characteristics of the population primarily responsible for deciding on the facility. Also indicated on the map in Figure 2.1 are counties with populations over 500,000 (i.e., high population).

\footnotetext{
${ }^{1}$ This approach follows the model adopted in the National Planning Association's regional demographic and economic data used in the analysis (Terleckyj and Coleman, 1990).
} 


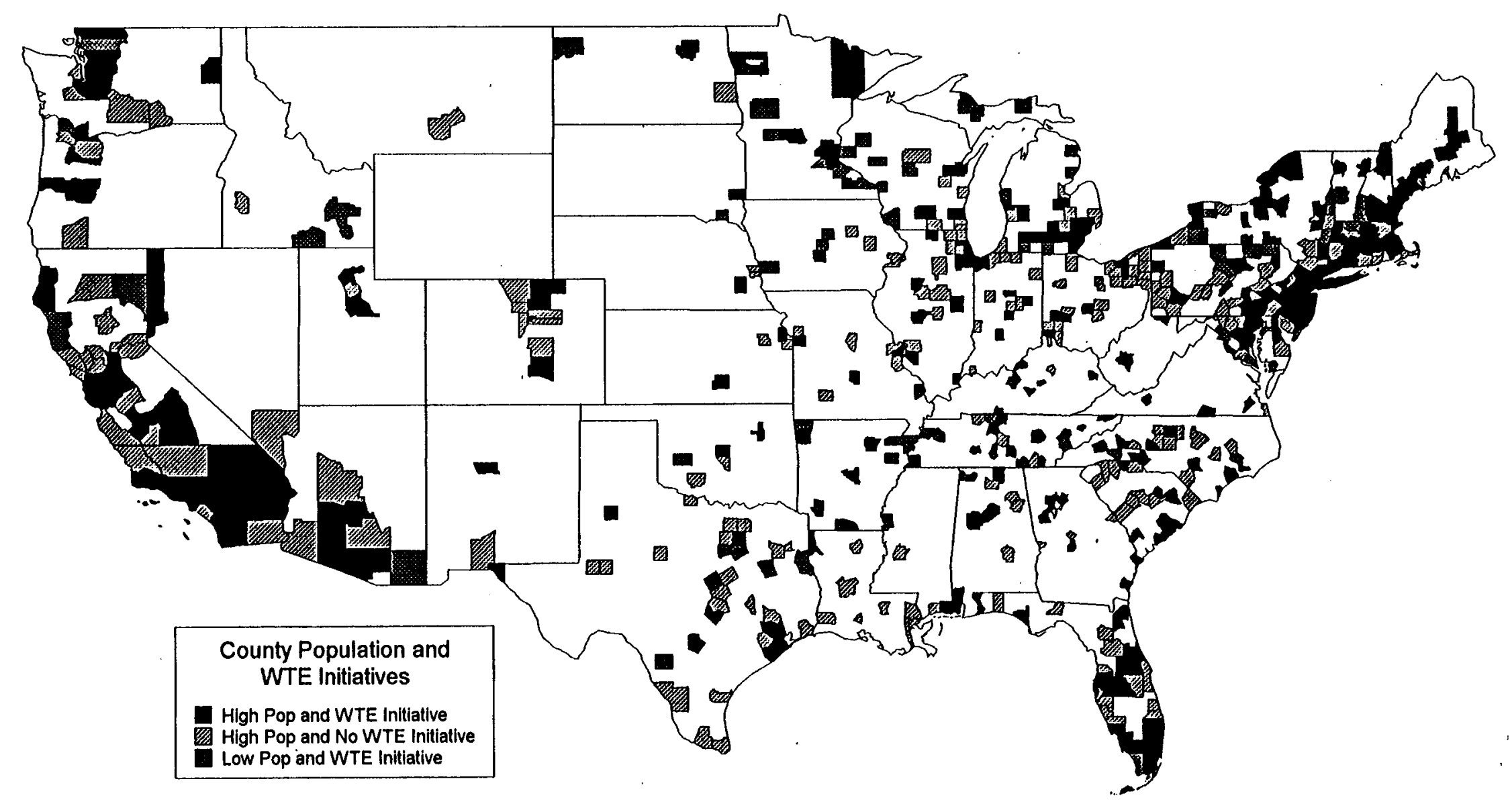

Figure 2.1 WTE Initiatives By County Size 


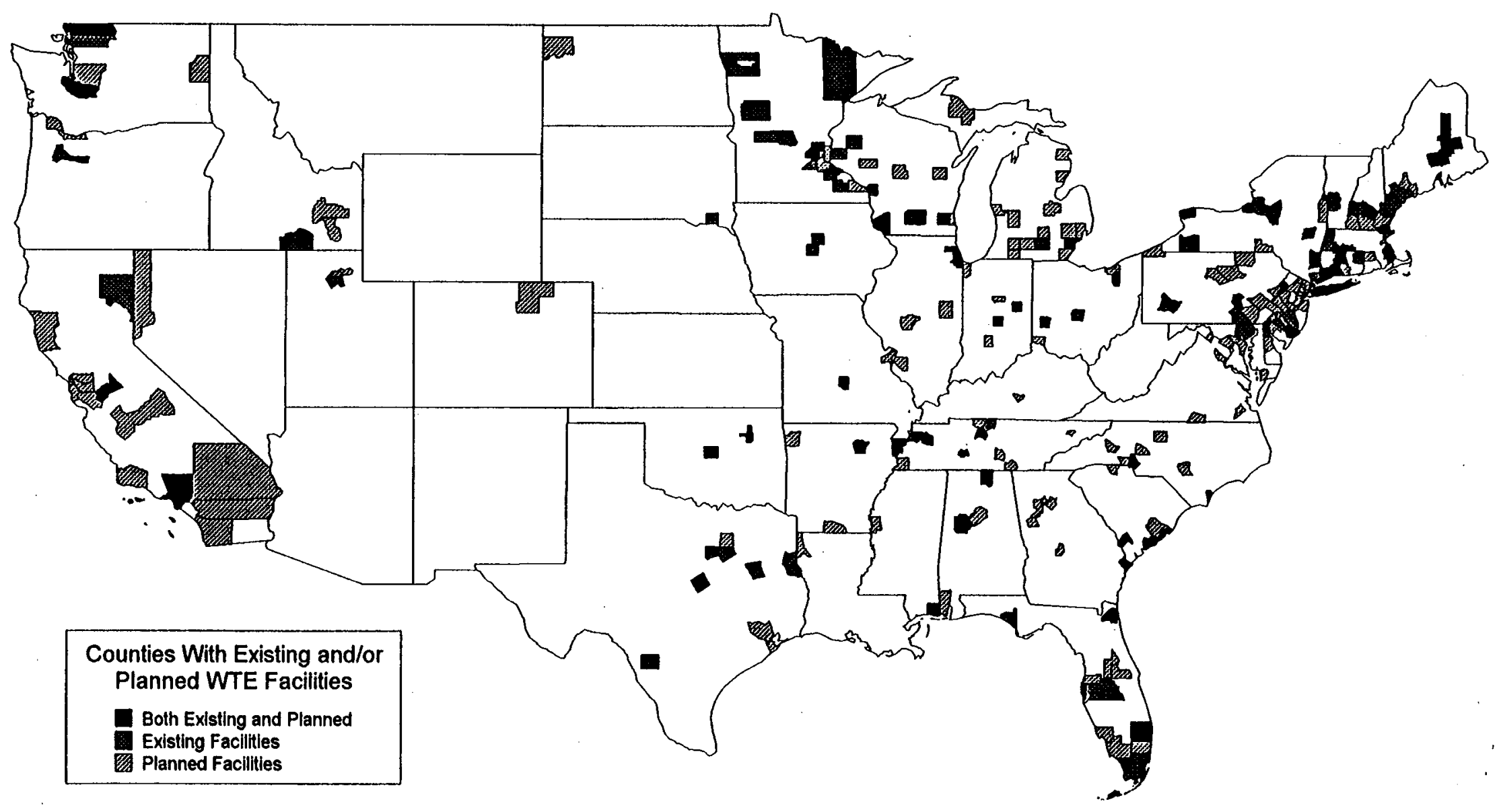

Figure 2.2 Counties with Existing and/or Planned WTE Facilities 


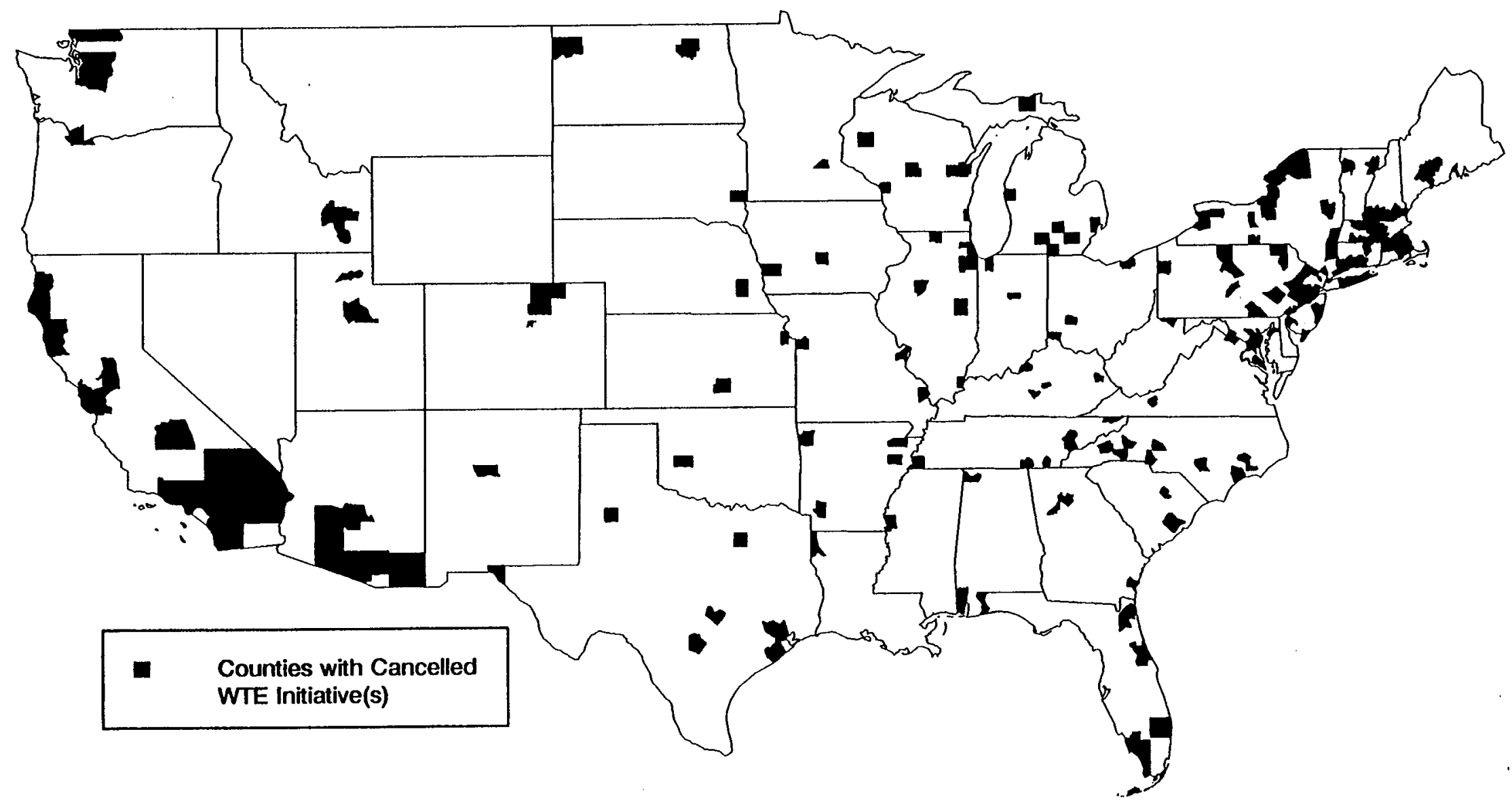

Figure 2.3 Counties with Cancelled Initiatives 
The combination of WTE sites and populous counties depicted in the map indicates that WTE initiatives are primarily a large-county phenomena. Indeed, early in the analysis it was found useful to conduct separate analyses based on the urban orientation of the counties. The U.S. Census Bureau classifies 721 continental U. S. counties as primarily metropolitan in character. These will be referred to as metro counties. The remaining 2,347 counties are referred to as non-metro. Table 2.1 presents a breakdown of WTE initiatives by metro versus non-metro counties. Almost five times as many WTE initiatives occurred in metro areas. However, less than half of the metro areas have had WTE initiatives. In non-metro counties, WTE initiatives took place in only 99 counties, a very small share of the total 2,347 non-metro counties.

The distribution of WTE initiative counties by the status of each initiative is presented in Table 2.2. The total number of counties indicated in this table is greater than in Table 2.1, because a county may have in different status classifications. The county would this be represented in more than one of the status categories listed in Table 2.2 .

A wide variety of data was available for each county from which interesting relationships could be investigated. A primary goal of this exploratory analysis was to identify community characteristics that appeared to be supportive of WTE initiatives, as well as to identify any that were correlated with the cancellation of initiatives. For discussion purposes, it is useful to consider the information collected and analyzed in four distinct sets: (1) the spatial settlement patterns of each community, (2) the socioeconomic characteristics of the local population, (3) the local availability of waste management alternatives and (4) the local climate of environmental concern. Analysis of each set of information was conducted in two parts. First, each of the socioeconomic characteristics in each set was examined independently through a comparison of mean scores for counties categorized by the nature of their WTE involvement. This comparison allowed us to address of questions about, for example, the significance of a relationship between a decision about WTE and county population 


\begin{tabular}{|c|c|c|c|}
\hline WTE Status & Metro Counties & Non-Metro Counties & Total \\
\hline No WTE & 470 & 2,248 & 2,718 \\
\hline With WTE & 252 & 99 & 351 \\
\hline Total & 722 & 2,347 & 3,069 \\
\hline
\end{tabular}

Source: Derived from Government Advisory Associates 1982, 1984, 1986 1987, 1988-1989, 1991.

Table 2.2 Distribution of WTE Initiative Counties by Status of Initiative (number of counties)

\begin{tabular}{||l|c|c|c||}
\hline \multicolumn{5}{|c|}{ (number of counties) } \\
\hline WTE Status & Metro Counties & Non-Metro Counties & Total \\
\hline Planning & 131 & 28 & 159 \\
\hline Operating & 80 & 33 & 113 \\
\hline Shutdown & 25 & 8 & 33 \\
\hline Cancelled & 136 & 48 & 184 \\
\hline Total WTE & 372 & 117 & 489 \\
\hline
\end{tabular}

Source: Derived from Government Advisory Associates 1982, 1984, 19861987, 1988-1989, 1991.

growth. A second step, multiple variable analysis, was also conducted that allows for the simultaneous examination of the complete set of factors. This second step allowed the assessment of questions about, for example, the significance of a relationship between a decision about WTE and county population growth, given that there is a significant relationship between WTE decisions and a number of other explanatory variables.

The following sub-sections introduce each issue area and the selected characteristic variables for that area and then present a comparison of WTE and non-WTE county scores for those variables. Particular attention is also given to any significant differences that can be identified between counties 
that initiate and complete a WTE project and counties that initiate and then cancel a WTE project. However, many of the variables to be examined are correlated with each other. The comparison of means is done primarily to introduce the variables to be considered. As the decision to select or not select a WTE initiative may relate to many characteristics of the counties, a multiple variable analysis needs to be used to more fully capture the impact of all characteristics, to identify each variables own contribution. The final sub-section completes the analysis with a discussion of the multiple regression analysis for the complete set of variables.

\section{Demographic Settlement Patterns}

The design size of WTE facilities has been increasing. This increase suggests (1) that economies of scale are important in the technology or (2) perhaps that some minimum plant size is required for profitable operations. Common sense suggests that size will be important. The catchment area should, for example, provide enough potential waste to support continuous WTE operations. Indeed, the data indicate that WTE initiatives are predominately in the larger metro counties. Additionally, if the sources of municipal waste in a region are highly concentrated due to a dense settlement pattern, the cost per ton of collecting the waste stream may be considerably less than in sparsely settled counties.

One discriminator among counties that could feasibly support a facility is settlement patterns. Large, densely populated counties may, in general, be more favorable toward WTE. Thus, it is of interest to examine whether the size or compactness of the local waste stream is an important determinant in the selection of WTE options. County population settlement patterns can serve as proxies for these characteristics of the waste stream. For this analysis, the relative size of a region's waste stream was measured by the county population, and the density was measured by the population relative to land area (i.e., persons per square mile in the county). A second measure of spatial settlement density-the percent of the population living in rural areas-was also considered in 
this analysis. Finally, a growing region may place greater pressure on solid waste management capacity and may, therefore, be more likely to be involved with a WTE initiative. To test for this characteristic in the analysis, the percentage growth in population from 1980 to 1990 was calculated for all counties. The average population growth of all counties for that ten year period was around four percent. The rate for metro counties (13.6 percent) was significantly greater than the non-metro counties (a low 1.1 percent growth rate).

In the analysis, counties that have had WTE initiatives were compared to counties that have not been involved with WTE. Means for each of the study indicators were calculated for all counties, counties with no WTE initiatives, and counties grouped by the nature of the WTE initiative, including cancelled initiatives. Tables 2.3 through 2.6 present the various county group means for each of the population settlement indicators discussed above. In the analysis, metro and non-metro counties are separated, and means and comparisons are presented for both types of counties. Also included in the tables are the standard errors of the means for each of the calculated means. Using the standard errors, one can test to determine if any two means are significantly different, i.e. the difference is greater than what might likely be attributed to chance. The standard procedure of indicating significant differences on the tables is not followed, because several different comparisons are relevant for any specific mean. WTE categories may be individually compared to the No-WTE case or to each other. A nule-of-thumb for comparing two means to identify a significant difference is to check if the difference between the means is greater than twice the larger of the two standard errors. In most instances this will provide a conservative test-usually greater than the 90 percent confidence level.

A striking pattern is evident in the data presented in Tables 2.3 to 2.6. In general, for all of the demographic settlement patterns, except for population growth, a significant difference appears between the WTE and non-WTE counties. In other words, counties that have had a WTE initiative i.e., a planned, operational, shut-down, or cancelled facility) are significantly different from counties 
that have not had a WTE initiative. However, and somewhat surprisingly, no significant differences are discernable among the various types of WTE initiatives, including differences between cancelled facilities and other categories of WTE initiatives. In other words, those communities that initiate planning for a WTE facility and subsequently cancel their project are not significantly different from communities that initiate a WTE project and see their facility through to completion. As this pattern is so striking and consistent, each factor will not be discussed in great detail. Rather, the basic findings as illustrated in the tables will be highlighted by focusing on population density.

To further simplify the following discussion, only metro counties are discussed in detail. The mean population density of metro counties with no WTE initiative is 249 persons per square mile. This value is significantly less than the mean of the counties with active WTE initiatives, e.g., counties planning a WTE initiative (2,335 persons per square mile) and those with operating facilities (1,086 persons per square mile).

Also of keen interest for this study was the relative ranking of counties that have cancelled WTE initiatives or shutdown facilities; these counties have densities of 1,418 and 1,367 persons per square mile, respectively. The population densities of these counties are also significantly greater than the non-WTE counties. However, they are not significantly different from the counties with active initiatives. While the population densities of the inactive counties are less than the counties planning WTE, as one might expect, their densities are greater than the counties currently operating plants. In any event, these differences are not significant. A similar pattern is presented by the nonmetro counties, except that the densities are considerably smaller.

Metro counties with no WTE initiatives are considerably smaller than those with initiatives (Table 2.4), suggesting that there may indeed be a minimum threshold population size for the initiation of a WTE project. Counties that have cancelled WTE plans are slightly, but not significantly, smaller than other WTE counties. Interestingly, the same pattern shows up in non- 


\begin{tabular}{|c|c|c|c|c|c|c|}
\hline \multicolumn{7}{|c|}{$\begin{array}{l}\text { Table } 23 \text { County Population Density } \\
\text { [persons per square mile] } \\
\text { (numbers in parentheses are standard errors of group means) }\end{array}$} \\
\hline & & \multicolumn{5}{|c|}{ WTE STATUS } \\
\hline & $\begin{array}{c}\text { All } \\
\text { Counties }\end{array}$ & \multicolumn{4}{|c|}{ WTE } & No WTE \\
\hline $\begin{array}{l}\text { Metro } \\
\text { Counties }\end{array}$ & $\begin{array}{c}727 \\
(122) \\
\end{array}$ & $\begin{array}{l}2,335 \\
(628) \\
\end{array}$ & $\begin{array}{l}1,367 \\
(283)\end{array}$ & $\begin{array}{l}1,085 \\
(246) \\
\end{array}$ & $\begin{array}{l}1,418 \\
(410) \\
\end{array}$ & $\begin{array}{l}249^{*} \\
(20)\end{array}$ \\
\hline $\begin{array}{l}\text { Non-metro } \\
\text { Counties }\end{array}$ & $\begin{array}{c}38 \\
(0.9)\end{array}$ & $\begin{array}{c}88 \\
(12.2)\end{array}$ & $\begin{array}{c}78 \\
(7.5)\end{array}$ & $\begin{array}{c}56 \\
(7.2)\end{array}$ & $\begin{array}{c}72 \\
(14.0)\end{array}$ & $\begin{array}{l}36^{*} \\
(0.9)\end{array}$ \\
\hline \multicolumn{7}{|c|}{$\begin{array}{l}\text { * Indicates a significant difference ( }>95 \% \text { ) between counties with no WTE and counties } \\
\text { with initiatives in the four WTE categories (planning, operating, shutdown, cancelled). }\end{array}$} \\
\hline
\end{tabular}

\begin{tabular}{||l|c|c|c|c|c|c||}
\hline \multicolumn{7}{|c||}{ Table 24 County Population Size } \\
[persons] \\
\hline \multicolumn{7}{|c||}{ WTE STATUS } \\
\hline & All & \multicolumn{5}{c||}{ WTE } \\
& Counties & Planning & Cancelled & Operating & Shutdown & No WTE \\
\hline Metro & 266,449 & 675,556 & 591,460 & 623,552 & 723,741 & $129,467^{*}$ \\
Counties & $(18,880)$ & $(85,775)$ & $(81,550)$ & $(128,890)$ & $(123,132)$ & $(8,406)$ \\
\hline Non-metro & 23,612 & 50,523 & 50,376 & 48,380 & 47,088 & $22,418^{*}$ \\
Counties & $(479)$ & $(5,704)$ & $(4,507)$ & $(6,112)$ & $(11,124)$ & $(463)$ \\
\hline$*$ Indicates a significant difference (>95\%) between counties with no WTE and counties \\
with initiatives in the four WTE categories (planning, operating, shutdown, cancelled). \\
\# Indicates a significant difference (>95\%) among the WTE counties. \\
\hline
\end{tabular}




\begin{tabular}{|c|c|c|c|c|c|c|}
\hline \multicolumn{7}{|c|}{$\begin{array}{l}\text { Table } 25 \text { County Rural Population } \\
\text { [percent rural] } \\
\text { (numbers in parentheses are standard errors of group means) }\end{array}$} \\
\hline & \multirow[b]{2}{*}{$\begin{array}{c}\text { All } \\
\text { Counties }\end{array}$} & \multicolumn{5}{|c|}{ WTE STATUS } \\
\hline & & \multicolumn{4}{|c|}{ WTE } & No WTE \\
\hline $\begin{array}{l}\text { Metro } \\
\text { Counties }\end{array}$ & $\begin{array}{c}36.1 \\
(0.98)\end{array}$ & $\begin{array}{c}18.4 \\
(1.63)\end{array}$ & $\begin{array}{c}20.8 \\
(1.60)\end{array}$ & $\begin{array}{c}20.0 \\
(1.98)\end{array}$ & $\begin{array}{c}14.4 \\
(3.23)\end{array}$ & $\begin{array}{l}44.5^{*} \\
(1.21)\end{array}$ \\
\hline $\begin{array}{l}\text { Non-metro } \\
\text { Counties }\end{array}$ & $\begin{array}{c}72.8 \\
(0.49)\end{array}$ & $\begin{array}{c}58.5 \\
(3.34)\end{array}$ & $\begin{array}{c}62.3 \\
(2.92)\end{array}$ & $\begin{array}{c}57.2 \\
(2.81)\end{array}$ & $\begin{array}{c}55.9 \\
(6.29)\end{array}$ & $\begin{array}{l}73.4^{*} \\
(0.50)\end{array}$ \\
\hline \multicolumn{7}{|c|}{$\begin{array}{l}\text { * Indicates a significant difference ( }>95 \% \text { ) between counties with no WTE and counties } \\
\text { with initiatives in the four WTE categories (planning, operating, shutdown, cancelled). }\end{array}$} \\
\hline
\end{tabular}

\begin{tabular}{|c|c|c|c|c|c|c|}
\hline \multicolumn{7}{|c|}{$\begin{array}{c}\text { Table 26 County Population Growth } \\
\text { [percent change 1980-1990] } \\
\text { (numbers in parentheses are standard errors of group means) }\end{array}$} \\
\hline & \multirow{3}{*}{$\begin{array}{c}\text { All } \\
\text { Counties }\end{array}$} & \multicolumn{5}{|c|}{ WTE STATUS } \\
\hline & & \multicolumn{4}{|c|}{ WTE } & \multirow[t]{2}{*}{ No WTE } \\
\hline & & Planning & Cancelled & Operating & Shutdown & \\
\hline $\begin{array}{l}\text { Metro } \\
\text { Counties }\end{array}$ & $\begin{array}{c}13.6 \\
(1.28)\end{array}$ & $\begin{array}{c}13.5 \\
(1.67)\end{array}$ & $\begin{array}{c}14.8 \\
(2.41)\end{array}$ & $\begin{array}{c}11.5 \\
(1.35)\end{array}$ & $\begin{array}{c}8.9 \\
(2.62)\end{array}$ & $\begin{array}{c}13.9 \\
(0.91)\end{array}$ \\
\hline $\begin{array}{l}\text { Non-metro } \\
\text { Counties }\end{array}$ & $\begin{array}{c}1.1 \\
(0.29)\end{array}$ & $\begin{array}{c}6.8 \\
(2.15)\end{array}$ & $\begin{array}{c}3.9 \\
(1.42)\end{array}$ & $\begin{array}{c}4.2 \\
(2.81)\end{array}$ & $\begin{array}{c}9.0 \\
(3.68)\end{array}$ & $\begin{array}{c}0.9^{*} \\
(0.30) \\
\end{array}$ \\
\hline \multicolumn{7}{|c|}{$\begin{array}{l}\text { * Indicates a significant difference ( }>95 \% \text { ) between counties with no WTE and counties } \\
\text { with initiatives in the four WTE categories (planning, operating, shutdown, cancelled). } \\
\text { \# Indicates a significant difference ( }>95 \% \text { ) among the WTE counties. }\end{array}$} \\
\hline
\end{tabular}

metro counties, i.e., the non-WTE counties are significantly smaller than ones with WTE. But the very different population size between the average metro and non-metro county suggests that two different scales of plant (market size) may exist for WTE technologies. This observation is, of course, 
consistent with our knowledge that modular units are used more in counties with smaller populations and large, mass-burn units are typically adopted in the larger metro areas.

In the average metro county, some 36 percent of the population lives in a rural environment. In non-metro counties, the average is around 73 percent rural. In a sparsely populated area distant from major cities, one would expect a mostly rural population. A county with a large population and area but adjacent to a major city could be classified as metro, but still have a significant rural population in the area far from the city. The distribution of the population between the city and rural areas would be measured by the rural percentage. For any given area and population size (i.e., population density) many different rural patterns could, therefore, be present. The rural composition of the population, consequently, can provide an additional dimension on the spatial distribution of the population.

For both metro and non-metro areas, the pattern for rural population is found to be the same as for population density. In metro counties without WTE initiatives, the rural population is around 44.5 percent, indicating more sparsely settled areas. Metro counties with WTE plans or facilities are significantly less rural-ranging from a high of 21 percent for the cancelled category to a low of 14 percent for the shutdown category. Again, the non-metro counties show the same pattern but at a different scale. Non-WTE, non-metro counties have a rural population of 73 percent, which is significantly greater than all of the means of the non-metro counties with WTE initiatives. This result, which is consistent with the other indicators, also indicates a dual market for WTE-one with a scale appropriate to large metro areas and the other with a scale appropriate to the larger of the non-metro counties.

Unlike other population measures, population growth during the period does not appear to have been a significant inducement for counties to consider WTE initiatives. In other words, counties with WTE initiatives do not show higher than average growth rates. This suggests that initiatives 
have been pursued to meet current population needs and not future needs based on projected county population growth. Alternately, WTE initiatives are pursued in areas where the current population can support a facility or in areas where a facility is considered as a substitute for other waste options. The lack of a significant relationship indicates that population growth has not been a prerequisite for the pursuit of a WTE facility.

\section{County Population Socioeconomic Characteristics}

This subsection explores possible relationships between several socioeconomic characteristics and a community's adoption of WTE. A large number of socio-demographic variables are available to classify communities. The approach of creating regional typologies is becoming more popular since it has been adopted as a strategy in market segmentation analysis. In this analysis, only a few key variables were selected that have been proven significant as county classification variables in other analyses. The factors identify differences in the population in terms of the general level of education, personal income, age structure, and population in industrial jobs.

Data and findings presented in Table 2.7 (education), Table 2.8 (per-capita income), Table 2.9 (population age), and Table 2.10 (industrial employment) suggest that metro counties with a lower industrial base, a wealthier and better educated population, a higher income population, or with a strong representation of persons at the family-formation age are more likely to consider a WTE initiative. Again, the differences between counties with WTE initiatives and non-WTE counties are significant with respect to all four of the characteristics, but not significantly different among the different classes of WTE initiative status, including cancelled facilities. In other words, there are no significant differences between counties that have cancelled facilities and counties that have built and operated WTE facilities.

In the case of non-metro counties, the test results are not as conclusive. With respect to population age structure, the metro and non-metro results are the similar, albeit with somewhat lower 


\begin{tabular}{||l|c|c|c|c|c|c||}
\hline \multicolumn{7}{|c||}{$\begin{array}{c}\text { Table 27 County Population with High School Degrees } \\
\text { [percent with a high school degree] } \\
\text { (numbers in parentheses are standard errors of group means) }\end{array}$} \\
\hline \multicolumn{7}{|c||}{ WTE STATUS } \\
\hline & All & \multicolumn{6}{c||}{ WTE } & No WTE \\
& Counties & Planning & Cancelled & Operating & Shutdown & \\
\hline Metro & 65.71 & 68.94 & 68.29 & 69.96 & 69.28 & $63.81^{*}$ \\
Counties & $(0.38)$ & $(0.78)$ & $(0.69)$ & $(0.75)$ & $(1.81)$ & $(0.49)$ \\
\hline Non-metro & 57.27 & 62.39 & 61.77 & 59.73 & 53.25 & 57.14 \\
Counties & $(0.25)$ & $(2.15)$ & $(1.51)$ & $(2.24)$ & $(2.92)$ & $(0.25)$ \\
\hline$*$ & Indicates a significant difference (>95\%) between counties with no WTE and counties \\
with initiatives in the four WTE categories (planning, operating, shutdown, cancelled). \\
\# Indicates a significant difference (>95\%) among the WTE counties. \\
\hline
\end{tabular}

\begin{tabular}{||l|c|c|c|c|c|c||}
\hline \multicolumn{7}{|c||}{$\begin{array}{c}\text { Table 28 County Per-Capita Income } \\
\text { [constant 1982 dollars per person] }\end{array}$} \\
\hline \multicolumn{7}{|c||}{ WTE STATUS } \\
\hline & $\begin{array}{c}\text { All } \\
\text { Counties }\end{array}$ & Planning & Cancelled & Operating & Shutdown & No WTE \\
\hline $\begin{array}{l}\text { Metro } \\
\text { Counties }\end{array}$ & $\begin{array}{c}13,408 \\
(111)\end{array}$ & $\begin{array}{c}15,491 \\
(312)\end{array}$ & $\begin{array}{c}14,910 \\
(271)\end{array}$ & $\begin{array}{c}14,967 \\
(370)\end{array}$ & $\begin{array}{c}15,620 \\
(794)\end{array}$ & $\begin{array}{c}12,622^{*} \\
(112)\end{array}$ \\
\hline $\begin{array}{l}\text { Non-metro } \\
\text { Counties }\end{array}$ & $\begin{array}{c}10,848 \\
(46)\end{array}$ & $\begin{array}{c}11,627 \\
(471)\end{array}$ & $\begin{array}{c}11,473 \\
(327)\end{array}$ & $\begin{array}{c}11,056 \\
(358)\end{array}$ & $\begin{array}{c}10,919 \\
(470)\end{array}$ & $\begin{array}{c}10,830 \\
(47)\end{array}$ \\
\hline$*$ & $\begin{array}{l}\text { Indicates a significant difference (>95\%) between counties with no WTE and counties } \\
\text { with initiatives in the four WTE categories (planning, operating, shutdown, cancelled). }\end{array}$ \\
\# \\
Indicates a significant difference (>95\%) among the WTE counties. \\
\hline
\end{tabular}




\begin{tabular}{|c|c|c|c|c|c|c|}
\hline \multicolumn{7}{|c|}{$\begin{array}{l}\text { Table } 29 \text { County Population at Family Formation Age } \\
\text { [percent of persons aged } 22 \text { to } 39 \text { ] } \\
\text { (numbers in parentheses are standard errors of group means) }\end{array}$} \\
\hline & \multirow{3}{*}{$\begin{array}{c}\text { All } \\
\text { Counties }\end{array}$} & \multicolumn{5}{|c|}{ WTE STATUS } \\
\hline & & \multicolumn{4}{|c|}{ WTE } & \multirow{2}{*}{ No WTE } \\
\hline & & Planning & Cancelled & Operating & Shutdown & \\
\hline $\begin{array}{l}\text { Metro } \\
\text { Counties }\end{array}$ & $\begin{array}{c}21.1 \\
(0.14)\end{array}$ & $\begin{array}{c}21.7 \\
(0.28)\end{array}$ & $\begin{array}{c}21.9 \\
(0.29)\end{array}$ & $\begin{array}{c}21.7 \\
(0.42)\end{array}$ & $\begin{array}{c}21.6 \\
(0.60)\end{array}$ & $\begin{array}{l}20.8^{*} \\
(0.17)\end{array}$ \\
\hline $\begin{array}{l}\text { Non-metro } \\
\text { Counties }\end{array}$ & $\begin{array}{c}17.7 \\
(0.08)\end{array}$ & $\begin{array}{c}19.2 \\
(0.58)\end{array}$ & $\begin{array}{c}19.3 \\
(0.45)\end{array}$ & $\begin{array}{c}19.5 \\
(0.68)\end{array}$ & $\begin{array}{l}17.1 \# \\
(0.35)\end{array}$ & $\begin{array}{l}17.6^{*} \\
(0.08\end{array}$ \\
\hline \multicolumn{7}{|c|}{$\begin{array}{l}\text { * Indicates a significant difference }(>95 \%) \text { between counties with no WTE and counties } \\
\text { with initiatives in the three WTE categories (planning, operating, shutdown, cancelled). }\end{array}$} \\
\hline
\end{tabular}

\begin{tabular}{|c|c|c|c|c|c|c|}
\hline \multicolumn{7}{|c|}{$\begin{array}{l}\text { Table } 210 \text { County Industrial Base } \\
\text { [percent of employment in manufacturing, mining \& construction] } \\
\text { (numbers in parentheses are standard errors of group means) }\end{array}$} \\
\hline & \multirow{3}{*}{$\begin{array}{c}\text { All } \\
\text { Counties }\end{array}$} & \multicolumn{5}{|c|}{ WTE STATUS } \\
\hline & & \multicolumn{4}{|c|}{ WTE } & \multirow{2}{*}{ No WTE } \\
\hline & & Planning & Cancelled & Operating & Shutdown & \\
\hline $\begin{array}{l}\text { Metro } \\
\text { Counties }\end{array}$ & $\begin{array}{c}27.7 \\
(0.40)\end{array}$ & $\begin{array}{c}24.7 \\
(0.78) \\
\end{array}$ & $\begin{array}{c}24.6 \\
(0.75)\end{array}$ & $\begin{array}{c}24.4 \\
(0.84)\end{array}$ & $\begin{array}{c}22.8 \\
(1.66)\end{array}$ & $\begin{array}{l}29.5^{*} \\
(0.52)\end{array}$ \\
\hline $\begin{array}{l}\text { Non-metro } \\
\text { Counties }\end{array}$ & $\begin{array}{c}31.0 \\
(0.30)\end{array}$ & $\begin{array}{c}35.0 \\
(2.67)\end{array}$ & $\begin{array}{c}30.0 \\
(1.74)\end{array}$ & $\begin{array}{c}31.0 \\
(2.17)\end{array}$ & $\begin{array}{c}43.4 \\
(5.96)\end{array}$ & $\begin{array}{c}31.0 \\
(0.30)\end{array}$ \\
\hline \multicolumn{7}{|c|}{$\begin{array}{l}\text { * Indicates a significant difference ( }>95 \% \text { ) between counties with no WTE a } \\
\text { with initiatives in the four WTE categories (planning, operating, shutdown, }\end{array}$} \\
\hline \# Indicat & s a significa & lifference & $5 \%$ ) among & WTE cour & & \\
\hline
\end{tabular}

values in the case of non-metro counties and lack distinction between no WTE counties and those with shutdown facilities. However, there appear to be no significant differences in education, income or industrial employment between non-metro WTE and non-WTE counties. 
In summary, population characteristics examined in this section provide results similar to those examined in the previous subsection. The selected factors do appear to discriminate between WTEinitiative and non-WTE-initiative counties. However, the factors do not differentiate those counties that have decided to cancel their WTE project from those communities that maintain an active WTE initiative.

\section{Availability of Waste Management Alternatives}

WTE facilities are only one of several MSW management options. Past perceptions of the scarcity of landfill space at the national, regional, or local levels may have promoted interest in WTE. Urban areas with high-cost landfills and severe difficulties in siting new landfills may have looked more favorably toward WTE. In addition, some communities may have looked to recycling as a substitute for the development of WTE. To examine these issues, several regional indicators were constructed. One set related to recycling options, and a second set examined the impact of landfill alternatives. Two recycling options were investigated: the presence of a local recycling program and the region's potential access to a materials recovery facility (MRF).

The American Plastics Council (APC) maintains a data base on plastics recycling programs in some 3,965 communities. The communities are further identified in terms of providing one or more recycling options, i.e., curb-side, drop-off, or buy-back programs. The APC data are designed primarily to cover programs that include plastics recycling; but according to the APC, the data cover virtually all recycling programs. For the needs of this study, all communities in the APC data base were located by county, and a county data base was constructed. A county was considered to have a recycling option if any community in the county had a program. Note that the intent of developing this indicator was not to measure the amount of recycling that might have taken place, but rather to provide an indicator of local perceptions about recycling as a serious waste management option. Consequently, it was assumed that the existence of a recycling program anywhere in the county 
suggested a community awareness of the recycling option. In developing the data base and examining the data on many of the counties with multiple community reports, it was noticed that recycling programs were sometimes county-wide.

Table 2.11 presents the results of the analysis of recycling programs and WTE initiatives. The recycle indicator was one if there was a recycling program in the county and zero otherwise. In this zero/one case, the arithmetic means can also be interpreted as the share of counties with a recycling program. Counties without WTE initiatives have a smaller share of recycling programs than counties with WTE initiatives. Recycling programs were found to be correlated with the presence of WTE programs. For both metro and non-metro counties, a significantly greater share of WTE counties have recycling programs.

The number of MRFs in each state as of 1990 was obtained from Glenn (1991) in BioCycle. The number of MRF's in a state was used as the county's potential accessibility to a MRF facility. If there are a large number of facilities in a state, then it was assumed that the average county in the state has a high accessibility. The typical metro county is in a state that has an average of about six MRFs (the mean of all metro counties is 6.5). In general, metro counties with WTE initiatives have significantly greater accessibility to MRFs than metro counties without WTE initiatives. The data show little difference among the WTE status categories, as is the case with other factors (see Table 2.12). The non-metro situation has no clear and dominant pattern.

The availability of landfills was examined similarly. Initially it was thought that local tipping fees and landfill capacity would be ideal indicators for the potential competitiveness of landfills. However, the development of a comprehensive data base on local landfills was beyond the scope of this project, and available alternatives appear to be fraught with problems. Current measures of capacity are not consistent across all regions, and recent environmental regulations have caused a major reassessment of potential capacity at many landfill operations. In addition, an examination of 


\begin{tabular}{||l|c|c|c|c|c|c||}
\hline \multicolumn{7}{|c||}{ Table 211 Recycling Programs } \\
\hline \multicolumn{7}{|c|}{ [indicator variable: no program $=0$, recycling program =1] } \\
(numbers in parentheses are standard errors of group means)
\end{tabular}

\begin{tabular}{|c|c|c|c|c|c|c|}
\hline \multicolumn{7}{|c|}{$\begin{array}{c}\text { Table } 2.12 \text { Access to MRFs } \\
\text { [number of MRFs in state] } \\
\text { (numbers in parentheses are standard errors of group means) }\end{array}$} \\
\hline & & \multicolumn{5}{|c|}{ WTE STATUS } \\
\hline & $\begin{array}{c}\text { All } \\
\text { Counties }\end{array}$ & \multicolumn{4}{|c|}{ WTE } & No WTE \\
\hline $\begin{array}{l}\text { Metro } \\
\text { Counties }\end{array}$ & $\begin{array}{c}6.52 \\
(0.35)\end{array}$ & $\begin{array}{l}10.50 \\
(0.92)\end{array}$ & $\begin{array}{c}9.65 \\
(0.88)\end{array}$ & $\begin{array}{c}9.22 \\
(1.17)\end{array}$ & $\begin{array}{c}8.32 \\
(1.96)\end{array}$ & $\begin{array}{l}4.97^{*} \\
(0.38)\end{array}$ \\
\hline $\begin{array}{l}\text { Non-metro } \\
\text { Counties }\end{array}$ & $\begin{array}{c}2.67 \\
(0.11)\end{array}$ & $\begin{array}{c}4.96 \\
(1.43)\end{array}$ & $\begin{array}{c}8.54 \\
(1.67)\end{array}$ & $\begin{array}{c}4.64 \\
(1.21)\end{array}$ & $\begin{array}{l}0.88 \# \\
(0.35)\end{array}$ & $\begin{array}{c}4.51 \\
(0.11)\end{array}$ \\
\hline \multicolumn{7}{|c|}{$\begin{array}{ll}\text { * } & \text { Indicates a significant difference (>95\%) between counties with no WTE and counties } \\
\text { with initiatives in the four WTE categories (planning, operating, shutdown, cancelled). } \\
\text { \# Indicates a significant difference ( }>95 \% \text { ) among the WTE counties. }\end{array}$} \\
\hline
\end{tabular}


tipping fees indicates little correlation with the current cost of landfill operations. The study concluded that landfill tipping fees are not a suitable measure of the cost of the landfill option. Consequently, simpler alternative measures of landfill capacity and cost were developed for this analysis.

The number of open municipal landfills in each state during 1989 is available from BioCycle magazine (Glenn and Riggle, 1991a). The number of landfills in the state is used as a measure of accessibility, similar to the MRF analysis above. Table 2.13 presents the results of this tabulation. The data show no significant differences between the WTE and non-WTE counties in either the metro or non-metro cases. Table 2.14 develops a scaled measure of landfill availability. The total number of landfills in the state was divided by the state population to provide a measure of the percapita availability. Even when so scaled, there are no significant differences between the different classes of counties.

Given that reliable landfill costs are not available at the county level, a measure of the cost of waste management practices in the typical county was developed from data presented in U.S. Bureau of the Census County Government Finances: 1989-90, where annual operating expenditures on solid waste management for counties with populations greater then 500,000 are available. These data were put on a per-capita basis for analysis, and Table 2.15 presents the results of the analysis. As noted in the table, this analysis is for a small subset of the total number of counties, and relates primarily to metro counties. Metro counties involved in WTE initiatives have significantly higher percapita solid waste costs as compared to metro counties with no WTE initiatives. Thus, a higher solid waste management budget is correlated with a greater likelihood of involvement in WTE projects. Table 2.15 also provides one of the few case where some discrimination among different WTE categories is observed. Counties with openly and planned WTE facilities have higher expenditures than cancelled or shutdown counties. The correlation is not indicative of causality - but suggests that 


\begin{tabular}{|c|c|c|c|c|c|c|}
\hline \multicolumn{7}{|c|}{$\begin{array}{c}\text { Table } 2.13 \text { Access to Landfills } \\
\text { [number of landfills in state] } \\
\text { (numbers in parentheses are standard errors of group means) }\end{array}$} \\
\hline & & \multicolumn{5}{|c|}{ WTE STATUS } \\
\hline & $\begin{array}{c}\text { All } \\
\text { Counties }\end{array}$ & \multicolumn{4}{|c|}{ WTE } & No WTE \\
\hline $\begin{array}{l}\text { Metro } \\
\text { Counties }\end{array}$ & $\begin{array}{c}203 \\
(8.8)\end{array}$ & $\begin{array}{c}183 \\
(16.4)\end{array}$ & $\begin{array}{c}204 \\
(19.4)\end{array}$ & $\begin{array}{c}201 \\
(24.1)\end{array}$ & $\begin{array}{c}190 \\
(33.4)\end{array}$ & $\begin{array}{c}207 \\
(11.5) \\
\end{array}$ \\
\hline $\begin{array}{l}\text { Non-metro } \\
\text { Counties }\end{array}$ & $\begin{array}{c}198 \\
(5.3)\end{array}$ & $\begin{array}{c}137 \\
(28.4)\end{array}$ & $\begin{array}{c}159 \\
(22.4)\end{array}$ & $\begin{array}{c}258 \\
(53.8)\end{array}$ & $\begin{array}{c}109 \\
(22.0)\end{array}$ & $\begin{array}{c}199 \\
(5.4)\end{array}$ \\
\hline \multicolumn{7}{|c|}{$\begin{array}{l}\text { * Indicates a significant difference ( }>95 \% \text { ) between counties with no WTE and counties } \\
\text { with initiatives in the four WTE categories (planning, operating, shutdown, cancelled). } \\
\text { \# Indicates a significant difference ( }>95 \% \text { ) among the WTE counties. }\end{array}$} \\
\hline
\end{tabular}

\begin{tabular}{||l|c|c|c|c|c|c||}
\hline \multicolumn{7}{|c||}{$\begin{array}{l}\text { Table 214 Availability of Landfills } \\
\text { [number of landfills per 1,000 persons in state] }\end{array}$} \\
(numbers in parentheses are standard errors of group means) \\
\hline & \multicolumn{6}{c||}{ WTE STATUS } \\
\hline & $\begin{array}{c}\text { All } \\
\text { Counties }\end{array}$ & Planning & Cancelled & Operating & Shutdown & No WTE \\
\hline Metro & 0.029 & 0.025 & 0.027 & 0.031 & 0.033 & 0.030 \\
Counties & $(0.001)$ & $(0.003)$ & $(0.003)$ & $(0.004)$ & $(0.008)$ & $(0.001)$ \\
\hline $\begin{array}{l}\text { Non-metro } \\
\text { Counties }\end{array}$ & $\begin{array}{c}0.043 \\
(0.001)\end{array}$ & $\begin{array}{c}0.040 \\
(0.008)\end{array}$ & $\begin{array}{c}0.041 \\
(0.007)\end{array}$ & $\begin{array}{c}0.047 \\
(0.007)\end{array}$ & $\begin{array}{c}0.032 \\
(0.004)\end{array}$ & $\begin{array}{c}0.043 \\
(0.001)\end{array}$ \\
\hline$* \quad$ Indicates a significant difference (>95\%) between counties with no WTE and counties \\
with initiatives in the four WTE categories (planning, operating, shutdown, cancelled). \\
\# Indicates a significant difference (>95\%) among the WTE counties. \\
\hline
\end{tabular}




\begin{tabular}{|c|c|c|c|c|c|c|}
\hline \multicolumn{7}{|c|}{$\begin{array}{l}\text { Table } 215 \text { County Municipal Solid Waste Disposal Expenditures } \\
\text { [\$ expenditures per capita; } n=\text { number of counties for which information about MSW } \\
\text { expenditures is available] }\end{array}$} \\
\hline & \multirow[b]{2}{*}{$\begin{array}{c}\text { All } \\
\text { Counties }\end{array}$} & \multicolumn{5}{|c|}{ WTE STATUS } \\
\hline & & \multicolumn{4}{|c|}{ WTE } & No WTE \\
\hline $\begin{array}{l}\text { Metro } \\
\text { Counties }\end{array}$ & $\begin{array}{l}13.80 \\
(1.28) \\
n=244\end{array}$ & $\begin{array}{l}17.84 \\
(2.97) \\
\mathrm{n}=70\end{array}$ & $\begin{array}{l}14.86 \\
(2.41) \\
\mathrm{n}=67\end{array}$ & $\begin{array}{l}24.73 \# \\
(4.21) \\
\mathbf{n}=43\end{array}$ & $\begin{array}{l}12.81 \# \\
(5.23) \\
n=13\end{array}$ & $\begin{array}{l}8.40^{*} \\
(1.19) \\
n=108\end{array}$ \\
\hline $\begin{array}{l}\text { Non-metro } \\
\text { Counties }\end{array}$ & $\begin{array}{l}9.32 \\
(2.23) \\
n=19\end{array}$ & $\begin{array}{c}9.64 \\
(7.12) \\
n=2\end{array}$ & $\begin{array}{l}9.43 \\
(2.86) \\
n=4\end{array}$ & $\underset{n=0}{(-)}$ & $\underset{n=0}{(-)}$ & $\begin{array}{l}9.23 \\
(3.10) \\
n=13\end{array}$ \\
\hline \multicolumn{7}{|c|}{$\begin{array}{l}\text { * Indicates a significant difference }(>95 \%) \text { between counties with no } \\
\text { with initiatives in the four WTE categories (planning, operating, shut } \\
\text { \# Indicates a significant difference }(>95 \% \text { ) among the WTE counties. }\end{array}$} \\
\hline
\end{tabular}

counties that face high waste-management cost are more likely to consider WTE as an option.

Counties with active initiatives also reflect higher per-capita waste costs than counties with other WTE status categories. However, the only significant mean is for counties with currently operating facilities. This result suggests that high alternative waste management costs may indeed be a key inducement or facilitator to WTE initiatives.

The general conclusions that can be drawn from this section are somewhat limited. The positive correlation between recycling options and WTE initiatives may simply reflect the fact that large, dense counties need to consider a variety of waste management strategies, or that recycling, like WTE, is facilitated by a dense urban environment. The nebulous results on the landfill indicators may be due to the aggregate and diffuse nature of the indicators available. More detailed and rigorous analyses of landfill costs and capacities may be fruitful avenues for future research.

\section{The Local Climate for Environmental Concern}

The initiation and acceptance of a WTE facility may be affected by the real and perceived 
status of environmental quality in the community. For example, state-mandated recycling programs and state source-reduction goals may discourage the consideration of WTE. In addition, if local atmospheric environmental quality has been compromised in the past, concerns may arise about any combustion technology. These and other similar issues were examined with a final set of indicators that reflect the condition of the county's environment and local and state regulations that deal with the environment.

In the recently published book, 1991-1992 Green Index, Hall and Kerr present a wide variety of indexes constructed to represent each state's level of environmental activism. One measure they include is membership in the Sierra Club, Greenpeace, and National Wildlife Federation. Each state's total membership is scaled by dividing by the state's population (in thousands). For this study, the state value was used for each county in the state, and the counties were grouped as in the earlier tests. Table 2.16 presents the summary results. Interestingly, metro counties with WTE initiatives are in states with significantly greater representation in conservation groups than is the case for nonWTE counties. As is the case in other parts of this chapter, there are no significant differences among the various classes of WTE counties, including cancelled facilities. Findings for non-metro counties are not as clear cut, with only the counties with active and cancelled initiatives having larger means than the non-WTE, non-metro counties.

The influence of local environmental quality was tested by identifying those counties that were in non-attainment for carbon monoxide, particulates, ozone and/or lead. A county data base was constructed with an indicator set to one if any part of the county was listed as in non-attainment in the Federal Register's final rule on air quality designations (1991; 40 CFR Part 60). Table 2.17 presents the result of this environmental quality analysis. Since a zero to one indicator was used, the means represent the proportion of counties that are in non-attainment. Sixty-three percent of the 


\begin{tabular}{|c|c|c|c|c|c|c|}
\hline \multicolumn{7}{|c|}{$\begin{array}{c}\text { Table } 216 \text { Membership in Conservation Groups } \\
\text { [state membership in Sierra Club, Greenpeace and National Wildlife Federations } \\
\text { per 1,000 persons] } \\
\text { (numbers in parentheses are standard errors of group means) }\end{array}$} \\
\hline & \multirow[b]{2}{*}{$\begin{array}{c}\text { All } \\
\text { Counties }\end{array}$} & \multicolumn{5}{|c|}{ WTE STATUS } \\
\hline & & \multicolumn{4}{|c|}{ WTE } & No WTE \\
\hline $\begin{array}{l}\text { Metro } \\
\text { Counties }\end{array}$ & $\begin{array}{c}7.78 \\
(0.11)\end{array}$ & $\begin{array}{c}9.37 \\
(0.25)\end{array}$ & $\begin{array}{c}9.32 \\
(0.27)\end{array}$ & $\begin{array}{c}9.24 \\
(0.33)\end{array}$ & $\begin{array}{c}9.82 \\
(0.66)\end{array}$ & $\begin{array}{l}7.09^{*} \\
(0.13)\end{array}$ \\
\hline $\begin{array}{l}\text { Non-metro } \\
\text { Counties }\end{array}$ & $\begin{array}{c}6.93 \\
(0.06)\end{array}$ & $\begin{array}{c}8.42 \\
(0.62)\end{array}$ & $\begin{array}{c}8.51 \\
(0.52)\end{array}$ & $\begin{array}{c}8.87 \\
(2.81)\end{array}$ & $\begin{array}{c}6.19 \\
(1.43)\end{array}$ & $\begin{array}{c}6.86 \\
(0.06)\end{array}$ \\
\hline \multicolumn{7}{|c|}{$\begin{array}{l}\text { * Indicates a significant difference (>95\%) between counties with no WTE and counties } \\
\text { with initiatives in the four WTE categories (planning, operating, shutdown, cancelled). } \\
\text { \# Indicates a significant difference ( }>95 \% \text { ) among the WTE counties. }\end{array}$} \\
\hline
\end{tabular}

\begin{tabular}{|c|c|c|c|c|c|c|}
\hline \multicolumn{7}{|c|}{$\begin{array}{l}\text { Table } 2.17 \text { Local Environmental Quality } \\
\text { [proportion of counties located in non-attainment areas] } \\
\text { (numbers in parentheses are standard errors of group means) }\end{array}$} \\
\hline & & \multicolumn{5}{|c|}{ WTE STATUS } \\
\hline & $\underset{\text { Counties }}{\text { All }}$ & \multicolumn{4}{|c|}{ WTE } & No WTE \\
\hline $\begin{array}{l}\text { Metro } \\
\text { Counties }\end{array}$ & $\begin{array}{c}0.05 \\
(0.02)\end{array}$ & $\begin{array}{c}0.79 \\
(0.04)\end{array}$ & $\begin{array}{c}0.71 \\
(0.04)\end{array}$ & $\begin{array}{c}0.70 \\
(0.05)\end{array}$ & $\begin{array}{c}0.76 \\
(0.09)\end{array}$ & $\begin{array}{l}0.40^{*} \\
(0.02)\end{array}$ \\
\hline $\begin{array}{l}\text { Non-metro } \\
\text { Counties }\end{array}$ & $\begin{array}{c}0.05 \\
(0.01)\end{array}$ & $\begin{array}{c}0.25 \\
(0.08)\end{array}$ & $\begin{array}{l}0.50 \# \\
(0.07)\end{array}$ & $\begin{array}{c}0.0 \\
(0.00)\end{array}$ & $\begin{array}{c}0.23 \\
(0.07)\end{array}$ & $\begin{array}{l}0.04^{*} \\
(0.01)\end{array}$ \\
\hline \multicolumn{7}{|c|}{$\begin{array}{l}\text { * Indicates a significant difference ( }>95 \% \text { ) between counties with no WTE } \\
\text { with initiatives in the four WTE categories (planning, operating, shutdow } \\
\text { \# Indicates a significant difference ( }>95 \% \text { ) among the WTE counties. }\end{array}$} \\
\hline
\end{tabular}


metro counties violate the limit on one or more of the pollutants. Rural counties indeed appear in general to be considerably more pristine, with only five percent of them in non-attainment. Nonattainment is in general a dense population phenomena. The data show that metro counties with WTE initiatives are almost twice as likely to be in non-attainment as non-WTE counties. Non-metro counties with WTE programs are similarly more likely to be in non-attainment. There is a significant positive correlation with non-attainment and WTE initiatives. It should be noted that this correlation does not imply causality. It is possible that characteristics that contribute to communities being out of attainment--dense population and industrial areas--also contribute to their need for waste management capacity and their considering multiple solid waste management options.

The last two indicators to be examined address the level of environmental regulation present in a state. A plausible hypothesis is that more stringent regulations-with respect to environmental controls and mandated incentives for recycling and source reduction-may hinder the adoption of WTE. The first policy index relates specifically to stated preferences for recycling and source reduction. The second index reflects a more general measure of environmental policy.

To construct the solid waste management index, state recycling regulations and policies as of 1990 were reviewed (Glenn and Riggle, 1991b). Each state was scored on six MSW policies: (1) the existence of a mandated goal of managing at least 25 percent of their waste stream by recycling, source reduction, and/or composting, (2) the existence of mandatory municipal ordinances to meet these goals, (3) state requirements for local governments to develop recycling programs, (4) state requirements that local governments meet waste reduction goals, (5) mandatory bottle-deposit laws, and (6) state financial incentives to produce recycled goods. The level of intensity on each policy was subjectively weighted and then summarized. The final score was set to zero for states that had not enacted any of the six criteria measures, to a value of one for states that had enacted no more than 
two of the six measures, and a value of two for states that had enacted three or more of the measures.

The solid waste management policy index for a state was assigned to all the counties in the state, and then mean scores were calculated for the various county groups. Table 2.18 presents the table of means. Metropolitan counties without WTE initiatives have a significantly lower score on the intensity of solid waste management policies than do counties with WTE programs. In other words, counties in states with few or no incentives for recycling, composting, and/or source reduction are less likely to have had a WTE initiative. Counties with shutdown or cancelled facilities have slightly lower, but not significantly different scores than do counties with existing facilities or active WTE initiatives. Non-metro counties depict basically the same relative patterns, but the differences between the WTE and the non-WTE counties are not significant.

A very similar pattern is shown by the broader environmental policy index. Hall and Kerr (1992) reviewed and scored 50 environmental policies for each state and then calculated a summary score. Table 2.19 presents county means of the environmental policy index.

The positive correlation of pollution, stringent policy initiatives, and environmental activism within counties involved with WTE initiatives most likely reflects a correlation of the problems of urban density with the need to consider a range of MSW alternatives. In large urban areas, the waste problem is more serious and, consequently, may induce interest in WTE facilities. It is also in these areas that interest in environmental issues may peak.

\section{Multiple Factor Analysis}

In the comparison of means analysis presented above, each of the indicators was examined independently. However, several of the factors are likely to be correlated with each other. A method in which the separate effects can be identified, while taking into account the other factors, is multiple regression analysis. Counties with WTE initiatives were given a value of one and counties 


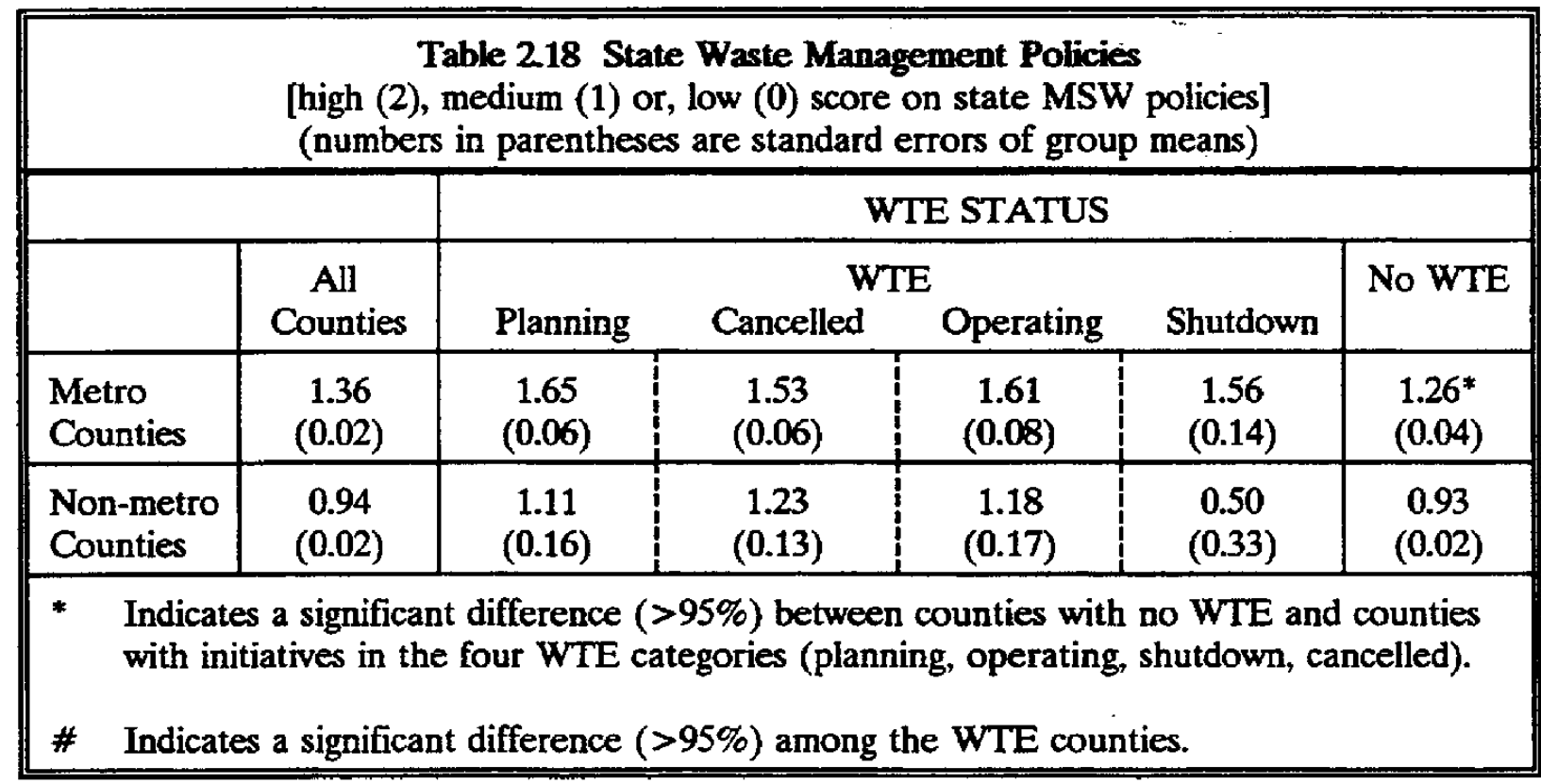

\begin{tabular}{|l|c|c|c|c|c|c||}
\hline \multicolumn{8}{||c||}{$\begin{array}{l}\text { Table 219 State Environmental Policies } \\
\text { [state score on 50 environmental policies] }\end{array}$} \\
\hline \multicolumn{7}{|c||}{ (numbers in parentheses are standard errors of group means) } \\
\hline & All & \multicolumn{6}{c||}{ WTE STATUS } \\
\hline & Counties & Planning & Cancelled & Operating & Shutdown & No WTE \\
\hline Metro & 48.4 & 56.2 & 54.5 & 55.3 & 54.9 & $45.3^{*}$ \\
Counties & $(0.51)$ & $(1.14)$ & $(1.20)$ & $(1.42)$ & $(3.08)$ & $(0.59)$ \\
\hline Non-metro & 42.2 & 47.9 & 48.8 & 49.2 & $34.2 \#$ & 42.0 \\
Counties & $(0.26)$ & $(2.83)$ & $(2.19)$ & $(2.67)$ & $(3.18)$ & $(0.26)$ \\
\hline$*$ & Indicates a significant difference (>95\%) between counties with no WTE and counties \\
with initiatives in the four WTE categories (planning, operating, shutdown, cancelled). \\
\# Indicates a significant difference (>95\%) among the WTE counties. \\
\hline
\end{tabular}


with no initiatives were given a value of zero. A regression analysis could then be conducted that tested the set of factors as to their importance in contributing to a WTE initiative in the typical county. A second analysis was also conducted in which the factors were studied as to their ability to discriminate between active initiatives (given a value of zero) from cancelled initiatives or shutdown facilities (given a value of one).

The results of the two regression analyses, along with the standard statistics, are presented in Tables 2.20 and 2.21 .

Combinations of the socioeconomic factors sometimes appear to show different responses in the regression analysis than in the comparison of means. For example, in the comparison of means, the percent of the population with a high school education was positively related to the existence of a WTE initiative. Yet, in the regression, when other factors (such as income) are taken into account, higher education is negatively related to WTE adoption. This difference in results is due to the nature of regression analyses, which attempts to standardize across a number of variables. In the above example, what is revealed using regression analysis, is the tendency for counties with higher levels of income, more rural population, and higher percentages of high school graduates to more likely consider WTE than other counties. The multivariable regression framework provides a more comprehensive picture of the individual and joint effects of the variables than can be inferred from analysis of means.

The coefficients for family-formation age, MSW cost, and state MSW policy variables are also significantly negative in the WTE/Non-WTE regression analysis. These variables were positively related in the means analysis. The change in sign between the two types of analysis indicates that these three variables are correlated with others in the analysis, primarily the urbanization variables.

The most interesting result of the regression analysis is that the basic findings presented in previous subsections are confirmed. The indicators examined are able (individually or jointly) to 
Dependent Variable:

WTE: $=0$ if there was not a WTE initiative in the county

$=1$ if there was a WTE initiative in the county

Mean: $\quad 0.11534702$

Std. Deviation: $\quad 0.31949232$

Regression Statistics:

Number of Observations: $\quad 3069$

Multiple correlation: $\quad 0.564$

Std Error: $\quad 0.264$

R-Squared: $\quad 0.318$

Adjusted R-Squared: $\quad 0.315$

Analysis of Variance:

\begin{tabular}{lccccc} 
Source & DF & Sum of Squares & Mean Square & F Value & Prob $>$ F \\
Model & 16 & 99.66507 & 6.22907 & 89.04 & 0.0000 \\
Error & 3,052 & 213.50208 & 0.06995 & & \\
Total & 3,068 & 313.16716 & & & \\
\hline
\end{tabular}

Parameter Estimates:

Variable

Constant Term

$\begin{array}{cccc}\text { Coefficient } & \text { Std. Error } & T & \text { Prob } \\ -0.731492 & 0.09407701 & -7.78 & 0.000\end{array}$

Metro

Density

Log Population

$0.047936 \quad 0.01646115$

2.91 0.004

0.00001194

0.00000318

$\begin{array}{ll}0.194270 & 0.01722079\end{array}$

3.76

0.000

$-0.00038219$

0.00027209

11.25

0.000

Percent Rural

$-0.00097468$

0.00033439

$-1.40$

0.160

Population Growth

$-0.00254649 \quad 0.00062532$

$-2.91$

0.004

HS Education

Per Capita Income

0.00001407

0.00000254

$-4.07$

0.000

$-0.00177783$

0.00139605

$-0.00136935$

0.00039399

5.53

0.000

Industrial Base

0.052450

0.01387853

$0.00154316 \quad 0.00090595$

$\begin{array}{ll}-0.0170920 & 0.14420343\end{array}$

$-0.00426311$

0.00160607

$-1.27$

0.203

$-3.48$

0.001

Access to MRF

Availability of Landfills

MSW Cost (1)

Conservation Members

$0.014733 \quad 0.00316514$

0.052586

0.01733998

$-0.029533$

0.00763059

3.78

0.000

$\begin{array}{ll}1.70 & 0.089\end{array}$

$-1.19 \quad 0.236$

$2.65 \quad 0.008$

Local Env Quality

State MSW Policy

$-0.00060668$

0.00066426

4.65

0.000

$3.03 \quad 0.002$

$\begin{array}{ll}-3.87 & 0.000\end{array}$

State Env Policy

$-0.91$

0.361

(1) MSW cost estimates from another regression using only 262 of counties with population over 500,000 . 


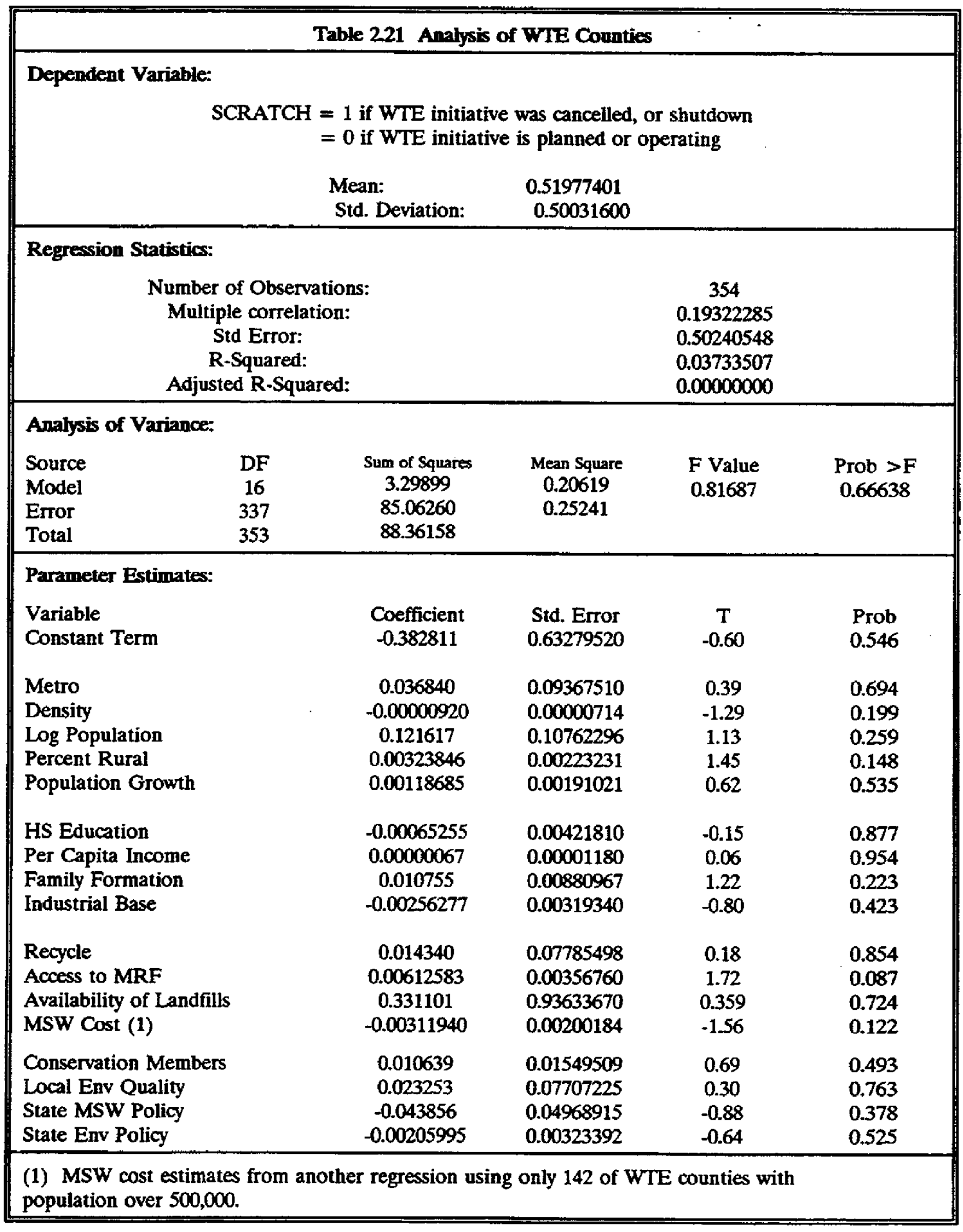


discriminate between those counties that have had a WTE initiative and those counties that have not had a WTE initiative. Most of the coefficients in the WTE/non-WTE regression presented in Table 2.20 are significant. The low $\mathrm{R}$-squared coefficient for the second analysis also indicates that the nonsignificance of the individual coefficients is not simply due to multicollinearity. None of the variables are significant in the active/non-active WTE regression. In other words, the factors useful for distinguishing between counties with and without WTE initiatives are not useful predictors of a WTE project's ultimate success or failure.

\subsection{CONCLUSIONS}

Three general conciusions may be drawn from this segment of the study. First, several factors may be used to define the set of counties likely to consider WTE programs. In particular, scores on population size, density, income, and other factors serve as thresholds to define the regions that consider WTE initiatives.

Second, counties that have had WTE initiatives may be grouped into two market sizes, metropolitan and non-metropolitan. The similarity of results in the mean comparisons for metro and non-metro counties is intriguing. It appears that two distinct markets exist: one market for large WTE facilities in large, densely populated metropolitan areas and another market for smaller modular units in the larger, non-metropolitan counties. Variables used in the regression analysis appear to identify those counties in which WTE may be a feasible option.

Finally, the factors that ultimately lead to the success or failure of a WTE initiative are not among the socioeconomic factors considered in this part of the overall study. Perhaps there are more subtle financial, political, and/or institutional factors that are important in determining the likely success of a WTE facility-even when the basic set of feasibility criteria is met. The next two chapters investigate several possible candidates. 


\section{CHAPTER 3. WTE AND FINANCIAL ISSUES.}

\subsection{INTRODUCTION}

In the previous chapter, the decision to abandon numerous WTE projects in the latter 1980s and early 1990 s was viewed in relation to various socioeconomic parameters. This chapter focuses specifically on financial trends that occurred during this time period and on the financial barriers that may have contributed to WTE project cancellation. In addition, this chapter examines current and anticipated financial trends and their potential impacts on the long-term viability of WTE.

Three major financial trends played a role in decisions about WTE projects in the late 1980s and early 1990 s and are the primary focuses of this chapter. First, the costs of WTE facilities escalated rapidly during this period, primarily in response to requirements for more sophisticated environmental controls and the movement toward large mass-burn and RDF technologies. Second, federal tax policy took a major turn in 1986 with the enactment of the Tax Reform Act (TRA86), which made it more difficult for local governments to finance capital-intensive WTE facilities with bonds that were exempt from federal taxes. Third, trends occurred that made it more difficult for communities to finance WTE facilities, aside from their increasing costs and difficulties in obtaining tax-exempt financing. For example, communities were faced with increasing across-the-board demands from federal and state governments to respond to numerous environmental concerns, while at the same time federal and state governments were taking various actions to make the financing of those projects more difficult and costly. Large capital expenditures, tax and expenditure limitations, and the inability of some communities to access national capital markets placed financing restrictions on some jurisdictions.

Some 209 projects in various stages of planning were cancelled between 1986 and 1990 . Cancellations have occurred at all major decision nodes: (1) at the initial decision node after preliminary investigation, (2) at the conceptual-planning stage, and (3) at the advanced-planning 
stage. ${ }^{1}$ Information from Government Advisory Associates (GAA) in combination with data gathered for this work indicate that, of those jurisdictions that initially made a decision to investigate WTE technology, 62 jurisdictions decided not to pursue the option and cancelled; 104 jurisdictions decided to proceed to the conceptual stage of planning and then cancelled; 43 decided to proceed to the advanced stages of planning before deciding to cancel. ${ }^{2}$

\subsection{THE INCREASING COSTS OF WTE FACILITIES}

Between 1982 and 1990, the mean adjusted constant capital costs of all existing and advancedplanned WTE facilities in the United States increased 19.6 percent, from $\$ 43.8$ million in 1982 to $\$ 52.4$ million in 1990 (in 1982 dollars). The total dollar amount of facility costs increased from $\$ 4.9$ billion in 1982 to $\$ 10.5$ billion in 1990 , reflecting an increase in total existing and advanced-planned facilities from 111 in 1982 to 201 in 1990 . More revealing is the fact that from 1982-1990, the mean cost of advanced-planned facilities increased by 40.6 percent, from $\$ 62.1$ million in 1982 to $\$ 87.3$ million in 1990 (see Table 3.1). The total cost of advanced-planned facilities increased from $\$ 3.8$ billion in 1982 to $\$ 5.3$ billion in 1990 , while the number of advanced-planned facilities was constant.

There are a number of reasons for the rapid escalation in facility costs over the decade. One of the most important reasons is that many of the advances in air pollution technology did not exist

${ }^{1}$ Government Advisory Associates (1991) defines a "conceptually planned facility" as one that has been the subject of a completed feasibility study, has had a request for qualification and proposal, or has been a proposed merchant facility. An "advanced-planned facility" is one that has initiated the permitting process, has established a construction schedule, and has selected a vendor.

2 These numbers are based on the GAA data bases (1986-1991) and include additional information collected as part of this work (Kelsay, 1992). (Kiser 1991, 1992 are other sources of information about combustion facility status, characterizing facilities according to three stages: planning, construction, and operational). Ten facilities classified as advanced planned in the 1990 GAA data base have subsequently been scratched. In addition, 27 facilities have been deleted for financial analysis purposes (e.g., captive armed forces facilities, prisons, and long-term shutdowns). The 27 deleted facilities had a total design capacity of 6,943 tpd with 17 facilities having design capacity of less than $125 \mathrm{tpd}$. The number of facilities presented in this chapter, therefore, differs from numbers reported in the previous chapter, which reflect GAA totals. 


\begin{tabular}{||l|l|r|r|r||}
\hline \multicolumn{5}{|c|}{ Table 3.1 Waste-to-Energy Facility Adjusted Capital Costs: 1982-1990 } \\
(in millions of constant 1982 dollars)
\end{tabular}

Sources: Adapted from information in Government Advisory Associates, Inc., Resource Recovery Yearbook, 1982, 1984, 1986, 1988, 1991.

or were not required when earlier facilities were constructed. Further cost escalations can be expected due to more stringent environmental controls. For example, the U.S. EPA has estimated that the national annualized cost of the New Source Performance Standards (NSPS) for MSW combustion technologies (as part of the Clean Air Act) will be $\$ 190$ million for new sources and $\$ 320$ million for existing sources. ${ }^{3}$

In addition, the distribution of WTE technologies explains a substantial portion of the rapid increase in facility costs, as there is a significant difference in the planned-and existing-facility design

${ }^{3}$ Edwards (1991) reports that these NSPS would result in national average cost increases of \$13/ton and $\$ 12 /$ ton, respectively, for waste burned at new and existing sources. These figures represent about a 20 percent increase in the cost of WTE technology. 
capacities (see Table 3.2). For 1990, the mean design capacity of all planned facilities was 1,101 tons per day (tpd) as compared with 656 tpd for existing facilities.

There are several reasons for this large discrepancy. First, 27 percent of existing WTE facilities are comprised of small, modular facilities, while only 6.5 percent of advanced-planned facilities are of this design. With respect to advanced-planned facilities, 79.3 and 12.9 percent will employ large-scale, mass-burn technology and RDF processes, respectively. Only 52.8 percent of existing facilities employ such designs. Second, the design capacity of all resource recovery facilities is increasing, regardless of the technology chosen. As of 1990 , advanced-planned, mass-burn facilities were slated to process an average of $1,151 \mathrm{tpd}$, while the mean for existing mass-burn facilities was 913 tpd. In addition, regional variations with respect to design capacity explain some of the cost differences (Table 3.3). For example, over 68 percent of all WTE facilities in the Northeast, which accounts for 53 percent of all advanced-planned facilities, have design capacities greater than 500 tpd, and only 15.1 percent have design capacities of less than 200 tpd, lowest of any region. In contrast, the other regions (the South, Northcentral, and West) are dominated by small-design capacities (i.e., less than 200 tpd). Those regions have $39.1,48.8$, and 40.9 percent, respectively, of their facilities in this "small-design" category.

\subsection{FEDERAL TAX POLICY}

Although the tax-exempt market is widely used to finance solid and hazardous waste facilities and a host of other "quasi-public" activities, federal tax policy has increasingly placed restrictions and limitations on federally tax-exempt state and local financing. ${ }^{4}$ Between 1968 and 1989, there were

\footnotetext{
${ }^{4}$ For an excellent review of tax-exempt bond legislation over the 1968 to 1989 period, see Zimmerman (1991).
} 


\begin{tabular}{||c|l|c|}
\hline \multicolumn{2}{|c|}{ Table 32 } & WTE Facility Design Capacities: 1990 \\
(in tons per day)
\end{tabular}

Source: Adopted from information in Government Advisory Associates, Inc: Resource Recovery Yearbook 1991.

\begin{tabular}{||l|c|c|c|c|}
\hline \multicolumn{5}{|c|}{$\begin{array}{c}\text { Table 3.3 WTE Design Capacity by Region: } \\
\text { Advanced-Planned and Existing Facilities (1990) }\end{array}$} \\
\hline DESIGN CAPACITY & NORTHEAST & SOUTH & NORTHCENTRAL & WEST \\
\hline $0-200$ & $15.1 \%$ & $39.1 \%$ & $48.8 \%$ & $40.9 \%$ \\
\hline $201-500$ & $16.4 \%$ & $15.6 \%$ & $14.0 \%$ & $18.2 \%$ \\
\hline $501-1,000$ & $31.5 \%$ & $20.3 \%$ & $18.6 \%$ & $18.2 \%$ \\
\hline OVER 1,000 & $37.0 \%$ & $25.0 \%$ & $18.6 \%$ & $22.7 \%$ \\
\hline \hline
\end{tabular}

Source: Adopted from information in Government Advisory Associates, Inc. Resource Recovery Yearbook 1991. 
17 major tax laws that significantly affected the municipal bond market and impacted the ability of state and local governments to raise public capital. Changes in the municipal bond market include changes in public purpose definition, arbitrage profits, tax shelters, private capital costs, targeting of beneficiaries, user restrictions, volume allocations, and other restrictions.

Beginning with the Revenue and Expenditure Control Act (RECA) of 1968, which stated that certain bonds that had an unacceptably large portion of proceeds being used for private purposes were taxable as an Industrial Development Bond (IDB), the federal government sought to limit the use of tax-exempts by state and local officials. However, this initial attempt to curb tax-exempt financing did not halt the movement toward tax-exempts. In fact, the share of private-activity bonds as a percentage of total bond volume increased from 20.6 percent in 1975 to 72.7 percent by 1984 . In order to slow this explosive growth and thus prevent further erosion of the federal tax base, Congress adopted a series of volume caps on the amount of private-activity bonds that could be issued by a state in any calendar year. Although RECA had attempted to place restrictions on certain types of tax-exempt activity prior to 1984, the Deficit Reduction Act of 1984 (DRA84) was the first piece of legislation to extend the volume caps to a large number of IDBs. DRA84 set state yearly volume caps for private-activity bonds at $\$ 150$ per capita or $\$ 200$ million per state, whichever was greater. The objective was to reduce the growth in private purpose bonds, while giving the state and local jurisdictions the flexibility to decide what activities should be recipients of the volume cap.

The TRA86 has been the most far-reaching attempt to curb the volume and applications of taxexempt, private-activity bonds. TRA86, which became effective in 1987, went a step further toward reducing the volume of private-activity bonds by establishing state volume caps of $\$ 50$ per capita or $\$ 150$ million, whichever was largest. (For 1987, the tax-exempt, public-activity bond cap was set at $\$ 75$ per capita or $\$ 250$ million.) TRA86 also further restricted the number of activities qualifying for exemption. The net effects of these various restrictions were to (1) limit the available tax-exempt 
financing that might be used for WTE facilities, (2) make it more difficult for WTE projects to qualify for tax-exempt financing, and as a result (3) increase the overall cost of WTE financing.

\subsection{OTHER FINANCIAL CONSTRAINTS ON LOCAL JURISDICTIONS}

The 1980 s presented a dual problem for local governments with respect to financing capitalintensive WTE facilities and other public infrastructure-i.e., increasing federal and state mandates for improving environmental protection in combination with constraints on funds to accomplish these mandates. Gold (1991) reports that revenues from taxes and fees and federal aid fared much better for state governments than for local governments. Federal aid to county and municipal governments during the period 1980 to 1988 decreased by 46.6 percent and 37.9 percent, respectively. At the same time, property taxes and non-property taxes increased substantially, more than doubling over the period at the county level. Because many local governments face real or perceived tax and expenditure limitations, the increasing demand for environmental capital may crowd out other local public investments. Most WTE facilities are financed through some type of revenue-bond mechanism; and if the debt service is greater than the user fees generated from a bond issue, the overall credit rating of the community may be impaired. It is generally agreed that a community's ability to raise user fees to support facility debt will be constrained once user fees reach an aggregate of one to two percent of median household income. ${ }^{5}$

\subsection{ADJUSTMENTS IN THE FINANCING OF WTE PROJECTS}

State and local governments are adjusting to altered financial conditions and increasing demands for environmental infrastructure by taking a four-prong approach to successfully finance

\footnotetext{
${ }^{5}$ For a thorough discussion of the financial options available to finance environmental facilities, see Environmental Financial Advisory Board (1991c).
} 
WTE facilities. First, in order to successfully finance large capital expenditures, local jurisdictions are using a combination of several financing mechanisms. Second, jurisdictions are increasingly using local-sector resources for financing (e.g., city and county revenues and taxable revenue bonds). Third, as traditional debt options become less viable because of restrictions imposed by, for example, TRA86, innovative and new methods of finance are being used to adjust to altered market conditions. (Appendix A summarizes the advantages and disadvantages of traditional and innovative financial methods.) Fourth, private-sector participation is being used more extensively. Private-sector participation allows local-sector resources to be reallocated elsewhere for other public good consumption and acknowledges the constraints imposed by federal legislation, such as TRA86. Tables 3.4 and 3.5 reflect these adjustments at the local level during the 1982 to 1990 period.

WTE facilities are sometimes financed alone, and sometimes-maybe increasingly so--financed as a componnent of a larger financing package obtained for a group or system of waste management facilities and programs. The following analysis does not segregate the two types types of financing packages. However, where WTE was included in a larger financing package, only the portion of financing dedicated to WTE is considered in the analysis (Kelsay 1992). Whether there are differences in the types of financing selected or in the success in constructing and obtaining WTE financing is not addressed herein and requires future research.

\subsubsection{Advanced-Planned and Operational Facilities}

The use of private equity to finance WTE projects continues to grow. In $1990,44.8$ percent of all existing and advanced-planned WTE facilities reported the use of equity capital as a component of their finance packages. The use of revenue bonds (both tax-exempt and taxable) have also increased over the decade, with 10.8 percent of 1982 facilities and 47.2 percent of 1990 facilities reporting these methods of finance. 


\begin{tabular}{|l|r|r|r|r|c||}
\hline \multicolumn{7}{|c|}{ Table 3.4 WTE Capital Finance: Historical Trends of Finance } \\
(\% of facilities using method)
\end{tabular}

Sources: Government Advisory Associates, Inc., Resource Recovery Yearbook, 1982, 1984, 1986-87, 1988-89, 1991.

* Multiple responses: firms reported multiple forms of finance.

** "Tax-Exempt Revenue Bond" and "IDB" are used interchangeably and many local officials do not distinguish between the two. A tax-exempt revenue bond generally refers to municipal financing (tax-exempt) for a municipal project. An IDB generally refers to tax-exempt financing of a private-sector project which a municipality views as beneficial for a municipality. 


\begin{tabular}{|c|c|c|c|c|}
\hline \multicolumn{5}{|c|}{$\begin{array}{l}\text { Table } 3.5 \text { Alternative Methods of Finance: } \\
\text { Advanced-Planned and Existing WTE Facilities 1984-1990 } \\
\text { (\% of facilities using method)* }\end{array}$} \\
\hline STAGE OF DEVELOPMENT & 1990 & 1988 & 1986 & 1984 \\
\hline \multicolumn{5}{|l|}{ Advanced Stage } \\
\hline $\begin{array}{l}\text { Private Investment } \\
\text { IDBs** } \\
\text { Municjpal Revenue Bonds** } \\
\text { General Obligation Bonds }\end{array}$ & $\begin{array}{r}57.4 \\
36.1 \\
55.7 \\
4.9\end{array}$ & $\begin{array}{r}33.7 \\
36.1 \\
13.6 \\
4.7\end{array}$ & $\begin{array}{r}42.9 \\
40.6 \\
6.0 \\
3.8\end{array}$ & $\begin{array}{r}37.5 \\
25.0 \\
12.5 \\
9.7\end{array}$ \\
\hline \multicolumn{5}{|l|}{ Existing Plants } \\
\hline $\begin{array}{l}\text { Private Investment } \\
\text { IDBs } \\
\text { Municipal Revenue Bonds } \\
\text { General Obligation Bonds } \\
\text { State and Federal Grants }\end{array}$ & $\begin{array}{r}39.3 \\
33.6 \\
27.9 \\
21.4 \\
8.2\end{array}$ & $\begin{array}{l}16.8 \\
17.8 \\
14.2 \\
13.0 \\
14.7\end{array}$ & $\begin{array}{r}17.9 \\
17.9 \\
8.7 \\
15.6 \\
23.4\end{array}$ & $\begin{array}{r}18.8 \\
12.5 \\
9.7 \\
18.7 \\
21.5\end{array}$ \\
\hline
\end{tabular}

Sources: Government Advisory Associates, Inc., Resource Recovery Yearbook, 1982, 1984, 1986-87, 1988-89, 1991.

* Multiple responses: some firms reported multiple forms of finance.

** "Tax-Exempt Revenue Bond" and "IDB" are used interchangeably and many local officials do not distinguish between the two. A tax-exempt revenue bond generally refers to municipal financing (tax-exempt) for a municipal project. An IDB generally refers to tax-exempt financing of a private-sector project which a municipality views as beneficial for a municipality. 
Federal grants have declined over the period 1982-1990, from a high-of 13.4 percent in 1982 to 8.5 percent in 1990 . State grants have increased from 10.2 percent in 1982 to 17.4 percent in 1990 . The use of city, municipal, and county revenues has also increased over the period from 4.7 percent in 1982 to 11.0 percent of all existing and advanced-planned facilities in 1990 . State loan guarantees and state bonding authorities were a financial component in six percent of facilities in 1990 , up slightly from the 1982 level.

Leasing and other innovative types of finance (e.g., bond insurance, letters of credit, and variable-rate debt) are emerging as a primary source of finance. Leveraged leasing or bank leasing was a component in the financing of 7.5 percent of facilities in 1990 , while 16.9 percent of existing and advanced-planned facilities report some type of credit enhancement in their financing package.

With respect to the advanced-planned facilities, IDB use has increased as a financing component, from 25.0 percent in 1984 to 36.1 percent in 1990 (Table 3.5). Municipal revenue bonds have increased from 12.5 percent in 1984 to 55.7 percent in 1990 . With respect to existing facilities, the use of IDBs and municipal-revenue bonds has increased from 12.5 percent and 9.7 percent in 1984, to 33.6 percent and 27.9 percent in 1990 , respectively. Private-equity investment has more than doubled during the period, increasing from 18.8 percent in 1984 to 39.3 percent in 1990 . State and federal grants have declined substantially during the period, reflecting decreased intergovernmental revenues.

For successful WTE facilities, private-equity capital, tax-exempt bonds, and taxable municipal bonds are the major sources of finance. More importantly, an emerging trend among successful facilities is the use of multiple financing mechanisms. As WTE participants adjust to a changing financial environment, innovative methods and a combination of several financial instruments are increasingly found in the financial packages of successful projects. In order to assess which financing mechanisms have accounted for the largest dollar volumes of total WTE financing (in contrast to 
their frequency of use), a data collection exercise (Kelsay, 1992) was undertaken to augment the GAA data base. Table 3.6 summarizes these results for 1990 .

When viewed from the perspective of total dollar financing, a somewhat different pattern emerges. IDBs and tax-exempt revenue bonds accounted for 46.3 percent and 21.4 percent, respectively, of total dollar volume. This reflects the predominant use of tax-exempt mechanisms prior to the 1986 tax reforms and the large lag time in facility planning. Private equity accounted for 12.6 percent of the total dollar amount. State and federal grants and city/county/municipal revenues were found to represent a small, but important, component of finance packages. In addition, there is a trend toward the increasing use of innovative financing. For example, lease-revenue bonds and other types of lease structures account for 7.6 percent of total financing; and the use of third-party credit enhancements (e.g., letters of credit, bond insurance, and guarantees) were involved in 16.9 percent of all transactions. A growing emphasis on minimizing the financial risks to the local community (due to political and other objections) and general difficulties with the use of traditional financial instruments suggest that the use of these innovative risk-spreading mechanisms will increase over time.

\subsubsection{Cancelled Facilities}

This chapter began with a supposition that financial changes in the latter 1980s played a role, possibly a key role, in the massive cancellations of WTE facilities. While there is clear evidence that the direction of change in financial markets in the latter 1980 s was toward making financing more difficult and costly, the importance of financial constraints in the actual decisions to abandon a WTE projects is less clear. This subsection reviews the information that is available with respect to this question. 


\begin{tabular}{||l|c|c|c||}
\hline \multicolumn{4}{|c|}{ Table 3.6 WTE Capital Finance Mechanisms: 1990 } \\
\hline Method of Finance & $\begin{array}{c}\text { Number } \\
\text { of Facilities Using Method* }\end{array}$ & $\begin{array}{c}\text { Amount } \\
\text { (in billions of dollars) }\end{array}$ & $\begin{array}{c}\text { \% of Total } \\
\text { Finance }\end{array}$ \\
\hline IDBs & 73 & $\$ 7.893$ & 46.3 \\
\hline $\begin{array}{l}\text { Tax-Exempt Revenue } \\
\text { Bonds }\end{array}$ & 38 & 3.642 & 21.4 \\
\hline Private Equity & 61 & 2.142 & 12.6 \\
\hline $\begin{array}{l}\text { General-Obligation } \\
\text { Bonds }\end{array}$ & 29 & 1.143 & 6.7 \\
\hline Taxable-Revenue Bonds & 15 & 0.524 & 3.1 \\
\hline State \& Federal Grants & 21 & 0.203 & 1.2 \\
\hline $\begin{array}{l}\text { City \& County } \\
\text { Revenues }\end{array}$ & 11 & 0.107 & 0.6 \\
\hline $\begin{array}{l}\text { Adjustable-Rate } \\
\text { Municipal Bonds }\end{array}$ & 2 & 0.081 & 0.5 \\
\hline Lease-Revenue Bonds & 15 & 1.300 & 7.6 \\
\hline \multicolumn{1}{|c|}{ Total } & $\$ 17.035$ & $100.0 \%$ \\
\hline $\begin{array}{l}\text { Credit Enhancements** } \\
\text { Letters of Credit, Bond } \\
\text { Insurance, and } \\
\text { Guarantees) }\end{array}$ & 265 & $\$ 2.824$ & $16.9 \%$ \\
\hline
\end{tabular}

Sources: Government Advisory Associates, Resource Recovery Yearbook, 1991 and Kelsay (1992).

* Some facilities use more than one method of finance.

** Credit enhancements are not a financing method, but rather are a means of improving the viability of the finance methods listed above. 
It is difficult to assess the magnitude of the impact of selecting a particular financing mechanism on the decision to cancel a WTE project because (1) it is not possible to disentangle the effects of financial barriers as compared to barriers presented by other factors considered in this study, and (2) many facilities that were cancelled had not yet gotten to the financing stage or had no specific financing mechanism yet selected. Finance mechanism data are almost nonexistent for cancellations that occurred in the early stages of planning. Nonetheless, data on the financing mechanism chosen by many advanced-planned facilities are available and were collected for this work. Tables 3.7 and 3.8 summarize these results.

In terms of the financing method used, private equity was a component in 31.9 percent of cancelled facilities for which data are available. IDBs and tax-exempt revenues were identified as potential finance components in 28.6 percent and 13.2 percent of projects, respectively. Generalobligation bonds were identified in 8.8 percent of cancelled projects. Upon examination of methods of finance with respect to total dollars, the data show 75.8 percent of facilities planned to use IDB and tax-exempt revenue bonds. Local sector revenues, adjustable rate bonds, and lease financing were insignificant or zero.

Possibly the most important finding here is that innovative methods of finance (e.g., lease arrangements, adjustable-rate debt, and third-party credit enhancements) were not present in any of the financial packages put together or considered for facilities that were eventually cancelled. It is unclear if the absence of multiple and innovative financing mechanisms was a contributor to the failure of the project, or if these projects simply did not get far enough down the development path to consider these innovative and possibly less obvious financing strategies. To the extent that public opposition arose to the WTE project on the basis of increased financial risk to the community, the absence of these innovative approaches, which are designed primarily to lower the community's level 


\begin{tabular}{|c|c|c|}
\hline METHOD OF FINANCE & $\begin{array}{c}\text { NUMBER OF FACILITIES } \\
\text { USING METHOD }\end{array}$ & $\begin{array}{l}\text { \% OF FACILITIES } \\
\text { USING METHOD }\end{array}$ \\
\hline Private Equity & 29 & 31.9 \\
\hline IDBs & 26 & 28.6 \\
\hline Tax-Exempt Revenue Bonds & 12 & 13.2 \\
\hline General Obligation Bonds & 8 & 8.8 \\
\hline Taxable Revenue Bonds & 4 & 4.4 \\
\hline State Grants & 7 & 7.7 \\
\hline Federal Grants & 2 & 2.2 \\
\hline City \& Municipal Revenues & 2 & 2.2 \\
\hline Lease or Bank Leases & 1 & 1.0 \\
\hline Total & 91 & 100.00 \\
\hline
\end{tabular}

Sources: Government Advisory Associates, Resource Recovery Yearbook, 1982, 1984, 198687, 1988-89, 1991, and Kelsay (1992).

* Information on financial methods used was available only for those facilities that were in the advanced stages of planning. Facilities in the conceptual stages or before had not decided on a finance mechanism. 


\begin{tabular}{|c|c|c|c|}
\hline \multicolumn{4}{|c|}{$\begin{array}{l}\text { Table 3.8 WTE Capital Finance Mechanisms at } \\
\text { Cancelled Facilities by Finance Amount: 1986-1990 }\end{array}$} \\
\hline METHOD OF FINANCE & NUMBER* & $\begin{array}{c}\text { AMOUNT } \\
\text { (in billions of dollars) }\end{array}$ & $\begin{array}{l}\% \text { of } \\
\text { TOTAL FINANCE }\end{array}$ \\
\hline IDBs & 21 & 2.511 & 51.2 \\
\hline Tax-Exempt Revenue Bonds & 12 & 1.20 & 24.6 \\
\hline Private Equity & 19 & 0.781 & 15.9 \\
\hline General Obligation & 7 & 0.249 & 5.1 \\
\hline Taxable Revenues & 2 & 0.087 & 1.8 \\
\hline State \& Federal Grants & 6 & 0.021 & 0.4 \\
\hline City \& County Revenues & 1 & 0.010 & 0.2 \\
\hline Adjustable Rate Muni Bonds & - & - & - \\
\hline Lease or Bank Leases & 1 & 0.038 & 0.8 \\
\hline Totals & 75 & $\$ 4.904$ & $100.0 \%$ \\
\hline
\end{tabular}

Sources: Government Advisory Associates, Resource Recovery Yearbook, 1982, 1984, 198687, 1988-89, 1991 and Kelsay (1992).

* Financial amounts were available only for those facilities that were in the advanced stages of planning. Those facilities in the conceptual stages or before had not decided on a finance mechanism. The number of facilities in Tables 3.7 and 3.8 differs because some facilities had decided on the financing mechanisms but not the dollar allocation toward each method.

of financial risk, may have played a role in project cancellation. Unfortunately, data do not currently exist on the degree to which financial risk to the community played a role in the various project abandonments. This issue is addressed further in the next chapter as part of our case studies.

With respect to restrictions placed on tax-exempt financing by TRA86, the situation is again less than clear. Recall that TRA86 (1) imposed caps on the amount of tax-exempt financing a state can issue to support projects such as WTE facilities and (2) imposed more severe restrictions on the types of projects that qualify for tax-exempt financing particularly with respect to the degree to which private firms are allowed to be involved in the project. 
There is little doubt that the restrictions imposed by TRA86 played. a significant role in escalating the rate at which WTE projects were introduced in the latter 1980s. Some projects that might have developed at a more leisurely pace were no doubt "moved along" to avoid the impending financing restrictions of TRA86. If TRA86, in fact, resulted in an upward surge in the number of WTE projects being considered in the latter 1980s, a follow-on argument is that the number of cancellations also increased even if the probability of a project making it through to operation remained unchanged.

With respect to the caps imposed by TRA86, available data show that six of the nine states that contributed more than 49 percent of all project cancellations came close to fully using their allotted caps on tax exempts. ${ }^{6}$ Further, this work has found that more than $\$ 750$ million in solidwaste financing requests were denied in $1991^{\circ}$ in those states as a result of the unified volume caps. However, three of those states-i.e., New Jersey, New York, and Pennsylvania-did not use more than 70 percent of their allocations in either 1989 or 1990, and Pennsylvania used only 35 percent of its allotment in $1989 .^{7}$ Therefore, analysis of the data in this area does not lead to any hard conclusions about the effects of the TRA86 caps on WTE cancellations.

\subsection{SUMMARY AND FUTURE OUTLOOK}

This chapter has examined how financial constraints changed during the 1980 s and the impacts of those changes on decisions to abandon WTE projects and on the overall viability of WTE. Three

\footnotetext{
${ }^{6}$ The data show that five states (California, Florida, Illinois, Texas, and Washington), which exhausted or came close to exhausting their volume caps, accounted for 38.5 percent of facility cancellations with respect to total design capacity. The same five states accounted for 29.5 percent of facility cancellations in terms of the number of facilities cancelled.

${ }^{7}$ Due to the inherent problems of the unified-volume-cap limitations (e.g., short-planning horizon, carryforward provisions, dedicated activity allocations, etc.) some states have, in effect, exhausted their volume caps if they utilize more than about 75 percent of their allocations.
} 
trends were particularly important. First, increasing facility costs led to very large financing packages, which for many communities were the largest financing packages ever considered. For advancedplanned WTE facilities, constant adjusted capital costs increased by more than 40 percent during the period 1982 to 1990 . Second, state and local tax and expenditure limitations and changes in the taxexempt market forced adjustments in the risk/return relationships necessary for successful finance. These adjustments led to more innovative methods of finance including leasing arrangements, adjustable-rate debt, letters of credit, municipal-bond insurance, and other third-party credit enhancements. Third, states and local communities have been faced with increasing demands for more expenditures on environmental infrastructure at the same time they have faced more difficult financing conditions. Federally imposed unified volume caps and severe restrictions on tax-exempt financing have led communities to adopt non-traditional and, in some cases, more expensive methods of finance. In addition, the extremely large capital outlays required for some WTE facilities have forced some communities to make hard decisions about where they allocate their limited credit lines. Communities are sometimes forced to make tradeoffs between funding environmental infrastructure and more traditional activities, such as housing and education. And although the costs of all MSW management options are expected to rise, the decisions of communities about WTE have not been, and will not be, made easier by WTE cost escalations resulting from mandates for stricter environmental controls.

The fundamentals of the long-term bond market are generally positive over the next decade, and, therefore, capital markets should show little strain in funding future expenditures for local environmental projects, such as WTE. The problem is whether local jurisdictions will have the financial ability and the political will to take on higher levels of debt burden. Large, capital-intensive WTE facilities can crowd out other local investments, and some small communities may face obstacles in accessing capital markets. 
On the positive side, however, innovative financial instruments are increasingly available that overcome to some extent the financial obstacles imposed during the 1980s. Adjustments on the parts of capital markets and communities to new financial realities are likely to improve the financial viability of capital-intensive projects, such as WTE facilities. Although financing constraints will continue to be problematic, especially for those communities with questionable credit ratings, financial constraints are not expected to severly limit the overall viability of WTE in the 1990s. 


\section{APPENDIX A \\ ALTERNATIVE FINANCE MECHANISMS FOR WTE FACILITIES ADVANTAGES AND DISADVANTAGES}

\section{Debt Obligations}

- Two General Types

- General Obligation Bonds

Advantages

- low interest cost to municipality

- low risk to investor

Disadvantages

- full faith and credit obligation of municipality

- requires unlimited tax authority of issuer in event of default

- Revenue Bond (e.g., IRB, Private Activity Bond, Taxable Municipal Bonds)

\section{Advantages: Tax-Exempt Revenue Bonds}

- bond pledges only revenue from project

- no obligation by issuer to use taxing powers in case of default

Advantages: Taxable Municipal Revenue Bonds

- exempt from state income taxes

- state and local pledges enhance creditworthiness of issue

- property, sales, and other tax exemptions

Disadvantages: Revenue Bonds

- shifting of risk results in higher interest cost

- state and local revenue loss due to exemption 


\section{Federal, State, and Local Grant and Revenue Enhancements}

- Federal and State Grants and Guarantees

\section{Advantages}

- Jow cost method to enhance creditworthiness of local jurisdictions

- allows small jurisdictions to tap national credit markets, lowering interest costs

- no direct federal and state outlay

\section{Disadvantages}

- guarantor may inherit some contingent liability

- encourages use of top quality tax shelters which compete with other debt instruments

- State Bonding Banks and Authorities

\section{Advantages}

- allows jurisdictions which are small and/or with no credit rating to tap national credit markets

- no direct state outłay

- direct borrowing capacity of state is unaffected

- lowers borrowing costs by elevating debt issue to highest security rating

\section{Disadvantages}

- presently funded at inadequate levels for large, capital-intensive projects

- guarantor may inherit contingent liability

\section{Innovative Market Approaches to Debt Financing}

- Leasing

\section{Advantages}

- alternative to immediate expensing of funds

- lease obligation not classified as long-term debt in calculation of applicable debt limitations

- does not require voter approval

- value of tax credits and depreciation created when none existed before (municipal perspective)

- eliminates balance-sheet debt instrument (private sector perspective)

- private sector involvement in financing is required 


\section{Disadvantages}

- large, illiquid investment limits scope of potential investors

- Letters of Credit (LOC)

Advantages

- issue's credit risk transferred to third party

- reduced borrowing costs because of top credit rating

- LOC recognized by Standard \& Poors and Moodys (bond insurance recognized only by Standard \& Poors)

\section{Disadvantages}

- additional annual charge is percent of total issue

- funds borrowed against either facility or bank may require higher interest charge (usually $50-100$ basis points above prime)

- appearance of dependency on bank's credit

- Bond Insurance

\section{Advantages}

- allows low rated or non-rated issues to reduce interest costs (insurance results in AAA rating)

- insurance issue can be large

\section{Disadvantages}

- premium rages from 0.1 percent to 2.0 percent of principal and interest over the life of loan

- insurance firms must spread risk-potential for capacity constraints in certain geographic regions

- high reserves an high debt coverage ratios required for revenue supported debt

- Variable Rate Municipal Debt

\section{Advantages}

- tax-exempt interest results in lower borrowing costs

- interest rate is lowest available to municipalities

- demand or put option enhances liquidity 
Disadvantages

- use of short-term debt to finance long-term capital investments

- interest rate risk borne by municipality

- need for access to financial institution

- risk that credit rating of credit facility provider may decline at remarketing

- Interest Rate Swaps

$\underline{\text { Advantages }}$

- debt management without resorting to new issuance

Disadvantages

- interest rate risk to parties involved in transaction 


\section{CHAPTER 4. CASE STUDIES}

\subsection{INTRODUCTION}

The management of municipal solid waste is clearly an issue of increasing public concern. Proponents view WTE as a key solution to this country's solid waste management problem. However, as discussed in previous chapters, many proposed WTE facilities have been cancelled during the late 1980 s and early 1990 s.

This chapter attempts to describe the range of factors that influence decisions regarding WTE that are made by municipalities but does not seek to judge the correctness of the decisions. Influential factors include the technical and financial issues previously discussed as well as social and political issues. Separately investigating these kinds of factors may not provide a composite or synthetic picture of the factors leading to decisions regarding WTE facilities in any one community. Detailed case studies, in contrast, allow a broad perspective about the decision-making process within communities. Describing this broad perspective is the primary objective of the case studies discussed in this chapter.

Decision making involves at least two components: the decisions that are made, which we label outcomes, and the process of making decisions. In the case of WTE, the outcomes of interest are decisions whether or not to proceed with the WTE facility and the degree to which those decisions are supported within the relevant municipalities. A municipality may decide to build a WTE facility without having the strong backing of citizens or politicians, as an example. The process of decision making involves the activities undertaken in the course of reaching an outcome. Process decisions include procedures for choosing host sites, whether and when to hold public meetings, whether to hold public referenda, and the like. Process clearly is linked to outcome, but like processes need not lead to like outcomes. 
The study reported here sought to discern the factors that are critical to decisions about WTE by examining and comparing two cases in which formalized decisions were made to proceed with the facilities with two cases in which formalized decisions were made not to proceed with WTE facilities. The framework for the study, which emphasizes the context within which decisions were made and the process of decision making, was developed from relevant literature primarily on WTE facility siting, public involvement, and on the siting of controversial facilities in general.

In general, documents about WTE or other solid waste management alternatives do not focus their attention on decision making. There are, however, three exceptions. One is Popp, Hecht, and Melberth (1985). These authors explicitly discuss resource recovery decision making, aiming to identify the most significant variables in that process. They distinguish the following three idealized categories of decision maker: rational, intuitive-emotional, and quasi-rational. Rational decision making is essential in the resource recovery arena, although time, the cost of information, incompatible goals, structural obstacles (e.g., fragmented authority in multi-jurisdictional settings), and political feasibility impede a rational decision-making process, according to Popp, Hecht, and Melberth. The authors recognize that participants in the decision-making process go well beyond elected, formal decision makers to include non-elected governmental administrators, business and industry representatives, community or neighborhood organizations, and the like. However, in discussing the variables that are critical to resource recovery decision making, Popp, Hecht, and Melberth delineate primarily technical and economic variables. They tend to specify the decisions that must be made in the course of planning and implementing resource recovery options instead of discussing the decision-making process or the links between interim decisions and outcomes. For instance, one variable they consider to be critical to decision making is facility siting. The authors cite the proximity of the market for steam and potential transmission losses as highly important and also state that "there will be the inevitable emotional issue of public acceptance to contend with" (p. 
131). They recommend that public awareness programs and citizen advisory group participation should begin in project planning and persist throughout the course of the project.

Much of Popp, Hecht, and Melberth's book is prescriptive, suggesting factors that ought to be considered in the course of developing and implementing resource recovery projects. Similarly, EPA's Decision-Makers Guide to Solid Waste Management (1989) offers practical guidance to communities involved in solid waste management, including WTE. Much of EPA's guide grapples with decisions that are necessary for project planning and implementation such as developing an integrated solid waste program, technical aspects of solid waste management (e.g., waste stream assessment, collection and transfer of solid waste), and a variety of waste management strategies. The chapter on municipal waste combustion focuses on technical (e.g., facility type, facility sizing), administrative (e.g., facility ownership and operation), and economic (e.g., the market for steam, financing options) aspects of that waste management option. In addition, a sidebar in that chapter addresses facility siting and a different chapter prescribes public education and involvement measures. Nonetheless, EPA's guide tends to discuss details about which decisions must be made, rather than stages in the decision-making process. It also does not describe links between components of decision making (either stages or factors) and outcomes.

In contrast, Chertoff and Buxbaum (1986) explicitly explore the factors that lead to public acceptance or rejection of WTE facilities with the goal of recommending measures to surmount public animosity toward the technology. These authors undertook case studies of 30 medium- and large-scale projects that were started from the late 1960 s through the early $1980 \mathrm{~s}$, conducting interviews with project managers or their surrogates. Among the interview questions were why the WTE option was selected, how it was announced publicly, what public responses were, and why the public responded in that fashion. These questions did not aim to investigate the role of the decisionmaking process in outcomes. Chertoff and Buxbaum concluded that the two factors that had the 
greatest effect on public support were the perceived need for a facility (i.e., the.absence of additional landfill capacity) and the existence of groundwater problems caused by existing landfills.

The remainder of this chapter discusses the methods used to conduct and analyze case studies, describes each of the case studies, and analyzes all of the case studies. The chapter concludes by portraying future trends in WTE decision making.

\subsection{METHODS}

Two methods were used to study the factors that contribute to WTE decisions within a community context, a literature review and case studies. The literature has focused on WTE facility siting and on the siting of controversial facilities in general. Literature on related topics, such as public involvement and risk communication, also was reviewed.

A case-study approach was adopted to allow a detailed examination of communities' WTE decision making. To discern the factors distinguishing 'proceed' outcomes from 'do not proceed' outcomes, the case-study approach also was comparative. Time and budgetary constraints limited the number of case studies to four $\rightarrow$ wo sites where formalized decisions were made to proceed with WTE and two sites where the opposite decision was made. While a sample size of four does not allow statistically meaningful generalizations or comparisons to be made, four detailed case studies do allow qualitative analyses and inferences.

\subsection{Selection of Case-Study Sites}

Several criteria were used to select appropriate case-study sites. First, there had to be two sites in which formalized decisions were made to proceed with WTE and two sites in which decisions had been made not to proceed with WTE because of the comparative approach taken in the study. Second, such decisions had to be made relatively recently because the passage of time, due to faulty memory and the influence of later events, makes reconstructing the decision-making process 
increasingly difficult. Also, recent decisions-especially decisions not to proceed with WTE-would enhance the likelihood of locating key participants to interview. Third, the sites had to be geographically diverse even though four sites could not represent every part of the nation. Fourth, to optimize comparisons to the extent practicable with four sites, variation was sought in such characteristics as regional population size and growth trends, local population density in close proximity to the proposed site, and general degree of industrialization.

\subsection{Data Collection.}

Extensive background research was undertaken for each case-study site. Available GAA data, journal articles, progress summaries in solid waste publications, and newspaper articles were examined. Preliminary telephone and facsimile contacts were made with people familiar with the local history of WTE. Researchers then conducted a series of face-to-face interviews with key informants (i.e., people who are knowledgeable about the topic and who may represent the views of a group of people) in each case-study location. All persons who were interviewed, as well as some key people who declined to be interviewed, were sent drafts of their case-study descriptions (sections 4.3-4.6) for their comment and review.

\subsubsection{Selection of Respondents}

The research design specified a goal of conducting 10 extensive interviews during each site visit. In a departure from Chertoff's and Buxbaum's (1986) strategy of interviewing only the project manager (or a surrogate), we recognized that there are many participants in WTE decision making (see also Popp, Hecht, and Melberth, 1985). Background research revealed enough about each case study's decision-making framework for researchers to identify categories of people involved, e.g., committees, government offices, and public groups. Criteria then were developed to select the people who should be interviewed. Researchers sought representation by WTE proponents and opponents. The people interviewed ideally included elected county and municipal government officials, appointed 
officials (e.g., participants in solid waste departments or authorities), relevant civic, religious, or environmental organization representatives (e.g., local environmental groups or neighborhood associations), and representatives of the news media. Respondents were contacted by telephone, facsimile, or letter to make interview appointments. Participation in the study was voluntary. Respondents were informed before participating that their names would not be used in subsequent publications. Most interviews were tape-recorded, with respondents' consent, to ensure that no information was lost in the course of note-taking.

\subsection{Interview Protocol}

The interview protocol was developed in conformance with the study's overall organizing framework that took a sequential approach to case studies. A protocol is a tool that structures interviews by specifying the topics to be covered, but one that allows interviewer discretion in the sequence and phrasing of questions. The protocol, which is reproduced in Appendix B, was divided into the following five sections: (1) demographic information; (2) context factors; (3) decision-making process; (4) decision-making issues; and (5) the resolution of the decision-making process. Respondents were encouraged to discuss relevant decision-making issues without prompting. Interviewers followed the respondents' lead in the order in which topics were raised, but prompted respondents when they did not otherwise discuss relevant issues.

\section{Analytical Methods}

Data gathered from case-study interviews and documents were analyzed qualitatively. Information from each site was examined to determine the sequence of decision-making events, the key players involved in WTE decision making over time, the issues raised by different parties over time, and the resolution of, and satisfaction with, the decision-making process. These elements are detailed in the descriptions of case-study sites in Sections 4.3-4.6. 
Case-study descriptions formed the basis for comparisons among case-study sites. Sites in which decisions were made to proceed with WTE were compared with each other, as were sites in which the opposite decisions were made. And, the two sites at which WTE was accepted were compared to the two sites at which WTE was rejected. These comparisons sought to serve two purposes. First, comparisons were made to determine the key factors that may determine the outcome of WTE decision making, i.e., the factors that distinguish WTE acceptance from WTE rejection. Second, comparisons were performed to discern the factors that are critical to the WTE decision-making process.

\section{BROWARD COUNTY, FLORIDA}

Located on south Florida's Atlantic coast, Broward County is home to 1.25 million people. Population is dense along the coastal one-third of the county, but the uninhabitable Everglades swamp occupies the western two-thirds of Broward County. Broward's burgeoning population $\rightarrow 100$ percent increase between 1970 and 1990-is largely the result of droves of emigres attracted by the subtropical climate. In 1980, less than 20 percent of Broward's population were native Floridians.

Broward's economy is predominately service-oriented, revolving primarily around tourism. The computer industry also is prominent in the county's economy. South Florida's fragile environment may be unable to support heavy industry.

Broward is governed by a seven member board of commissioners; only two new members have been introduced since 1984. Leaders of each of the 28 incorporated municipalities in Broward have membership in the Broward League of Cities. The League provides an avenue for cooperation among cities and for lobbying the cities' needs to county and state government. 


\subsubsection{Waste Management Context}

Broward County generates approximately 1.6 million tons of solid waste annually, an average of 4,400 tpd (1987 estimate). Solid waste management activities in Broward County have included landfilling and combustion, and now include recycling. Mixed waste composting in Broward County was begun in 1992 by Reuter, Inc., which provides service to four municipalities that elected not to participate in the county's program. Broward County's waste management practices are summarized below.

Landfilling: Two operating; history of contamination, e.g., closed county landfill is Superfund site; private and municipal ownership.

Combustion: Four incinerators closed in late 1970s because of failure to meet emissions standards.

Recycling: Only small-scale program until 1988.

Vegetative composting: No municipally sponsored program.

Solid waste exporting: Prohibited by law of recipient county (after 1980).

\subsubsection{Previous Siting Controversies}

When the county's combustion facilities became unavailable in the late 1970s, Broward County began landfill siting activities but soon discontinued them when siting became a political issue. Numerous medical waste incinerators in Broward County, sited with little or no controversy, now are controversial because of poorly enforced regulations governing their emissions.

\subsubsection{Decision-Making Process}

\subsubsection{Events}

In 1982, when the Broward County government decided to provide additional disposal capacity for its solid waste, no state legislation encouraged or required certain solid waste disposal activities. However, Florida's Department of Environmental Regulation (DER) informally promoted WTE to 
reduce reliance on landfills. Broward County consultants conducted a waste disposal technologies review in 1982 and recommended mass-burning WTE. The Commission accepted the recommendation and in January 1983 approved the use of WTE technology at two sites, provided by full-service vendors. Each site would host a 2,250 tpd WTE facility (expandable to 3,000 tpd; size was not finalized until after negotiations with the vendors), an ash monofill, and a landfill for bypass waste.

County staff initiated the vendor selection process immediately. The Commission appointed a committee on which the county and cities were equally represented to review the proposals and select a vendor. The process of requesting proposals from qualified vendors, initiated in the summer of 1983, was discontinued after one vendor refused to respond claiming that the request for proposals unfairly favored other vendors. Consequently, in the fall of 1984 the Commission reviewed the entire program, reaffirming the WTE choice, hiring a new project director, and revising and reissuing the request for proposals. In July 1985 the Commission approved the vendor selection committee's suggestion of Waste Management, Inc. (WMI) for the northern site and Wheelabrator Environmental Systems for the southern site. The county intended competition between two vendors to keep waste disposal costs down. However, in April 1990 WMI acquired a significant interest in Wheelabrator, giving WMI a near monopoly on solid waste disposal in Broward County.

The site-identification process occurred concurrently with the county's technology review in 1982. In April 1983, the county selected a northern site neighboring Pompano Beach and a southern site neighboring Davie. Pompano Beach immediately annexed the northern site and initiated rezoning activities to preclude siting the WTE facility and its accompanying landfill. County efforts to rezone the northern site to allow the WTE facility failed. However, because WMI indicated a willingness to locate the WTE facility on its own property in its two proposals, the county entered 
into negotiations with WMI to site the WTE facility at WMI's site and to accept a WMI-proposed WTE facility larger than that originally proposed by the county.

In April 1984 the county commission decided to finance up to $\$ 590$ million in project costs with tax-exempt industrial development bonds. However, by late 1984 project activities had not proceeded sufficiently to qualify for industrial development bonds. Therefore, the Commission agreed to a project financing plan that authorized the issuance of up to $\$ 590$ million of tax-exempt revenue bonds to be converted to industrial development bonds (IDBs) when vendor selection was completed. In December 1984, the county issued over $\$ 520$ million in tax-exempt municipal bonds which were then held in escrow; the county filed to convert the bonds to IDBs in 1987. A local group, organized to oppose the project, joined the state attorney's office to challenge the bond issuance ${ }^{x}$ claiming that municipal bonds could be issued legally only if the county intended to operate the project itself. Two lower courts ruled against the bonds, but in October 1988 the Florida Supreme Court ruled that the bonds could be converted legally to industrial development bonds; they therefore were grandfathered in under tax laws that granted them tax-exempt status.

The county sought permits for the two facilities under a consolidated permitting process required for all power plants over a threshold size in Florida. Although permitted as power plants only rather than as solid waste management facilities, the consolidated permitting process addressed all state and federal regulations applicable to WTE facilities. Discussions between the county and permitting agencies (Florida's DER and the Army Corp of Engineers) began in the fall of 1983, long before the county filed permit applications in April 1985 (southern site) and February 1986 (northern site). The DER recommended additional air pollution control equipment, acid gas scrubbers and baghouses for the southern facility. The county objected, arguing that performance standards and

\footnotetext{
${ }^{1}$ In a process called bond validation, every bond issuance comes before a judge with the State Attorney's Office acting as an adversary to ensure that the bond sale is legal.
} 
not particular types of equipment were requisite. In June 1986, the governor- and cabinet certified the southern site with only county-proposed air pollution control equipment. The state gave the same certification to the northern site in January 1987, A permit for dredge and fill activities, required from the Army Corp of Engineers because of wetlands protection, was obtained in November 1986.

The U.S. EPA, whose certification also was required, notified the DER in October 1986 that all permits should contain limits requiring the installation of acid gas scrubbers. Two meetings with U.S. EPA representatives failed to gain exceptions for Broward's facilities, and in December 1986 the county began negotiating with its two vendors regarding the installation and cost of acid gas controls. In May and July 1987 the U.S. EPA certified the southern and northern sites, respectively.

Because the county had no control over waste flow, it sought to guarantee cities' participation in the project, i.e., delivering waste to the county facilities. The county project team began negotiating interlocal agreements (ILAs) with the cities in late 1983, through representatives of the Broward League of Cities. The county's original proposed agreement included a put-or-pay clause for each city. Cities objected strongly. In a revised agreement, each contract city guaranteed delivery of all-but no specific tonnage- of its waste other than that waste expressly targeted for recycling. County representatives met individually with each Broward city in the summer of 1985 to work out specific details and encourage participation. The Commission implemented the ILA in early 1987, at which time 20 cities qualified. Three other cities joined later, bringing the number of participating cities to 23 . These cities chose representatives to serve with county commissioners on the Resource Recovery Board that oversaw construction and now oversees operation of the WTE facilities.

\subsubsection{Participation}

Basic decisions regarding WTE adoption and implementation were made by Broward County Commissioners, who despite sometimes heated debates, almost always voted unanimously in favor of the facilities. During the entire WTE decision-making process, approximately 30 public hearings were 
held relating to the site zoning, bond issuance, DER air quality permit, and wetlands permit. These hearings and county commission meetings were the only formal avenues for citizen input. Some meetings and hearings attracted up to 300 people, characterized by some respondents as enormous turnout relative to most meetings and hearings.

Citizen's groups and other participants and their activities are summarized below.

Citizen's group 1: Grew from small neighborhood association near the southern site to membership of 300 ; opposed to facility because of potential health effects from air emissions and possible leachate from ash monofill; attended public hearings, distributed fliers, but initially had difficulty obtaining media coverage; expended $\$ 35,000$ supporting suit against county's bond conversion.

Citizen's group 2: Formed in late 1990 to prevent WTE facilities from opening because of concern about potential health effects; 100 active members; distributed literature, held public information meetings, circulated petition mandating recycling of 60 percent of Broward's waste stream.

National groups: Recent involvement of Greenpeace and Clean Water Action; organized protests including human barricade of southern facility.

Cîties: One of four non-participating cities countered county threats to deny access to landfill with a suit; another annexed and rezoned land to prevent facility siting; Broward League of Cities served as liaison between cities and county, yet some cities assert that county threats to deny them landfill use influenced their decisions to sign ILAs; some municipal officials dissatisfied with their opportunities to influence facility size and monitoring.

\subsubsection{Mitigation}

Mitigation of adverse WTE impacts involved wetlands restoration surrounding the southern facility, constructed on "jurisdictional wetlands" (a determination based on soil type). The U.S. Army Corp of Engineers permit required four acres of wetlands to be created for each acre of wetlands destroyed on- and off-site. Additional mitigation included tree planting. The county appears to have compensated only one neighboring municipality by building a park.

\subsubsection{Regulations and Laws}

Although state and federal regulations were considered from the project's outset, the evolving environmental and financial regulatory climate had a considerable effect on WTE facility planning 
in Broward County. For instance, the county and its vendors anticipated now-existing requirements for double-lined ash monofills and upgraded the originally planned single-lined monofill to one that employs a liner consisting of clay sandwiched between two geotextile membranes. As a result of requirements for acid gas controls, imposed by U.S. EPA after facility design was completed and DER permits had been obtained, baghouses were installed on the facilities. These additional pollution control measures added over $\$ 32$ million to the facilities' cost.

Because of tax law changes, particularly the Deficit Reduction Act of 1984, and the county's desire to obtain favorable financing, Broward hastily issued bonds in December 1984. It faced a protracted legal battle because of this action, although the financing eventually was approved. (See Section 4.3.3.1).

\subsubsection{Decision-Making Issues}

The county's decision to use WTE technology was driven by a desire to provide long-term solid waste disposal capacity of proven reliability that would minimize the use of landfills and their resultant environmental impacts. Although proactive, the county responded to its dwindling solid waste disposal capacity.

The primary issues of concern among opponents of the WTE facilities were the potential for adverse environmental and health effects from the facilities' air emissions. Another major concern for opponents, and the primary concern of non-participating municipalities, was the cost of the facilities particularly as translated into tipping fees.

\subsubsection{Summary of Issues}

\section{Site Selection Issues}

- Criteria: in unincorporated area; near center of waste generation.

- Municipal opposition to northern site forced county to select alternative site; public opposition to southern site based on environmental concerns. 


\section{WTE Technology Issues}

- County's previous experience with waste combustion and availability of new technology led it to conclude WTE is safe and reliabie.

- Opponents expressed concerns about cumulative mercury contamination.

- Facility size upgraded per vendors' request; county asserted that facilities were sized properly; later asserted facilities were intentionally oversized.

\section{Economic Issues}

- $\quad 1.1$ million ton quota established in "put or pay" clause.

- Vendor could market excess capacity at tipping fees less than those paid by county.

- County selected vendor ownership to insulate itself from financial risk.

- Some municipalities opted not to participate partly because no firm estimate of tipping fee was available.

- Method of project financing faced legal challenge.

\subsubsection{Public Attitudes and Participants' Relations}

Attitudes about WTE, generally, and Broward's WTE program, specifically, differed among elected public officials, ranging from wholehearted support, to acceptance because of a belief that there is no other viable solid waste management alternative, to absolute opposition. Some municipal officials supported the concept of WTE but disapproved of the county's system or the county's handling of the WTE decision-making and planning process.

General public attitudes were more elusive to gauge. Public apathy about solid waste disposal issues, prevalent in the mid-1980s in Broward County, declined in the late-1980s as awareness of, and demand for, recycling increased locally and nationally. Respondents described the general public as somewhat apathetic and uninformed about WTE, despite relatively high public attendance at meetings and hearings about the county's WTE facilities and media coverage since 1983. However, no surveys of public attitudes toward WTE technology or Broward's proposed system were conducted. 
Respondents characterized municipalities' trust in, and relations with, county government as fair-to-good prior to the WTE decision-making process. County government has managed large public service programs on behalf of its member municipalities and worked with the Broward League of Cities to consider city interests in county government.

The county's handling of solid waste planning has made relations between some municipal officials and county government acrimonious. The county's acquiescence to vendors regarding facility size and its failure to negotiate a "put-or-pay" clause more favorable to the county caused considerable mistrust of county staff. Some municipal officials and media representatives indicated that county staff members on occasion deliberately misinformed them to gain acceptance for the WTE facilities. Using threats of discontinued services to convince municipalities to participate in the project and the consultants' history of support for WTE were additional reasons for the mistrust that currently exists.

\subsubsection{Improving the Decision-Making Process}

Respondents' suggestions for improving the decision-making process differed, but there was general agreement that an informed public is essential to good decision making. Although respondents stated that public participation in any form is contingent upon the public's ability and willingness to become informed, there were no clear suggestions about how the public should become informed.

Some respondents suggested that all decisions about solid waste management are premature unless they consider the interrelationships among components of an integrated system, including strong mandates for recycling.

Respondents (other than county staff) said that the county would be more responsive to the opinions of the public and less so to the vendor if the county owned the WTE facilities. There was 
general agreement that county ownership would eliminate the arduous negotiation process between the county and the vendor.

Half of the respondents suggested that the general public should bear the responsibility for a decision that affects every household and requires the expenditure of hundreds of millions of dollars. These same people did not, however, think that a public referendum, or any of the other suggestions to improve the decision-making process, necessarily would change the outcome of the decision-making process.

\subsection{OAKLAND COUNTY, MICHIGAN}

Oakland County, Michigan, with a population of approximately 1.1 million, lies just north of Detroit. Long home to the American automobile industry, several automotive plants provided employment for thousands of residents until the mid- and late-1980s, when two large General Motors (GM) plants ciosed.

Before the auto industry faltered, diversification had already begun in the county, softening the blow and keeping unemployment below the national average. Research and development operations, some related to the auto industry, have ventured into Oakland County. The Oakland Technology Park, which neighbors Oakland University in Auburn Hills, features the new Chrysler Technology Center and is the focal point of development in Oakland County. Also in Auburn Hills is the newly constructed Palace, home of Detroit's National Basketball Association team.

Development activities are led by the 61 individual municipalities in Oakland County. The apparent move away from manufacturing industries and toward commercial- and service-related companies in part reflects municipalities' desire to steer away from "smoke-stack" industries. Some municipalities have enacted zoning ordinances that make siting heavy industrial facilities difficult. 


\subsubsection{Waste Management Context}

As with development activities, most municipalities handle solid waste disposal independently. Some municipalities contract with private companies for solid waste pickup and disposal; some are not at all involved, allowing individual residents to contract for waste pickup. Two consortiums were formed to handle the solid waste of their member municipalities. The Southeast Oakland County Resource Recovery Authority (SOCRRA) includes 14 municipalities in southeast Oakland County and was formed in the early 1950s; the Resource Recovery Authority of Southwest Oakland County (RRASOC) serves municipalities in southwest Oakland County and was formed in 1990. Until recently, in response to state mandates, the county had little involvement in managing the 3,600 tpd of waste produced in Oakland County.

In 1978 Michigan enacted the Solid Waste Management Act (also known as Act 641) that required each county to develop a solid waste management plan demonstrating that the county has five years of waste disposal capacity available and is planning for 20-year capacity. Although capacity could be provided by waste exportation, no waste could be exported unless the receiving county accounted for it in its five-year plan, thereby limiting the flow of waste across county borders. ${ }^{2}$ Act 641 directed solid waste planning activities to be led by a solid waste planning committee composed of county and municipal officials, representatives of the waste industry, an environmentalist, and general citizens. Members are recommended and approved by the county commission.

A decade after the enactment of Act 641, Michigan established a solid waste policy whose goal was to reduce landfill waste to 10 percent of the waste stream by 2005 . Landfilling was to be used only when "no other environmentally sound management alternatives exist." The policy called for WTE to manage 40 percent of the waste stream; other waste reduction methods (recycling, reuse,

\footnotetext{
${ }^{2}$ Waste importation restrictions across state lines were struck down in the U.S. Supreme Court in 1992. The applicability of this rule to cross-county transport is undetermined.
} 
source reduction, and composting) were to manage 50 percent of the waste stream by 2005 . Current waste management practices are presented below.

Landfilling: Four operating (three privately owned); four closed landfills on Superfund list; regulation bans yard clippings by late 1994 .

Combustion: SOCRRA 600 tpd incinerator opened in 1957, retrofitted twice, closed 1988 because of residents' complaints about emissions; SOCRRA's plans to upgrade and reopen the facility are controversial. GM combustion facility for commercial use only.

Recycling: Most municipalities provide drop-off centers or curbside pickup; recycling rate under 10 percent.

Vegetative compasting: Began in 1971; 1990 lawsuit centered on odor problems.

Solid waste exporting: Some restrictions in county solid waste management plans; net exporter.

\subsubsection{Previous Siting Controversies}

In the mid-1970s, a hazardous waste incinerator was proposed for Oakland County. The company had obtained Department of Natural Resources (DNR) permits when a loosely organized group emerged to oppose the site. The city of Auburn Hills responded by establishing a pollution control review board that set stringent guidelines for siting hazardous waste facilities. The proposal ultimately was abandoned.

Pontiac, considered seriously as a site for a new state penal facility in the 1980 s, protested the proposed facility site claiming that Oakland County had recommended a Pontiac site because it has a greater percentage of minority and low income residents than other areas of Oakland County. The state, for reasons unrelated to the siting controversy, did not proceed with the penal facility.

The county sought to identify site(s) for a county-owned landfill that would be an integral component of the county's solid waste management system (in addition to the WTE facility). A 25-member siting committee, with the assistance of technical consultants, initiated a blind siting process. County consultants used published data to identify candidate areas based on: protected 
farmland and open space, public recreational areas, airport restrictions, lakes and streams, wetlands, surficial geology, land use, historic and cultural areas, areas experiencing new and rapid growth, and threatened and endangered species habitats. The landfill siting committee established weighted criteria for ranking sites, but members were unaware of candidate site locations. When the locations of the 10 ranked candidate sites were revealed, protests immediately emerged from representatives of municipalities where sites were identified. A simple mathematical error in totalling the scores of the weighted criteria caused two sites' rankings to change and, in the minds of some, cast doubt on the whole process. Local opposition groups soon formed in each township where a site was identified. The opposition was based primarily on the credibility of the process and the accuracy of the geological data used. Opponents claimed that the data were not technically accurate, had not been verified, and in some cases better data were available.

\subsubsection{Decision-Making Process}

\subsubsection{Events}

Oakland County's proposed WTE system originated in the early 1980 s as part of the statemandated, county-wide solid waste management plan. The original plan proposed one large WTE plant and three small WTE plants (approximately 200 tpd each), and included two WTE facilities and several landfills already operating in the county. The plan was approved by county commissioners in 1982 and subsequently by over two-thirds of the county's municipalities and the DNR. By 1985, 30 municipalities signed intergovernmental agreements (IGAs) committing their waste to the county system. (Because the county did not control the flow of waste in the county, these flow-control agreements were required to determine the size of the facility and to guarantee to the financier and the operator that the facility would be viable.) Plan implementation was delayed because there was no provision in Michigan law for a county executive form of government to issue bonds for such a

system. Special legislation was passed in 1989. However, during the interim, the recession of the 
early 1980 s meant that some proposed WTE facilities no longer were viable because potential users of steam scaled back operations or closed their factories.

The state requires an updated solid waste management plan every five years. When work on the second plan began in 1987 , before the 1982 plan was implemented, awareness about recycling was increasing. The second plan set a goal of reducing the waste stream 30 percent by 1995 and 50 percent by 2005 through waste reduction and recycling (anticipating Michigan solid waste policy requirements). Increased emphasis on recycling lessened the need for WTE facilities, and the new plan included the two existing combustion facilities (SOCRRA's and GM's) in the county and one proposed 2,000 tpd WTE facility. A new, 40-year landfill originally in this plan was dropped; instead the county's plan relied on expansions of existing landfills. After public hearings on the plan were held, it, like the first, was approved by the county commissioners, DNR, and over two-thirds of the county's municipalities.

The county then developed and began to carry out an implementation plan. In 1989 , the county selected Westinghouse to design, build, and operate the WTE facility. Environmental impact and health risk assessments were completed by county consultants as part of the air quality permit application, which was filed with the DNR in December of 1989 . The DNR delayed action on the permit application while it studied existing mercury contamination in Michigan waters and reviewed its mercury emissions policies. Also slowing progress was the governor's attempt to restructure the DNR and disband several DNR commissions, including the Air Quality Commission where public hearings regarding the WTE facility permit would be held. The lower courts reversed the restructuring.

The site first selected to host the WTE facility was near the county government complex in Pontiac. Opposition to this site arose in 1985 when Pontiac, under a new administration, sued the county to prevent siting the WTE facility there. The county, wanting to avoid long delays, rethought 
its decision and in 1989 selected Aubum Hills as the site for the WTE facility.. It is unclear whether Auburn Hills volunteered to host the facility (as is suggested by county officials and staff) or was selected by the county (as is suggested by Aubum Hills officials). The chairman of the county commission, who represented the northern portion of Auburn Hills, realized the project was stalling and pushed to identify a new site. The chairman and Auburn Hills' mayor negotiated a host community agreement allowing the facility to be built in Aubum Hills and stipulating that Auburn Hills will do nothing to hinder project development. Because the 641 process does not require the approval of the municipality in which the facility is sited, Auburn Hills officials believed it was in their best interest to get involved. The 641 plan was amended to include the new site.

In late 1990 , the county drafted new IGAs reflecting the changes in the county's solid waste management plan and excluding the "put-or-pay" clauses included in the original IGAs. The county asked the municipalities to commit their waste (no specified tonnage) to the county's proposed solid waste management system. Although more than two-thirds of the municipalities had approved the county's solid waste management plan, only 18 of the 61 municipalities committed their waste, totalling approximately 400 tpd.

Among the reasons for so few positive responses was SOCRRA communities' decision to take no action until DNR ruled on air quality permits for their combustion facility. Some communities hesitated because of DNR's mercury emissions review, emerging public opposition to the WTE component of the system, and other existing, less expensive waste disposal options offered by the Detroit WTE facility and private landfill owners. Other communities expressed concern that specific landfill capacity was not identified in the plan. Some municipalities used the IGA as a bargaining tool to gain county support for non-WTE related agendas.

Staff and elected officials, concerned that the plan was stalling, responded with several activities. First, the county contracted with WMI for sole use of the expansion of its landfill in Orion 
township. Second, the county discussed implementing the solid waste management plan in two phases, first by waste reduction education and recycling and, second by building the WTE facility. No agreement to implement the phased plan resulted because it was unclear whether it would meet Act 641 requirements, if agreeing to the first phase mandated participation in the second, and the consequences if tonnage commitments required for the second phase were not achieved. Third, the county commission decided to hold a public referendum on the bond issue funding the solid waste management system.

Michigan law requires that all tax increases be approved by public referendum. However, rarely are limited general-obligation bonds to be paid by project-generated revenues brought to public referendum. It is likely that mounting political pressure, a desire to act to revive the program, and requirements of Michigan law were the reasons a referendum was called.

During the summer and fall months before the November 5, 1991 referendum, local groups opposed to the facility actively distributed literature and held public rallies. A committee funded primarily by Westinghouse began advertising in support of the project in late August, spending several times the amount of money expended by opposition groups.

The proposed system was approved by less than 200 votes in an election whose voter turnout was approximately 15 percent, average for local elections. However, voters in 76 percent of Oakland County's municipalities approved the referendum. In general, those areas where WTE facilities (including the SOCRRA combustion facility) were sited experienced higher voter turnout and voted against the proposed system. Revised IGAs were issued to municipalities after the election.

In March 1992, Westinghouse exercised a pull-out clause in its contract and withdrew from the project, citing the lengthy permit application time and absence of IGAs as its reasons. (Recent financial trouble at Westinghouse also contributed to its withdrawal). The county now is considering several options, including rebidding the project, selecting the runner-up from among the original 
bidders, dropping the WTE portion of the plan (requiring additional landfill eapacity) and continuing with the other portions of the solid waste plan, or ceasing to be involved altogether. In the latter case, the state mandates that first municipalities, then the regional planning agency, and then the DNR must try to develop a solid waste management plan for the county.

\subsubsection{Participation}

The 641 planning process mandates the involvement of several parties including the planning committee (county and municipal officials), waste industry representatives, an environmentalist, general citizens (usually with technical backgrounds related to solid waste management), and a citizens' advisory committee. In Oakland County the committee apparently had little influence and did not serve as a conduit for information to the public. Other opportunities for public input to the 641 plan include 641 committee meetings and hearings held once the 641 plan is completed. Each municipality may review the 641 plan, but has limited input in plan development. However, the DNR reviews all 641 plans, makes recommendations, and requires changes.

Existing and newly formed groups opposing the county's proposed and existing solid waste disposal practices mostly acted independently. The groups and their positions are summarized below.

Cïtzen's group 1: County-wide group concerned about environmental and health effects of WTE and poorly sited landfills; divided into two factions, one based near the proposed WTE site; the second faction is small and loosely organized group of county-wide residents with history of environmental activism and opposes WTE facility because of environmental and financial considerations.

Cütizen's group 2: $\quad$ Long-standing, loosely organized group; not categorically opposed to WTE; opposition to county's system because of environmental and waste management concerns.

Cützen's group 3: $\quad$ Large group based in Auburn Hills and Rochester Hills emerged when site was selected; received considerable media attention and support of national environmental organization; opposition based primarily on health effects; affiliated with Madison Heights group that opposed the SOCRRA combustion facility. 
Each group commented at 641 committee meetings and public hearings as well as distributed fliers. Other tactics differed. Some groups quietly collected and disseminated information and others intentionally disrupted county and city government meetings. Members of the most active group, who, with the assistance of two national environmental organizations, held public rallies and conducted door-to-door surveys and campaigns, continued their activities even after the election and Westinghouse's withdrawal.

Other significant participants in the process include city administrations, who affected the outcome by their decisions to join (or not join) the county's system. Municipalities had representation on the 641 Committee but apparently did not act in concert to have their concerns represented. Some municipal administrations who opposed the WTE aspect of the county's proposal took highly visible actions against it, including litigation, mailing newsletters to residents, and hosting proposals from companies promoting other waste management technologies.

Westinghouse, the WTE system vendor, also was an important participant providing information to the county and its consultants. Westinghouse campaigned heavily beginning in late August for the county's system, but did so under a committee name, rather than its own.

\subsubsection{Mitigation}

Although no community host agreement was negotiated with Pontiac for the original site, an agreement was offered to Auburn Hills (comparable agreements were negotiated with the municipalities hosting the materials recycling facilities and the landfill expansion). Contingent upon the facility being built in Auburn Hills, the county offered cash payments and forgiven debt totalling over $\$ 9$ million and a community host fee of $\$ 1.50$ per ton to be paid in lieu of taxes. The community host agreement did not allow Auburn Hills any input into facility monitoring or control, factors key to the city council's later consideration of withdrawing from the project. 


\subsubsection{Regulations and Laws}

Michigan DNR holds permitting jurisdiction over the proposed WTE facility. No county agencies require permits. Although many municipalities, including Auburn Hills, have a pollution control board that establishes standards for facilities, Michigan Act 641 states that municipal ordinances are not applicable to facilities included in the 641 plan.

A separate Michigan law, Act 64 , governs hazardous waste disposal. It originally defined WTE ash as a hazardous waste but the Oakland County legislative delegation supported a successful change in ash classification from hazardous waste to non-hazardous waste that requires disposal in a double-lined monofill. No ash testing is required.

County staff considered all federal regulations early in the planning process when the request for qualifications from vendors occurred. Proposals were requested only from companies who demonstrated an ability to meet these standards.

\subsubsection{Decision-Making Issues}

The single most important issue was Oakland County's need to reduce reliance on landfills. Groundwater contamination resulting from several uncontained landfills in the county had heightened public awareness of the potential environmental impacts of landfills. The county also experienced difficulties in landfill siting. As early as the 1970 s municipalities in Oakland County asked the county government to provide an alternative to reduce reliance on landfills.

Opponents believed that the county's WTE plant would affect the health of residents and should be considered only after recycling programs and waste reduction education were fully implemented in Oakland County. A summary of these and additional issues follows. The section concludes with a discussion of public attitudes and participants' relations. 


\subsubsection{Summary of Issues}

\section{Site Selection Issues}

- First site selected because of proximity to county buildings. Host community protested and filed suit claiming racial discrimination.

- Second site chosen through personal negotiation of county commissioner and mayor of host community; host community's council later opposes siting; opposed by area environmental group because of concerns about air inversion conditions and unsafe truck access.

\section{WTE Technology Issues}

- County assessments concluded WTE would result in minimal health risk.

Opponents concerned about health effects of emissions (lead, mercury, dioxins, furans).

- General concern that recycling, reuse, and reduction strategies should be implemented before considering WTE.

- Host community concerned about facility operating procedures, e.g., emergency shutdown and monitoring.

\section{Economic Issues}

- Concern that tipping fees at WTE facility were underestimated.

- County position that its financial situation would be enhanced by long-term solid waste management system.

\subsubsection{Public Attitudes and Participants' Relations}

In early 1991 county consultants conducted focus groups and telephone surveys to ascertain public awareness and attitudes regarding solid waste disposal. Awareness among residents about existing and planned solid waste disposal practices varied, but almost all believed that Oakland County was facing a major waste disposal problem. Opinions about the county's proposed waste management plan, including the WTE facility, mostly were favorable. A separate survey conducted by a national environmental group found that 57 percent of those polled disapproved of the county's planned WTE facility. 
An official in Auburn Hills commented that during his extensive door-to-door campaign in the fall of 1990 , only a very few residents raised the WTE facility as an issue. The low voter turnout in November might suggest that apathy among Oakland County residents about solid waste management activities remained high.

The results of the referendum in November 1991 also suggest patterns of public attitudes about the county's proposed system. Voters in municipalities that would host or neighbor various facilities, particularly the landfill and the WTE facility, experienced high voter turnout and rejected the bond proposal. Municipalities in the north and west of the county supported the county's system. Various officials and the local media interpreted these votes as being as much against landfills as for the WTE facility.

Aspects of the campaign that preceded the election caused some county residents to mistrust

the county's efforts. Among them were the hiring of a public relations firm without the commission's approval; a county-sponsored informational brochure that did not acknowledge its funding source; Westinghouse's campaign expenditures under the guise of a committee supporting the county's plan; and an incorrect Westinghouse claim that the county's WTE facility was supported by a particular local environmental group.

Until Act 641 mandated otherwise, all solid waste management activities were under the purview of the municipalities. Oakland County historically had little involvement in other municipal activities or large-scale, high visibility projects requiring full public disclosure and close negotiations with member municipalities.

\subsubsection{Improving the Decision-Making Process}

All participants in the research believed that improvements to the decision-making process were necessary, some of which would require changes to Act 641 . Two major themes emerge, which are related to the decision-making process itself. 
The first theme is improving representation on the county's solid waste planning committee. Several participants thought that environmentalists' representation should be improved (not necessarily increased) by allowing local environmental groups to select or help select the one environmentalist on the committee. Participants also favored increased municipality representation.

The second theme states that early and full disclosure of information is essential to any solid waste management planning. Some respondents distinguished between public information or education and public relations. The former includes full disclosure and acknowledges shortcomings, while the latter attempts to "sell" the plan by highlighting only the most positive features. Facility opponents suggested that readily available, accurate information builds trust.

Other suggested improvements to the process included full implementation of recycling and waste reduction strategies before sizing and building a WTE facility and providing mitigation measures in addition to financial compensation. Mitigations might include removing mercury from the waste stream or increasing land buffers between the facility and residential areas.

\subsection{KNOX COUNTY, TENNESSEE}

Knox County is nestled in the protected valley between the Cumberland Mountains and the Great Smoky Mountains of eastern Tennessee. Its principal city, home to half of Knox County's 336,000 residents, is Knoxville. Farragut, with a population of approximately 13,000 , is the only other incorporated municipality in Knox County. Population has decreased over five percent in Knoxville

during the last decade but increased by five percent in the county as a whole largely because of significant growth in Farragut.

Knoxville's economy has been dominated historically by a pair of large industrial facilities, apparel factories, the Tennessee Valley Authority, and the state university. Jobs lost due to scaledback industrial production and apparel manufacture have been replaced by service-oriented jobs and 
research and development activities locally and in neighboring counties. Much of Knox County remains devoted to low-density residential development and agriculture.

Knox County is governed by a county executive and a board of commissioners; Knoxville has a mayor and council. Antagonism between Knox County and Knoxville is demonstrated by disagreements over annexation, funding infrastructure projects, and past school consolidation.

\subsubsection{Waste Management Context}

Knox County traditionally has relied on landfills to dispose of its solid waste. It was only during WTE planning that the Metropolitan Knoxville Solid Waste Authority (MKSWA) initiated pilot recycling programs. Current waste management practices are highlighted below.

Landfilling. Knox County landfill approaching capacity during WTE planning; minor operational problems.

Combustion: No previous experience.

Recycling: Initiated during WTE planning.

Vegetative composting: No municipally sponsored program.

Solid waste exporting: Almost complete reliance on privately owned out-of-county landfill.

\subsection{Previous Siting Controversies}

Residents reliant on well water opposed a private company's mid-to-late 1980s attempt to site a new landfill. After the company purchased the site, the metropolitan planning commission refused zoning. The county commission also denied the company's appeal.

\subsubsection{Decision-Making Process}

\subsubsection{Events}

In the mid-1970s and again in the early 1980 s an east Tennessee regional development agency, on the behalf of several counties, examined solid waste management alternatives and identified WTE as a feasible option. No initiative ensued immediately, however. 
After touring European WTE facilities, the Knox County executive discovered that favorable tax status for such facilities would soon expire. This official proposed developing a WTE facility to other county officials and then requested Knoxville's assistance. In early 1986, an informally organized group of county and city officials visited WTE facilities and decided to pursue the use of WTE.

In August of 1986, the Knox County Commission and the Knoxville City Council created the nine-member MKSWA to plan and implement WTE use. The county retained its role as lead agency. Members, mostly elected officials selected by the county executive and city mayor according to their experience with public works projects and willingness to support WTE, were approved by their respective governing bodies. The MKSWA's original director resigned in February 1988 because of conflict of interest and was replaced by a university professor.

The MKSWA, based on its own facility cost estimate, issued $\$ 175$ million in tax-exempt bonds in August of 1986 . The bonds were guaranteed by the city and county. Subsequent MKSWA planning activities were funded by bond arbitrage. Bonds, reissued in April 1989, were up for reissuance again in April 1990. In June 1989 and August 1989, respectively, the county commission and city council voted to back MKSWA's 1989-1990 spending.

The MKSWA hired a consulting engineering firm to examine the technical and economic feasibility of the proposed WTE facility. In addition, the consultants estimated the waste stream size and recommended facility siting procedures.

Because the WTE facility originally was conceived as a regional facility that would accept waste from neighboring counties, a 1,200 to 1,500 tpd facility was planned. When neighboring counties decided not to participate primarily because of cost considerations, the facility size was adjusted to 750 to $800 \mathrm{tpd}$. Later it was readjusted to $900 \mathrm{tpd}$ in accordance with new waste stream size estimates. 
In January 1988, Knoxville's new major immediately suggested he would ask the MKSWA for a three-month delay to review the project. The news media made it apparent that the authority would deny his request; consequently he never made it. The mayor did, however, delay by one month the city council's vote on the flow control agreement. He also called for a new project director (hired in October 1988) and had the U.S. Department of Housing and Urban Development (HUD) conduct an independent project review. The mayor's support for the waste flow control agreement was contingent upon its inclusion of HUD findings. HUD's recommendations-developing a recycling program, forming a citizens advisory committee, reevaluating the proposed site, and more extensive air and traffic studies $\rightarrow$ were included in the flow control legislation approved by Knoxville's city council in March 1988.

Three candidate sites, all within Knoxville city limits, were identified in 1987 based primarily on technical criteria: easy transportation access and proximity to the center of the waste stream. One was not considered seriously ostensibly because of transportation problems, but MKSWA perceptions that area residents would oppose the site contributed to its quick dismissal. Another site relied on the University of Tennessee's role as a potential steam user, but the university determined it was not economically feasible to purchase steam from the facility. The third site was in an area of light industrial and commercial use neighboring residential areas.

The MKSWA identified the latter site as the preferred alternative. The MKSWA's second review of sites (called for in Knoxville's waste control agreement) concluded that the site was acceptable. A third review of the site, conducted by the University of Tennessee, determined that a WTE facility could meet environmental requirements but suggested that a more thorough study might have identified additional sites for consideration. The MKSWA then approved this site-the Baxter Avenue site-in late April 1988. In June 1988, the Metropolitan Planning Commission, under 
public pressure to deny rezoning, disregarded its professional staff's recommendation and voted almost unanimously to deny rezoning. The city council denied the MKSWA's appeal in July.

The MKSWA resumed site identification and selection activities almost immediately and developed site-selection criteria after consulting various business organizations. Two public hearings regarding the site-selection criteria were held. Consultants identified 22 potential sites. The MKSWA narrowed the list to four sites outside Knoxville city limits in east Knox County and identified a preferred site which drew much protest at a public hearing primarily because it was the site of a Civil War battle and fort. The MKSWA's selection of another host site bordering the Holston River was approved by the Metropolitan Planning Commission in January 1989.

Site identification for a new ash and bypass waste landfill were resumed by the MKSWA. A plan to divide the county into regions and prevent the siting of the WTE facility and a new landfill in the same region was considered, refused, and then restored. In November 1989, two private companies in a neighboring county bid on WTE ash disposal; the MKSWA took no definitive action. In the spring of 1990 , the MKSWA identified a landfill site.

Vendor procurement activities occurred concurrently with WTE facility site selection. Three companies responded to the authority's 1988 request for proposals; Foster Wheeler Power Systems, Inc. submitted the lowest bid (approximately $\$ 83$ million for construction and $\$ 4.4$ million annually for operation). Negotiations with Foster Wheeler ensued during the summer of 1989, and a contract was signed in July. Bonds were reissued for a one year term because no vendor had been contracted by the April 1989 bond refinancing date.

During the summer of 1989 , the MKSWA heard proposals for alternatives to its proposed WTE facility including landfilling at a yet unpermitted site and a central waste separation and recycling facility, a technology the authority deemed unproven. In the absence of firm cost estimates for the alternatives, the MKSWA proceeded with its WTE plan. An authority member later resigned 
because he favored the recycle proposal. New life estimates of the landfill receiving the bulk of the county and city's waste also clouded the authority's decision. Remaining capacity was an estimated 9.5 years; a proposed expansion would extend landfill life to 16 years.

The county commission and the city council in February 1990 endorsed state legislation allowing authorities to directly bill users. An energy sale contract was finalized with the Tennessee Valley Authority in March 1990 and state permits (filed in October 1989) were acquired before the April 1990 financing deadline.

The first plan to repay the bonds, considered as early as 1986 , required state legislation to add a facility user fee to every utility bill. The legislation was not approved. The MKSWA then sought special legislation granting it authority to directly assess fees to city and county residents and businesses; this legislation failed passage on April 11, 1990.

Therefore, bond repayment required assessments levied directly by the city and county. Faced with this possibility, and harboring concerns about the project's cost and potential environmental impacts, Knoxville's major called the New York bond insurer two days before the April 19 deadline for bond remarketing. He informed the insurer that "the administration of the city of Knoxville no longer supports the project." The bond insurer consequently withdrew, leaving the bonds unmarketable and effectively ending the project.

\subsection{Participation}

The Knox County executive and commissioners, the Knoxville city mayor and council, and the MKSWA participated in formal decision making by planning and approving project activities. Through 1989, MKSWA members agreed on substantive issues, but bickering and "political haggling" caused the resignation of some MKSWA members and staff. Advising these decision makers were engineering consultants, the MKSWA's lawyer, securities brokers, and, eventually, a financial advisor. The Metropolitan Planning Commission reviewed land use. Local government officials (not the 
MKSWA) called for a reevaluation of facility site, size, and need for the project and to expand the MKSWA to include a woman or minority.

The state legislature played an important role in project development. Examples of the many pieces of legisiation affecting the project included a bill requiring authorities to be subject to sunshine laws, to have their decisions approved by a two-thirds majority vote of councils and commissioners of participating cities and counties, and to allow state review of bond issuance as well as the two proposed plans to repay bonds discussed earlier.

Several citizens groups participated in the decision-making process. The groups and their positions are summarized below.

Citizen's Advisory Committee: Formed by MKSWA in mid-1988; members uncertain about group's role; poorly attended meetings

Cïizen's group 1: Coalition of church groups and neighborhood associations near first proposed site; constituents opposed to WTE facility for different reasons, e.g., facility's proximity to churches and residences, WTE considered before recycling developed, being unaware of planned facility, concern for environmental and health effects

Citizen's group 2: $\quad$ Association of East Knox County residents opposed to second site because the general region had hosted most of the county's landfills and the population included disproportionate number of African Americans

Consumer advocacy group: Long-standing group opposed facility because of potential environmental and health effects, belief that recycling and waste reduction should be implemented first, and its projections that solid waste disposal costs would rise; sued MKSWA before 1989 bond remarketing

Public awareness of the MKSWA's activities and the proposed WTE facility was extremely low until late 1987 , despite county commission and city council votes and occasional print media coverage. Most residents neighboring the first proposed WTE facility site were unaware of planning activities until they were notified by the chance call of their city council person. 
Until 1988, the public was not allowed to comment at MKSWA meetings. The MKSWA did not undertake any public participation activities until mid-1988, when the citizens advisory committee was formed. A public relations firm, hired in February 1988 to conduct public information activities, was dismissed the following month.

In 1989 the MKSWA held public hearings on site selection criteria; in 1990 the Tennessee Department of Health and Environment held hearings on permits. A citizen's group hosted forums, held rallies, attended meetings, and lobbied the city council, the Metropolitan Planning Commission, and the state legislature.

The MKSWA sought the business community's support and contacted the Metro Knox Chamber of Commerce to inform them of the proposal. The Chamber supported the WTE plan, and on at least two occasions before important votes submitted letters to commissioners and council members indicating the Chamber's support, but requesting additional information. Two local newspapers supported the MKSWA WTE facility but advised careful planning.

\subsubsection{Mitigation}

The MKSWA considered providing an air filtration system to an unair-conditioned garment manufacturing building neighboring the first site due to concerns about garment contamination by odors and threats to relocate. Concerns about parking and worker safety were addressed by offering reserved parking space for employees and planning a cross walk.

MKSWA offered no mitigation for property value depreciation after consultants found that property values had not depreciated around existing facilities.

\subsubsection{Regulations and Laws}

The MKSWA's August 1986 issuance of project-financing bonds was intended to obtain favorable financing for the project. Restrictions on the bonds effectively established a project implementation schedule. For instance, final bond issuance required that a vendor contract be in 
place and that all permits be obtained. Because these activities were incomplete in 1989 , the bonds were reissued temporarily forcing the county and city to make a financial commitment to the project before the April 1990 date for final bond reissuance. When faced with this situation, Knoxville's mayor withdrew his support one day before reissuance was to occur.

The MKSWA's engineering consultants' requests for proposals required emissions standards comparable to California's, among the country's most stringent standards, to account for the possibility of stricter future environmental regulations. Although MKSWA staff and the vendor later determined that facility emissions would meet the U.S. EPA's new draft emissions standards, facility opponents disagreed.

\subsubsection{Decision-Making Issues}

The major issues for county and city WTE planners were limited landfill capacity and reducing future reliance on landfills. Key issues for the public were: (1) controlling solid waste disposal costs, emissions, and potential environmental and health effects; (2) providing comprehensive waste management; and (3) the lack of public information. A summary of these and additional issues follows. The section concludes with a discussion of public attitudes and participants' relations.

\subsubsection{Summary of Issues}

\section{Site Selection Issues}

- First selection process focused on technical characteristics, did not fully consider an alternative site, and caused considerable public concern.

- Second selection process emphasized neighboring land uses but drew opposition because minority population in the general region.

\section{WTE Technology Issues}

- Concern from project opponents and the National Park Service about air emissions.

- Proposed facility size based on estimated size of waste stream; concern that oversized facility would preclude implementation of recycling.

- Not proposed as part of comprehensive waste management plan. 


\section{Economic Issues}

Method for fee assessment problematic because the authority had insufficient incentive to control costs.

\subsubsection{Public Attitudes and Participants' Relations}

Polls taken during the course of WTE planning indicated the public generally favored the concept of WTE over landfilling. Eighty-two percent of Knoxville's residents (1987 poll) and 86 percent of Knox County's residents supported WTE (1988 poll). Sixty-eight percent of residents polled in 1988 in a five-county area preferred WTE to landfilling. Nevertheless, there was considerable public opposition to the proposed WTE facility. Some media representatives, city council members, and county commissioners thought opposition was lessening in 1989 and 1990 due to a new recycling program and greater acceptance of the second site.

The relationship between the city of Knoxville and Knox County has been characterized by animosity and bickering. During planning, county officials commonly accused the mayor of undermining the project; others questioned the relationship between the county executive and one bond underwriting firm.

WTE planning activities themselves, particularly the lack of public information and of opportunities for public involvement, became an issue for WTE opponents. Some opposition centered on public exclusion from the decision-making process.

\subsubsection{Improving the Decision-Making Process}

Respondents agreed that a more credible and trustworthy decision-making process would include early activities to inform and involve the public, even though some segments of the public would likely still oppose a WTE facility. Some respondents suggested that explaining technical issues early on allows citizens to make informed decisions about specific proposals and alternatives. Some respondents said that Knoxville's solid waste task force, established after the WTE project folded, exemplifies improved public involvement in solid waste management planning, particularly when 
community members with substantial experience in various solid waste management issues are involved.

Another recommendation, almost unanimously made, was to approach solid waste management comprehensively. A final recommendation was to make financing the last step in project planning and implementation, primarily to avoid arbitrary project deadlines.

\subsection{MONMOUTH COUNTY, NEW JERSEY}

Monmouth County's eastern margin is dominated by the Atlantic Ocean and highly developed tourism and fishing industries. The remainder of the county is far less densely populated and developed; small cities and towns are interspersed with horse farms and rural agricultural areas. The county's economy is service-oriented. High-technology industries have settled in Monmouth County, but large, heavy-industrial facilities common in Newark, just north of Monmouth County, are absent.

Just over one half million people reside in Monmouth County; less than 13 percent of these people are minority races. The county is home to many emigres from crowded New York and northern New Jersey. Population grew slowly during the last decade and is only two percent higher now than in 1980.

County government is headed by a five-member Board of Chosen Freeholders. These Freeholders choose a county administrator, a job that is more managerial than political in nature. The Freeholders and county administrator manage an annual budget of $\$ 270$ million. Within the bounds of Monmouth County are 53 separate cities and townships.

\subsubsection{Waste Management Context}

Monmouth County's proposed WTE facility must be viewed in the larger context of solid waste management. The primary solid waste management methods in the county are landfilling, recycling, and vegetative composting. All respondents indicated that the landfill is well-operated, has 
had minimal environmental effects, and think that the public holds the same opinion. The general public apparently sees composting and recycling as environmentally benign. The county's waste management practices are highlighted below.

Landfilling: One county-owned facility operating since 1976; second phase opened mid1980s; third phase of undetermined acreage planned during WTE planning; environmental status perceived to be good; all other landfills closed by 1986; leaves banned; grass ban anticipated.

Combutsion: No previous experience.

Recycling: County- and state-mandated in 1987; overall recycling rate exceeds 50 percent.

Vegetative composting: Approximately 80,000 tons per year at municipal sites.

Solid waste exporting. Allowed with permission of state Department of Environmental Protection.

\subsubsection{Previous Siting Controversies}

Monmouth County Reclamation Center (MCRC) siting was not controversial due to general perceptions of site suitability. A 1986 attempt by the state to site a hazardous waste incinerator in Millstone Township (west Monmouth County) received considerable opposition from local residents; one protest drew approximately 5,000 persons. Opponents argued that the siting criteria were ignored so that Millstone, where little opposition was expected, could be selected. The MCRC site proposed for the solid waste combustion facility also was considered for the hazardous waste incinerator, but New Jersey state law exempted it from consideration because the site had already been targeted for a solid waste disposal facility.

\subsubsection{Decision-Making Process}

\subsubsection{Events}

In the mid 1970s New Jersey began solid waste planning in response to increasing amounts of solid waste and garbage exportation, tighter landfill regulations, and landfill closings. The 1975 
Solid Waste Management Act (PL 1975, chapter 326) required each county to handle its own solid waste problems and plan for ten years of disposal capacity. The New Jersey Department of Environmental Protection (NJDEP) encouraged the use of solid waste combustion. The NJDEP review of Monmouth County's solid waste management plan of the early 1980 s found it deficient because it did not include the "maximum practicable use of resource recovery procedures." The plan did not identify a specific resource recovery method, although it generally suggested pursuing resource recovery.

Responding to this criticism, consultants to Monmouth County conducted a resource recovery study that analyzed resource recovery technologies for their suitability in Monmouth County and developed a strategy for developing a resource recovery facility (including management, procurement, and financing). As a result of this study, Monmouth County's July 1985 solid waste management plan amendments identified WTE as the favored technology. August 1986 amendments, however, dropped the identification of a favored technology. Nevertheless, in early 1986, the Freeholders designated available land at the MCRC as the site for any centralized resource recovery facility the county would choose.

In late 1986, the county began a full-scale study of available solid waste management technologies looking for a technology that could reduce landfill reliance, provide reliable and environmentally sound waste disposal, increase re-use of resources, and be economically acceptable. An analysis of a variety of technologies, conducted by the county's consulting engineers and recorded in several volumes, identified four possibilities for Monmouth County: refuse-derived fuel, materials recovery with landfilling, materials recovery with combustion, and mass burning. In July 1988, the Board of Freeholders unanimously voted to proceed with a combined recycling-combustion system (capacity 1,700 tpd). Although the recycling component, which involved a front-end separation process, was more expensive than a mass burn facility, Freeholders believed they were complying with 
state directives for recycling, establishing long-term disposal capacity, and-conserving increasingly limited open land in Monmouth County. In response to public opposition, Monmouth County again in early 1991 reviewed alternative technologies and again concluded that a materials recovery system and WTE best met county needs.

By early 1991, the vendor review process that selected Westinghouse and a preliminary health and environmental risk assessment had been completed. However, organized public opposition had surfaced, and the state changed its guidance on county-level solid waste management. The state's new administration encouraged regional management of solid waste rather than the previous administration's policy that directed each county to handle its own garbage. Also, state government emphasized recycling, relegating WTE to an "option of last resort." In April 1990, the governor placed a four-month moratorium on WTE construction, and it became increasingly clear that only regional WTE facilities would receive NJDEP approval.

The Freeholders decided in February 1991 to bring the WTE proposal to public referendum because of the possibility of being forced to accept out-of-county trash, growing public opposition, and some Freeholders' reluctance to proceed. Freeholders then allowed planning to proceed by signing a service agreement with Westinghouse to build and operate the facility.

Feverish activity preceded the November referendum. Both sides' campaigns included fliers and newspaper advertisements. Westinghouse, which also used glossy direct mail, spent over three times the opponents' total expenditures. Opponents used a telephone campaign, advertisements on a local cable television station, and developed an alternative solid waste management plan that excluded WTE. Debates on the WTE facility were held throughout Monmouth County. One month before the election, Monmouth County released a comparative health risk assessment that determined composting to be 100 times more risky than WTE. Members of the county's health risk assessment committee were not involved in developing the comparative health risk assessment. The county also 
revised its cost estimates (per ton tipping fees) after it submitted its application to sell power and could, therefore, better estimate its revenue. The timing of these revisions caused skepticism among project opponents.

Forty-seven percent of the registered voters voiced an opinion on the solid waste management plan at the polls in November 1991. When 52 percent of those voters opposed the project, Freeholders exercised the "pull-out" clause and withdrew from the contract with Westinghouse.

The county since has organized a Recycling and Alternative Technologies Committee, whose members include opponents of the county's WTE facility, to review solid waste management technologies and make recommendations to the county. Neither its activities nor the November 1991 referendum preclude the county from using WTE technology in the future.

\subsubsection{Participation}

Numerous groups became involved in the debate over the Monmouth County WTE facility, including local chapters of longstanding national and state environmental groups. Other citizen's groups ${ }^{3}$ that emerged during the process are described below.

Citizen's group 1: Organized in 1988 but faded away because of infighting about technical issues.

Citizen's group 2: $\quad$ Organized in 1990 and led opposition to WTE facility; based in Tinton Falls but built large county-wide membership through its own publicity efforts and media coverage; concerns focused on health and environmental effects and financial considerations.

Citizen's group 3: Composed of 150 medical professionals; opposed because of potential health effects.

Cütizen's group 4: $\quad$ Formed in 1991 to support county WTE plan; membership above 100; conducted financial analysis of project; aligned with tax watchdog group.

${ }^{3}$ Representatives of groups opposing the project declined opportunities to participate in this research. Consequently, information about the groups, their activities, and their opinions is derived from publicly available materials (including reports, fliers, and other documents they produced) and through other participants in the research. 
Governmental and quasi-governmental groups that participated included the NJDEP; the county's solid waste advisory committee, composed of Freeholder representatives, waste haulers, and county staff; and the county's health risk assessment committee with citizen representation. NJDEP approval, required for all county solid waste management plans and amendments, is based on technical considerations and adherence to state solid waste management policy. Health risk assessment committee members characterize it as having made little progress; though not formally disbanded, the committee ceased to meet in April 1991. Its facilitator was a non-local expert in risk assessment whom project opponents viewed as completely biased toward the use and safety of WTE facilities.

In making decisions about WTE, the county Freeholders initially supported the WTE facility unanimously. With the introduction of new members and forced regionalization, three voted to bring the issue to referendum. Subsequently, one Freeholder moved to kill the project altogether.

County-offered opportunities for public participation included citizen members on the solid waste advisory and the health risk assessment committees and a series of public hearings. A public hearing on an early version of Monmouth's solid waste management plan drew approximately 200 people; later hearings drew even more. The most encompassing and direct opportunity for public participation was the November 1991 public referendum.

By 1990 , opponents became more visible by planning and attending numerous events. Opponent groups, civic and environmental groups, and business organizations throughout Monmouth County held public forums for county representatives, Westinghouse officials, and opposition group leaders to discuss the solid waste management plan. Rallies, signs, fliers, and booths at county fairs delivered the opposition's viewpoint to the public. The lead opposition group also made its own solid waste management plan, presented it to the county as an alternative to WTE, and petitioned the 
county to include the word "incinerator" and to remove the reference to a specific location in the referendum.

\subsubsection{Mitigation}

The New Jersey law requiring financial compensation to the city hosting a solid waste facility would apply. [Tinton Falls currently receives upwards of $\$ 7$ million annually (an amount higher than that mandated by state law)]. The county also offered to construct a public facility, e.g., a fire station, as a compensatory gesture to Tinton Falls.

\subsubsection{Regulations and Laws}

County officials, staff, and consultants considered environmental regulations throughout the planning process. Proposals from companies unable to meet NJDEP and U.S. EPA standards were excluded from consideration. New Jersey regulations regarding the testing and disposal of WTE ash are stricter than existing federal regulations. Each load must be tested, remain segregated, and, if it meets New Jersey criteria for hazardous waste (which are stricter than U.S. EPA standards), it must be disposed of as such. Air emissions estimates, developed by county consultants, were based on the throughput of the unsegregated waste stream, although the front-end separation process would remove hazardous materials and metals that contribute to the toxicity of the air emissions and ash. Despite the conservatism of the estimates, they were within state and federal emissions standards. County officials or staff were not concerned that environmental regulations would affect the viability of the facility.

Changes in the state's interpretation of Public Utilities Regulatory Policy Act (PURPA) motivated the county to sign an agreement with its vendor quickly in an attempt to be grandfathered in under the old power purchase regulations. Before 1989, the state's interpretation of PURPA caused utilities to purchase power at 110 percent of their avoided cost. The new interpretation, 
allowing an annual public bidding system to establish the market price for power, could result in substantially lower payment to the county for power produced at the WTE facility.

\subsubsection{Decision-Making Issues}

The key issue for county officials and staff was developing solid waste management capacity that would reduce reliance on landfills, provide environmentally sound waste disposal, be reliable (i.e., was proven to be reliable at other sites in the United States), recover resources, and be economically acceptable. County staff and most officials believed that WTE with a front-end separation process was the technology that could meet these parameters.

Initially, key decision-making issues important to the public focused specifically on WTE facilities rather than on solid waste management generally. The first issue to which the public reacted was the possibility of adverse health effects from WTE emissions. Following closely was the financial impact of the project on county residents. However, once opponents began to offer alternatives to WTE, they framed issues in terms of broad solid waste management concerns. In particular, they wanted solid waste management activities to have minimal effects on the health of county residents and sought to keep solid waste disposal costs reasonable.

\subsubsection{Summary of Issues}

A summary of these and additional issues follows. This section concludes with a discussion of public attitudes and participants' relations.

\section{Site Selection Issues}

- Believed by most to be a "logical" site but caused some concern because of proximity to residences.

\section{WTE Technology Issues}

- County concluded that health risk is minimal, but organization of health professionals and other opponents expressed concern about exposures to dioxin, mercury, and lead. 
- Facility size included surplus capacity of $\mathbf{4 0 0}$ tpd; concern that excess capacity would preclude further implementation of recycling and waste reduction, and would allow importation of waste.

- Concern over Westinghouse's environmental (and financial) record.

\section{Economic Issues}

- Secondary to environmental issues.

- Disagreement over projected tipping fees at proposed WTE facility and alternative facilities, and WTE construction and operating costs.

\subsubsection{Public Attitudes and Participants' Relations}

Before Monmouth County proposed its WTE facility, the general public knew little about the county's solid waste disposal. The MCRC had never drawn much public attention. Newspaper coverage of county solid waste management plans began in early 1986. Although public hearings first were held in 1986, most respondents agreed that the WTE facility became general public knowledge in 1989. The highly visible campaigns regarding the WTE facility increased public awareness of solid waste issues and solid waste management in Monmouth County.

A local newspaper survey conducted shortly before the November referendum found that 48 percent of the public favored composting, 29 percent favored WTE, and 10 percent favored continued landfilling. The remaining 13 percent were undecided. Audience responses at the county's public hearings and independently held forums also indicated public attitudes. Despite apparent public opposition to WTE, the two Freeholders who most strongly supported it were reelected by wide margins in a November 1990 election in which the WTE facility was the primary issue.

Public leaders and local and state elected officials adopted one of the three possible public stances: favoring WTE, opposing it, or supporting the public's right to decide. The latter two positions, respondents suggested, sometimes were adopted for political expedience. The most widely read newspaper in Monmouth County publicly opposed the project; the business community remained relatively silent on the issue. 
Several respondents characterized the interactions among parties involved in the campaign as a manifestation of a classic clash of the powerful and the powerless. On one side was a large corporation wielding its power and financial clout with paternalistic county officials trying to tell the public to accept what was best for it. On the other side was the seemingly powerless public about to be trampled by big business and government. Several respondents said that skepticism of government and big business made the general public wary of the project. This mistrust was extended to the county's consultants, whom opponents labeled "hired guns." That the solid waste issue perhaps was the first to engender public mistrust of local government in New Jersey may be part of a larger pattern of mistrust of state and federal governments.

Difficult situations arose at public forums. The Westinghouse representative had difficulty communicating with the public. Also, according to some forum attendants, county staff seemed illprepared because they were unable to provide immediate responses to some questions. A business community representative suggested that the county staff therefore missed opportunities to allay doubts raised by opponents' claims of adverse health effects.

Other county actions fostered mistrust among the public and municipalities. For example, a request by Tinton Falls to have immediate access to data from monitoring wells around the landfill first was denied by the county because the county claimed the data were highly technical, and accordingly beyond the grasp of representatives of the municipality. Changing facility cost estimates and releasing comparative health risk assessment data shortly before the referendum were viewed suspiciously by opponents and some of the general public. County staff, in retrospect, suggested that these information releases hurt the county's image.

\subsubsection{Improving the Decision-Making Process}

No research participants expressed complete satisfaction with the WTE decision-making process in Monmouth County. While all participants suggested increased public participation, some 
suggested greater and meaningful citizen representation on committees contributing to the decisionmaking process, and others recommended an increased role for municipalities within the county.

Opinions about relying on a public vote to decide such an issue varied. Some respondents firmly believed that the public should decide but others, having just endured the protracted ordeal, questioned whether the public could become informed well enough to make such a decision. All respondents agreed that if a referendum is held the public should be obligated to become informed; some argued that it is the county's responsibility to provide information and to provide increased opportunities for public involvement.

Most participants were unsure whether such improvements would have affected the outcome of the solid waste decision-making process, but they believed the outcome would have better reflected an informed public's attitude.

\subsection{ANALYSIS}

The four case studies were compared to identify factors that influence decisions to accept or reject WTE facilities. These factors are organized into two major categories: context and process. The decision-making context category is organized into two sub-categories of information about counties: past waste management practices and demographic variables. The decision-making process category identifies who was involved, what happened, and how it happened and is organized into five subcategories: (1) the proposed system, (2) the siting process, (3) the interaction among parties, (4) public participation, and (5) catalysts driving the project. Tables 4-1 and 4-2 summarize this information. Cross-cutting factors related to context and process are the issues raised during the course of decision-making.

Comparisons between case-study sites where WTE has been accepted to those where it has been rejected should consider the timing of proposed projects and the degree to which WTE was 
Table 4.1. Summary of decision-making context

\begin{tabular}{|c|c|c|c|c|}
\hline & \multicolumn{2}{|c|}{ Accepted } & \multicolumn{2}{|c|}{ Rejected } \\
\hline & Broward & Oakland & Knox & Monmouth \\
\hline \multicolumn{5}{|c|}{ Warte Management } \\
\hline $\begin{array}{l}\text { Size of waste stream } \\
\text { (approx. 1988) }\end{array}$ & 4,400 tpd $^{1}$ & 3,600 tpd & 800 tpd & 2,300 tpd \\
\hline $\begin{array}{l}\text { Environmental status of } \\
\text { landfills in county }\end{array}$ & Mixed & Mixed & Good & Mostly good \\
\hline $\begin{array}{l}\text { Other combustion } \\
\text { facility }^{1} \text { in county }\end{array}$ & Yes, closed & Yes, closed & No & No \\
\hline SW exported & $\begin{array}{l}\text { Prohibited by } \\
\text { law of recipient } \\
\text { county (after } \\
\text { 1980) }\end{array}$ & $\begin{array}{l}\text { Some restrictions } \\
\text { in county SWM } \\
\text { plans }\end{array}$ & Yes & Yes. \\
\hline \multicolumn{5}{|c|}{ Key Demographic Variables } \\
\hline Population $55+(1990)$ & $34.5 \%$ & $19.4 \%$ & $22.5 \%$ & $20.9 \%$ \\
\hline $\begin{array}{l}\text { Population growth } \\
1980-90\end{array}$ & $23 \%$ & $7 \%$ & $5 \%$ & $10 \%$ \\
\hline $\begin{array}{l}\text { Projected population } \\
\text { growth } 1990-2010\end{array}$ & $35 \%$ & $12 \%$ & $15 \%$ & $20 \%$ \\
\hline
\end{tabular}

${ }^{1}$ Acronyms: SW-solid waste; sum-solid waste management; tpd_tons per day. 
Table 4.2 Summary of decision-making process

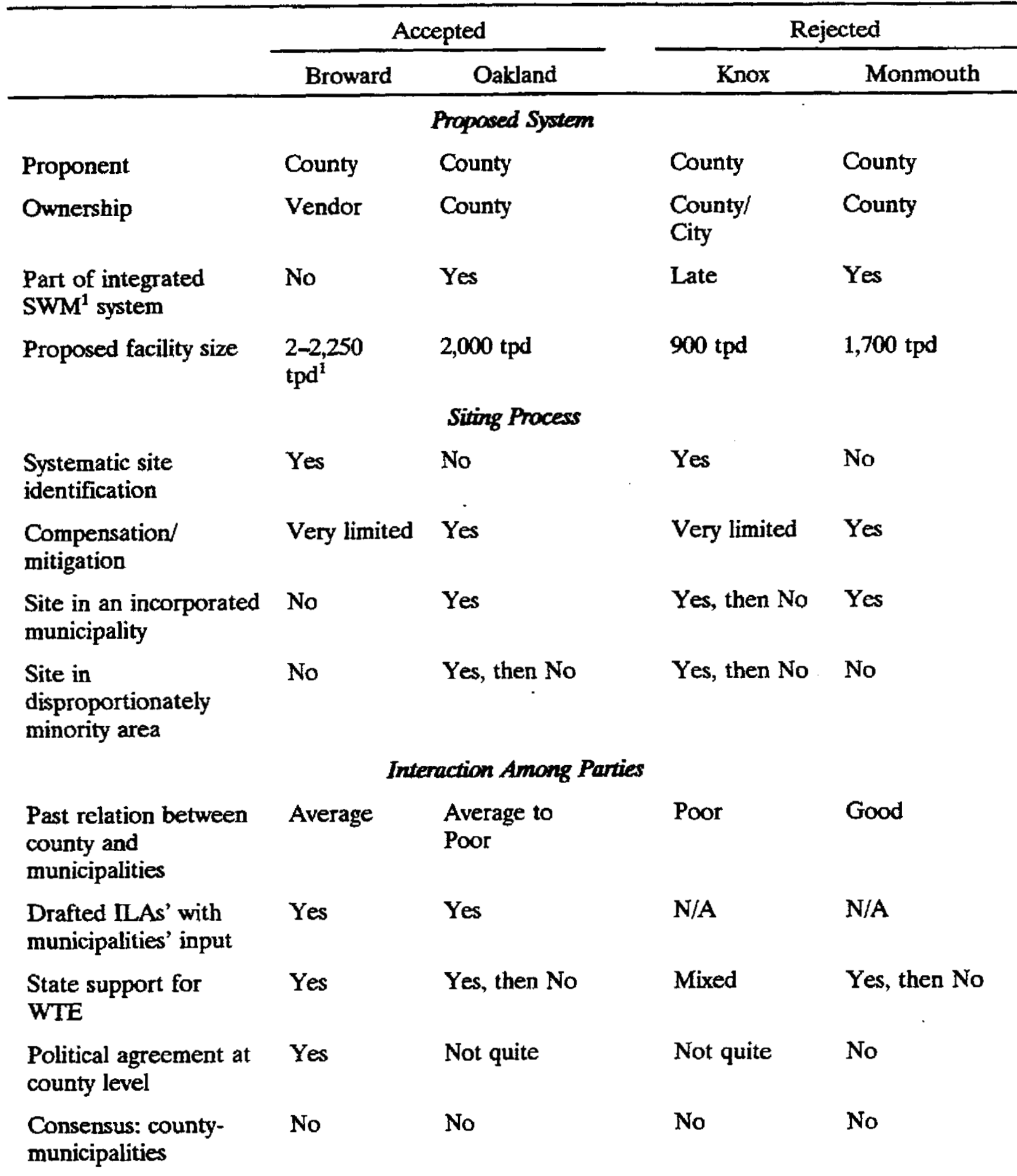


Table 4.2 Continued

\begin{tabular}{|c|c|c|c|c|}
\hline & \multicolumn{2}{|c|}{ Accepted } & \multicolumn{2}{|c|}{ Rejected } \\
\hline & Broward & Oakland & Knox & Monmouth \\
\hline \multicolumn{5}{|c|}{ Public Participation } \\
\hline $\begin{array}{l}\text { Information provided } \\
\text { to public }\end{array}$ & PR ad & $\begin{array}{l}\text { Info. brochure, } \\
\text { presentations } \\
\text { to civic groups, } \\
\text { Westinghouse } \\
\text { PR ads }\end{array}$ & Forum & $\begin{array}{l}\text { Forums, } \\
\text { Westinghouse } \\
\text { PR ads }\end{array}$ \\
\hline $\begin{array}{l}\text { Public involvement } \\
\text { (other than } \\
\text { referendum and } \\
\text { hearings) }\end{array}$ & No & $\begin{array}{l}\text { Advisory } \\
\text { committee }\end{array}$ & $\begin{array}{l}\text { Advisory } \\
\text { committee }\end{array}$ & $\begin{array}{l}\text { Advisory } \\
\text { committee }\end{array}$ \\
\hline $\begin{array}{l}\text { Who decided to } \\
\text { proceed or not }\end{array}$ & $\begin{array}{l}\text { County } \\
\text { Commission }\end{array}$ & $\begin{array}{l}\text { Public } \\
\text { referendum }\end{array}$ & City Mayor & $\begin{array}{l}\text { Public } \\
\text { referendum }\end{array}$ \\
\hline \multicolumn{5}{|c|}{ Catalysts Driving Project } \\
\hline $\begin{array}{l}\text { State mandates for SW } \\
\text { capacity }\end{array}$ & No & Yes & No & Yes \\
\hline Financing deadlines & Yes (1984) & No & Yes (1986) & $\begin{array}{l}\text { Yes (PURPA } \\
\text { related) }\end{array}$ \\
\hline
\end{tabular}

${ }^{1}$ Acronyms: SWM-solid waste management; SW-solid waste; ILA-interlocal agreement; PR-public relations; tpd-ions per day.

accepted or rejected. The timing of project initiation and implementation, as well as changes occurring on a national level during the 1980 s, affected the decision-making process at each of the Decisions to proceed with WTE projects also do not fall neatly into simple "acceptance" or "rejection" categories. There are differences in the degree to which WTE was accepted at each case-study site. At the "acceptance" extreme was Broward County, which has two WTE facilities now operating. Oakland County's mandate to proceed with WTE implementation is less clear. For instance, although a public referendum narrowly approved WTE use, municipalities failed to sign IGAs committing their waste to the county's system. Monmouth County voters rejected the county's WTE proposal by a 
very small margin. Except for Knoxville's mayor's withdrawal of support, driven largely by concerns for political liability, the Knox County project might have proceeded unhindered.

Comparisons between case-study sites in this chapter focus on the outcome of decision making -whether or not to proceed with WTE-and the decision-making process itself. Examining the decision-making process does not presuppose that either WTE acceptance or rejection is the more desired outcome. It does, however, provide insights into process factors that influence the final WTE decisions, even though any one factor affecting the decision-making process may not lead to consistent outcomes.

The following sections compare the decision-making contexts and the decision-making processes of the four case-study sites. For each factor, similarities and differences are analyzed to determine whether, how, and why that factor may have influenced the decision-making process and/or outcome. Major issues raised and addressed during the course of decision-making are summarized in the final section of this chapter.

\subsubsection{Decision-Making Process}

\subsubsection{Proposed System}

The following factors apparently did not affect decision-making outcomes at case-study sites: (1) who initiated the project; (2) proposed facility ownership; and (3) vendor negotiations. The size of the proposed facility relative to the size of the waste stream was a significant decision-making factor. Sizing considerations include the current waste stream size, projected changes in the amount of waste to be handled, and economic feasibility. Broward and Knox Counties proposed facilities with a maximum daily throughput 100 tons greater than their average daily waste production. Oakland and Monmouth Counties considered WTE as part of an integrated solid waste management system and proposed WTE capacities much less than their current average daily production. Decisions about facility sizing may have important implications for public acceptance of WTE because of resultant 
opportunities for waste importation and actual or perceived effects on other waste reduction methods, especially recycling. For example, the Knox County facility, sized 100 tpd larger than the current waste stream, and the Oakland County facility, sized to account for recycling and other waste reduction methods, both engendered public concern about WTE facilities reducing the viability of other waste reduction programs. This concern suggests that the timing of WTE implementation relative to other waste reduction programs also affects WTE decision making.

Proposing WTE as a component of an integrated solid waste management system apparently does not affect the ultimate acceptance or rejection of WTE. Except for Broward County, where WTE planning largely preceded a push toward integrated waste management systems, planners considered the effects of existing or planned recycling programs on the proposed WTE facilities.

Respondents' suggestions that implementing waste reduction, reuse, and recycling activities before WTE planning would improve the decision-making process are amplified in recent literature about hierarchical waste management strategies (Blumberg and Gottlieb, 1989, pp. 203-211). Hierarchical waste strategies could reduce public apprehensions about recycling and competition for limited quantities of waste. For example, in Monmouth County, where recycling is mandatory, concerns about WTE's effects on recycling were insignificant and apparently did not surface until changes in the projected waste stream size resulted in the prepared facility having $\mathbf{4 0 0}$ tpd of excess capacity. The inclusion of WTE in an integrated waste management system therefore may affect what issues are raised during WTE planning, as well as the timing and degree of concern about these issues.

\subsubsection{Siting}

Case-study comparisons indicate that there is no clear link between siting activities, site characteristics, or mitigation or compensation, and the outcome of WTE decision making. For example, systematic site identification processes were undertaken by Broward County, where WTE 
was accepted, and by Knox County, where WTE was rejected. Both Oakland-County and Monmouth County offered considerable financial compensation to the host communities, yet WTE was rejected at Monmouth. Broward and Knox Counties intentionally selected sites on unincorporated county land, although Knox did so only after an unsuccessful siting attempt in Knoxville.

Though siting literature suggests that a technically correct, systematic, and comparative siting process is essential to siting a WTE facility (see, for example, Buhler, 1987), case-study siting activities in Monmouth County suggest that participants can be satisfied that a proposed site is technically and environmentally suitable in the absence of multi-site comparisons. Broward, Oakland, and Knox Counties' site selection difficulties affirm literature findings (U.S. EPA, 1990b) that a site's political and public acceptability is equally as important as its environmental and technical acceptability. Broward and Knox sought political acceptability by siting in unincorporated areas, while Oakland and Monmouth offered financial incentives to increase political acceptability.

Issues of environmental equity regarding the location of hazardous waste sites recently have received considerable attention (Bullard, 1990; Commission for Racial Justice, 1987; and General Accounting Office, 1983). Oakland and Knox County abandoned their original sites partly because of accusations that the counties were unduly burdening their minority population by proposing to site an undesirable facility in areas where minorities reside. Oakland's rationale for the original site was to provide steam to nearby county buildings. Knox County's siting strategy emphasized a central location and easy transportation access. However, none of the final locations proposed for WTE facilities at case-study sites were in areas where minority populations are disproportionately represented.

\subsubsection{Interaction Among Parties}

There are clear differences between Broward and the other case-study sites in the types of interaction and the level of agreement among participants. Broward's negotiations with its member 
municipalities occurred against a backdrop of generally satisfactory past relations with its municipalities and a tradition of interaction with the Broward League of Cities. In contrast, for example, Knoxville and Knox County have had a troubled relationship.

The case-study counties' member municipalities participated differently in WTE planning. In Knox County, the only major city, Knoxville, became a project co-sponsor. In Monmouth, planning proceeded with very little consultation with Monmouth's municipalities. Although Broward and Oakland drafted ILAs with their member municipalities, there were subtle differences in the interactive processes in the two counties. Interaction between Broward and its member municipalities occurred through the League of Cities, an organization that traditionally represents the joint interests of Broward municipalities. In contrast, Oakland's municipalities were represented by officials and legal representatives who did not represent the collective interest of all municipalities.

None of the case-study counties' member municipalities were completely supportive of the WTE projects. For example, Knoxville agreed to co-sponsor the Knox County's WTE project, but the city council did not support siting the facility in Knoxville, and ultimately the mayor withdrew his support for the project. Oakland and Monmouth municipalities neighboring or hosting proposed WTE facilities generally opposed them, but municipalities opposing the Broward project did not neighbor proposed facilities. That at least two of the municipalities that refused participation in Broward's WTE facilities have had poor relations with the county suggests that patterns of mistrust that result from unrelated matters may exacerbate dissatisfaction with the WTE decision-making process.

Because WTE planners and decision makers attempt to follow state guidelines for solid waste management, state positions supporting WTE (often expressed only as goals) facilitate WTE adoption at the local level. Complete or partial withdrawal of state support for WTE slows the decisionmaking process when permits are delayed or moratoria are enacted. Also, the public might be swayed 
by the positions of state governments because it may perceive state staff to be better trained and more qualified than local government staff. Unfaltering state support for WTE was clear only at the Broward County case study. In Oakland County there was a long delay in permitting because the state's permitting agency was restructured and because of a state review of mercury contamination. Changes in state support for WTE in New Jersey resulted in a temporary moratorium on WTE planning activities and eventually forced regionalization of Monmouth's planned WTE facility. State support for Knox's WTE was mixed, with permitting almost assured but difficulty in obtaining state legislature approval for a financing mechanism.

Having constant and unanimous support from county officials also significantly influences the decision-making outcome. Unanimous, unfaltering county support for WTE existed only at Broward County. There are several likely reasons why political support existed in Broward. Unlike the other case study sites, Broward experienced very little turnover in key decision makers, i.e., county commissioners, during WTE planning and implementation. Broward's commissioners' security in office may have reduced their political liability from decisions about WTE. The continuity of Broward's decision makers prevented project planning from slowing while new decision makers reviewed past events and decisions. In contrast, the new mayor who took office in Knoxville during WTE planning altered the decision-making process and eventually withdrew from the Knox County project.

Perceptions of need for waste management capacity also might have contributed to agreement among Broward County Commissioners. Closure of the county landfill and projections of continuing population growth might have made Broward's decision makers and the public perceive a dire need for a WTE facility. At the other sites the public perceived no such urgency and prompted decision makers to delay action. 


\subsubsection{Public Participation}

Although public information activities at the case-study sites were limited and occurred late in the decision-making process, respondents uniformly agreed that public information is crucial early in the planning process. There were, however, few recommendations about how this education process might occur or who should be responsible.

There also were strong recommendations for increasing public involvement in the decisionmaking process, but few concrete suggestions about how this might be accomplished. A lack of decision makers' familiarity with available guidelines for public participation (e.g., Institute for Participatory Planning, 1981) may, in part, account for the lack of public involvement programs at the case-study sites. Further, some information became available only after years of WTE planning already had occurred at the case-study sites (U.S. EPA, 1990; see also Syme and Eaton, 1989).

Facilitating public participation in the decision-making process may not produce uniform decisions about WTE, but dissatisfaction with the decision making that generally excludes or makes public participation difficult may exacerbate opposition to the decision. For instance, opposition to the Knox County project solidified partly because opponents perceived that early planning activities had been conducted in an almost clandestine manner and because they experienced difficulty obtaining documentation about the project.

Further, while the case-study sites demonstrate no tendency toward WTE acceptance or rejection based upon who makes the decision, it is likely that decisions made by public referendum (in Oakland and Monmouth) generally were more publicly acceptable than those made otherwise. Decision making that includes a public referendum is vastly different from a process that does not primarily due to direct public participation and also because of the massive campaigns a referendum spawns. A decision-making process acceptable to all parties might also make the outcome of such a process acceptable. 


\subsubsection{Catalysts Driving the Project}

Two sets of regulations spurred project activities at each case-study site, those concerning solid waste management activities and project financing. For example, state mandates affected the Michigan and New Jersey cases required counties to plan for or provide solid waste management capacity for a specified number of years. Michigan's regulations mandated unprecedented levels of county involvement in solid waste management.

Regulations also effectively established deadlines for the completion of certain activities to achieve favorable financing or revenue arrangements. For example, both Broward and Knox Counties hastily issued bonds to take advantage of soon-to-expire tax-exempt status. Monmouth County rushed to execute a power sales agreement before state reinterpretation of PURPA would significantly reduce revenue available from power sales.

\subsubsection{Decision-Making Context}

\subsubsection{Waste Management}

The general solid waste management experience of sites where WTE has been accepted differs from that where WTE was rejected. It may be that alone none of the contextual factors at sites where WTE was accepted-contaminated landfills, experience with combustion facilities, and limited opportunities for waste exportation-are significant enough to affect WTE decisions. In concert, however, the occurrence of these factors at case-study sites where WTE has been accepted suggests that such experience positively influences acceptance of WTE.

Waste stream size relative to the size of the proposed WTE facility, is an important decisionmaking factor (see Section 4.7.1.1). Because the size of each county's waste stream reflects its population and economy, Broward's waste stream is largest and Knox's is smallest. On a per capita basis, however, Monmouth is the largest generator of waste. 
Each of the case-study sites has hosted landfills and dumps, but only-Knox County no longer has an operating landfill within its bounds. Each site houses landfills closed because of relatively recent, stringent state and federal regulations and because retrofits were not economically feasible. Closed landfills in Broward and Oakland are listed as Superfund sites.

Municipally owned combustion facilities in Broward and Oakland Counties were closed in the late 1970 s and 1980 s, respectively, because they failed to meet emissions standards. Neither Knox nor Monmouth have had municipal combustion facilities.

Each site exports solid waste. The county that had been importing Broward's waste prohibited waste importation shortly before WTE planning began but did not actively enforce its regulations. In Oakland, inter-county waste exportation was restricted by state requirements for agreement between importing and exporting counties. Current New Jersey policy encourages regional waste facilities. Out-of-county and state waste exportation is allowed with NJDEP approval, but Monmouth County historically has not exported its waste. Tennessee does not restrict inter-county waste exportation and, after the privately owned Knox County landfill closed, all solid waste was exported to a privately owned landfill in a neighboring county.

\subsection{Key Demographic Variables}

Researchers have suggested that environmentalism is a concern primarily of the affluent young who also reject traditional authority in favor of participatory decision-making (Milbrath, 1984; Jones and Dunlap, 1992). In Broward persons aged 55 and older represent over one-third of the population. At the other case-study sites, this cohort represents only between one-fifth and onequarter of the population.

Past and projected population growth probably contributes to perceptions of immediate need for solid waste management capacity. Broward County's population grew 23 percent between 1980 and 1990 , exceeding the national average by 13 percent (U.S. Bureau of the Census, 1988, 1992). 
Projected population from 1990-2010 is 35 percent (Terleckyj and-Coleman, 1990). In Broward-unlike the other study sites-past and projected population growth led to general agreement on the urgent need for solid waste management capacity.

\subsubsection{Issues}

How the numerous issues raised by planners and other players for consideration by decision makers, representatives of associated municipalities, non-governmental organizations, and the public are addressed during WTE planning affects the decision-making process and outcomes. People who believe that their concerns about potential adverse health effects have not been addressed adequately are unlikely to support WTE in a public referendum, an outcome-related example. The ways in which public concerns are addressed, for instance by modifying the decision-making process to include mitigation measures, is process-related.

Similar issues were raised at each case study site; most were topics of disagreement between WTE proponents and opponents due to a lack of information, mistrust of available information or the sources of information, and conflicting viewpoints held by credible organizations. Issues raised at the case-study sites are listed below.

\section{Waste Management Issues}

- Immediacy of the need for solid waste management capacity.

- Need to reduce reliance on landfills.

- WTE's effects on recycling and other waste reduction programs.

\section{Health and Environmental Issues}

- Impacts of WTE relative to other waste management options, e.g., landfilling and composting.

- Potential adverse health effects on humans.

- Potential adverse environmental effects (e.g., to water and wildlife) of emissions.

\section{Financial Issues}

- Projected waste disposal costs.

- Property value depreciation. 


\section{Process Issues}

- Access to formal decision-making process.

Most participants at case-study sites agreed that the need to reduce reliance on landfills was a key issue. This issue is related to their perceptions that landfills pose significant threats to health and the environment and that alternatives such as recycling are more environmentally benign than landfilling. Within case studies, except Broward, respondents disagreed on the potential impacts of WTE on the viability of recycling and other waste reduction programs. At Monmouth, for example, this disagreement became an issue because of the proposed excess 400 tpd of capacity.

Agreement about the immediate need for additional waste management capacity likely contributed significantly to the adoption of WTE in Broward County. Elsewhere, particularly in Oakland and Knox Counties, participants opposed WTE because they believed that a critical need for solid waste management capacity would not occur for several years.

Although addressing health and environmental issues may affect some aspects of the decisionmaking process, its greatest influence is on its outcome. There was general disagreement about WTE's impacts on health and the environment. Opponents thought health and environmental risks were unacceptable; project proponents, using detailed health and environmental risk assessments, characterized them as negligible or minor. Communicating the results of scientifically based risk assessments is difficult (Konheim, 1989; Luderer, 1990) and, where trust is lacking, opponents' emotionally charged appeals can effectively sway public opinion (Konheim, 1989). For instance, the Monmouth County public trusted an organization of local medical professionals (WTE opponents) more than the unfamiliar, non-local scientist leading the health risk assessment committee.

Two unrelated financial issues arose at the case-study sites. The first was how WTE project costs would affect waste disposal costs. Projected tipping fees often were revised because of changed 
estimates of project revenues or project costs. Municipal officials and the public consequently were concerned about uncontrollable project costs necessitating additional taxes or increased disposal fees.

The second financial issue was the impact WTE facilities might have on the value of neighboring properties. Many respondents who were WTE proponents assert that fears of decreasing property values were the underlying cause for opposition to WTE. However, with the possible exception of Knox County, WTE opposition at the case-study sites was broad enough to suggest that other concerns, particularly health and financial issues, predominated.

The final issue was the set of formalized procedures that lead to decisions about WTE. While representatives of groups and municipalities thought they had insufficient access to early stages of the formal decision-making process, many respondents actually involved in formalized decision making thought that meetings and hearings provided the public ample access to the formalized decisionmaking process. Public referenda at two sites and the introduction of a new, key decision-maker at a third site enhanced public access during later decision-making stages.

Participants in formalized WTE planning and decision making generally identified the need for solid waste management capacity and reduced reliance on landfills as the most critical issues in WTE decision making. In contrast, WTE opponents tended to identify health and environmental impacts and waste disposal costs as the most important issues.

\subsection{SUMMARY AND FUTURE OUTLOOK}

This chapter has examined the decision-making contexts, processes, and outcomes at four case-study sites to determine what factors influenced WTE decision making. Key factors have been identified by comparing their occurrence at the case-study sites, by considering respondents' recommendations, and by examining relevant literature. 
These factors can influence the decision-making process, its outcome, or both. The inextricable link between how a decision is made and what decision is made suggests that any factor related to the decision-making process may in turn affect the outcome. The following is a list of key decision-making factors categorized according to whether they affect the decision-making process or the decision-making outcome.

Key Decision-Making Factors: Process

- Provisions for public information.

- Provisions for, and the type of, public involvement.

- Municipalities' involvement.

- Planning WTE as a component of an integrated solid waste management system.

Key Decision-Making Factors: Outcome

- Perceived need for facility.

- State's support for WTE.

- Public's support for WTE.

- Elected officials' support for WTE.

- Concern about environmental and health risks.

- Concern about increased solid waste disposal costs.

Factors within categories, particularly outcome-related factors, are uniquely intertwined. For example, concern about environmental and health effects contributes to state, public, and elected officials' support for WTE; public support for WTE contributes to elected officials' support; and state support for WTE contributes to public and elected officials' support.

The limited number of case studies allows only tentative estimates of WTE decision-making trends that might occur in the near future. One likely change is that decisions about WTE increasingly will be made only in the context of integrated (or partly integrated) solid waste management systems. Voluntary or mandatory recycling programs, waste separation programs, vegetative composting, and waste reduction programs already are operating in many municipalities; their relationship to WTE will have to be considered during WTE planning. Further, the popularity 
of recycling programs relative to WTE may demand that the former be implemented before the latter is planned.

Another probable trend is that WTE decision-making processes increasingly will include public information and public involvement programs from their inception. Case studies present only limited evidence of this trend; the three case-study WTE programs introduced in the mid-1980s offered more public information and opportunities for public involvement than the case study introduced in the early 1980s. In addition, increasing concern about solid waste issues and public demands for participatory decision making may promote this trend. Lastly, at both sites where WTE proposals were rejected, the ensuing solid waste management planning activities included broad-based citizen participation.

Based on the occurrence and intensity of public opposition at the case-study sites and antiincineration stances of prominent national medical and environmental associations, it is likely that considerable public opposition to WTE proposals will continue. This opposition may be mitigated by changes in decision making, such as those discussed above, that will make the process, and thus the outcome of the process, more publicly acceptable. 


\section{APPENDIX B WASTE-TO-ENERGY FACILITIES PROTOCOL}

Preface: The results of this study will be used by researchers at Oak Ridge National Laboratory to investigate decision making affecting the development, as well as abandonment of, proposed Waste-to-Energy (WTE) facilities in various communities in the United States. Your identity will be kept confidential. If you wish, we will notify you as to the availability of the final results of the study and tell you how to obtain a copy.

\section{Section I. Demographic Information}

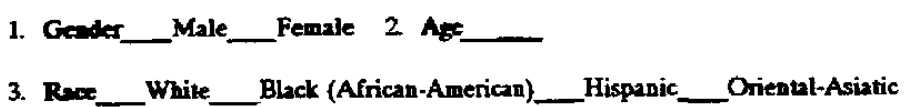

4. Name

5. Occupation

6. Job/position title

7. Organization/role

\section{Section II. Context Factors Checklist}

1. Community

- characterization of community (development, industry, economy)

- development plans...vision of future (ideal vs. real)

2. Waste management policies and practices

- how wastes handled currently

- service region

- rationale behind decisions

- reliability

- safety

- environmental impact

-operator training

-overall management

3. Previous siting controversies:

- waste facilities

- other industrial/noxious facilities

- central issues:

- environmental concerns

-land use

- site availability

- site suitability

- low income/racial minority communities 
Section III. Decision Making Process (sequence of events; respondents' perceptions; when and if things become issues...opportunities and constraints; who is involved)

\section{Sequence of events}

- who was proponent

- when initiated by proponent

- when discovered by community...by respondent

- how was decision reached

2. Participation (at each stage)

- what groups are involved [new vs. established organizations; civic vs. environmental groups; local, regional, or external groups (sought or required)]

- types (public or private; via public meetings, negotiation, protest)

- why did the groups first get involved (issues)

3. Degree of agreement (at each stage)

- among what parties (e.g., community and proponent, different stakeholders)

- public or private agreements

-negotiation

- formal or informal agreements

-iterations (what required, how long a period of time, what result)

4. Mitigation (at different stages)

- what methods

- how idea originated

- offered to whom (regional or local)

- offered by whom (regional, local or external)

5. Compensation (at different stages) Kstes in Seetios IV

- what form

- to whom

-by whom

6. Regulations and laws: role and effect on viability of WTE (at different stages)

- What agencies had permitting jurisdiction

- EPA Municipal Waste Combustor (MWC) guidelines

- Clean Air Act of 1990 (restrictions on atmospheric emissions from MWCs)

- Resource Conservation and Recovery Act of 1980s landfill disposal rules

- Public Utility Regulatory Policy Act (PURPA)

-1986 Tax Law Changes (financing rules) 
Section IV. Decision Making Issues (personal view vs. community view; effects on viability of WTE)
A. Key issues
-at different points in time

B. Environmental and technology issues

1. Siting selection

- where (characterize; suitability, neighboring populations)

- alternatives (where...characterize)

- basis for selection (criteria; who selected site)

- responses to selection (local, regional)

2. Proposed WTE facility and technology (here or elsewhere)

- reliability

- safety

-environmental impact

-operator training

- overall management

- a reasonable size facility?

3. Waste management and environmental practices and regulations

- recycling requirements and their impacts

- emissions requirements and their impacts

Tept introduced in Section In

- landfill disposal requirements and their impacts

- ash management requirements and their impacts

-interstate transport restrictions and their impacts

C. Public/community issues

1. Public attitudes

- general public

- elite public (organizational leaders, public officials, powerful people)

- how became aware of public attitudes

2. Proponent/public (local, regional)/municipality relations:

- trust and confidence

-if mistrust, what caused it, when begun

\section{Mitigation}

- what was offered...by whom

\section{Faite harodined in Secton III}

- mitigating adverse economic/environmental impacts through specific measures (e.g. operator training, pollution control

- permitting, permit enforcement, local control, supervision, monitoring of the facility

-restriction on garbage importing 
4. Compensation

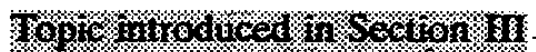

- insuring property values against depreciation

- compensation for adverse impacts in the form of direct payments or other policies

- payment of host fees to the local community or region

D. Economic issues

1. Dispasal costs

- recycling

- source reduction

- landfill

2. Financing altematives

- what alternatives considered

-(financial) risks of each alternative

3. Effect of the Tax Reform Act of 1986 (tax-exempt status of industrial development bonds for WTE projects)

- economic viability of WTE facility

\section{Effect of Public Utility Regulatory Policy Act (PURPA)}

- power generation

- economic viability of WTE facility

- if no restriction on power generating capacity, effect on viability of WTE facility

- customer for power identified

\section{Section V. Conclusion}

1. How was the decision making process regarding the proposed WTE facility resolved?

- if failure to site: other facility; interim decision; future projections; site no facility

- if decide to site: what conditions

2. How could the decision making process be improved?

- toward what end(s)

3. Was the correct decision made?

4. Is there anything else you would like to tell us about WTE decision making? 


\section{CHAPTER 5. CONCLUSIONS}

\subsection{INTRODUCTION}

This study has addressed numerous socioeconomic factors that may have contributed to communities' decisions about WTE. Also considered within this study was the decision-making process itself. More specifically, the study adopted a three-pronged approach to investigate (1) the relationships between a municipality's decision to consider and accept/reject WTE and key socioeconomic parameters, (2) the potential impacts of recent changes in financial markets on the viability of WTE, and (3) the WTE decision-making process and the socioeconomic parameters that are most important in the municipality's decision. The first two objectives were met by the collection and analysis of aggregate data on all U.S. WTE initiatives during the 1982 to 1990 time frame. The latter objective was met by way of four in-depth case studies-two directed at communities that have accepted WTE and two that have cancelled WTE projects. This final chapter summarizes the study's findings.

\subsection{FINDINGS FROM AN AGGREGATE PERSPECTIVE}

Chapters 2 and 3 of this study presented the results of an intensive data collection and analysis exercise in which information about each existing, planned, and cancelled WTE project was collected and studied. Numerous potential relationships between decisions about WTE and socioeconomic characteristics were examined.

This work identified a total of 354 counties with WTE initiatives. Almost two-thirds of all WTE initiatives have occurred in metropolitan counties-with 54 percent of the total in metro counties with populations in excess of 100,000 . Non-metropolitan counties account for 30 percent of initiatives.

The study concludes that non-metro counties have cancelled relatively more facilities than 
metro counties -41 percent of all initiatives in non-metro counties and 37 percent in metro counties. Counties with WTE initiatives are generally wealthier, more educated (i.e., percent completing high school), less blue collar (i.e., percent of workers in manufacturing, mining, and construction), less rural (i.e., percent of population in a rural environment), and have a higher percentage of individuals in what is called the "builder" stage (i.e., 22 to 39 years old). Counties that have WTE initiatives are more likely to have existing recycling programs and material recovery facilities (MRFs). There is no identifiable relationship between the availability of landfills (measured in terms of number of landfils per capita) and the decision to consider WTE; and, surprisingly, there is no significant difference between WTE and non-WTE counties in terms of population growth. Communities in states with stronger environmental regulations and incentives and goals for recycling are more likely to have considered WTE. Communities that have considered WTE facilities have average populations of about 385,000 , as compared to communities that have not had WTE initiatives with average populations of only 41,000 . Within those metropolitan counties that have actively considered WTE, larger and less rural populations appear to be key characteristics. The study finds that these same conclusions are generally true for WTE initiatives in non-metro counties.

The results therefore suggest numerous differences between counties that have formally considered a WTE initiative and those counties that have not. Possibly more important, however, is the finding that there are virtually no differences between counties with existing WTE facilities and counties that have cancelled WTE projects. In other words, when only those counties that have had a WTE initiative are considered, there are no significant differences between communities that see those initiatives through to completion and those communities that cancel their projects at some point in the planning process. If there are particular socioeconomic factors that have contributed to the massive cancellations of WTE projects during recent years, they are factors other than those considered in this segment of the study. 


\subsection{WTE AND FINANCIAL ISSUES}

Chapter 3 of this work focused specifically on recent financial trends that may have contributed to WTE project cancellations and altered the relative attractiveness of waste combustion. Three major trends were assessed. First, the costs of WTE facilities escalated rapidly during the 1980s, as many communities moved toward large mass-burn and refuse-derived-fuel facilities. Second, federal tax policy took a major turn in 1986 with the enactment of the Tax Reform Act (TRA86), which placed limits on the local government's ability to finance WTE and other projects with federally tax-exempt financing. Third, trends, such as increased demands for other environmental infrastructure, local and state tax and expenditure limitations, and difficulties in accessing national capital markets, hindered some financial packages.

During the 1980s the federal government imposed new restrictions on the types of local debt that could qualify for federal tax-exempt status and placed unified volume caps on each state's allotment of tax-exempt private-activity bonds. In order to qualify as tax-exempt bonds under TRA86, the bonds must be classified as (1) governmental bonds (on which there are no limits), or (2) privateactivity bonds that are also "qualified bonds" for solid and hazardous waste facilities (which are subject to unified volume caps). Governmental bonds have their down side in that the municipality must retain an almost proprietary interest in the facility, forego its share of the tax benefits, and observe the restrictions on private use of facilities imposed by TRA86. And in order to be classified as "qualified bond," a host of restrictions must be met. To the extent that tax-exempt bonds cannot be used to finance WTE facilities, the total cost of project financing will be higher.

The higher cost of facilities and restrictions on tax-exempt financing came at a time local governments faced other environmental expenditures. Further escalations in local environmental expenditures are expected. Although capital markets can accommodate this increased demand, large capital-intensive environmental projects can crowd out other local investments. The extremely large 
capital outlays required for some WTE facilities may force some communities to make hard decisions about where they allocate their limited credit lines. Communities may be forced to make tradeoffs between funding environmental infrastructure and more traditional activities, such as housing and education.

Although financial problems exist, this study finds that, in general, municipalities are successfully adjusting to altered financial conditions by taking a four-pronged approach to finance WTE projects. First, local jurisdictions are using a combination of several financing mechanisms in their financial packages. Second, jurisdictions are increasingly using local-sector resources for financing (e.g., city and county revenues and taxable revenue bonds). Third, -as traditional debt options become less viable because of restrictions imposed by, for example TRA86, innovative and new methods of finance are being used. Fourth, private-sector participation is being used more extensively. Private-sector participation allows local-sector resources to be reallocated elsewhere for other public good consumption.

In terms of the impacts of financial changes on WTE project cancellations, the results are somewhat mixed. Study findings show that most successful WTE projects utilize multiple and innovative forms of finance. Innovative methods of finance were not present in any of the financial packages put together or considered for facilities that were eventually cancelled. It is unclear, however, if the absence of multiple and innovative financing mechanisms was a contributor to the failure of the projects, or if these projects simply did not get far enough down the development path to consider these innovate and possibly less obvious financing strategies. To the extent that public opposition arose to the WTE project on the basis of increased financial risk to the community, the absence of innovative approaches, which are designed primarily to lower the community's level of financial risk, may have played a role in project cancellation. An analysis of the available data shows that a large share of the proposed financing for abandoned projects was to be public financing. 
The unified volume caps may also have hindered WTE project- development, but the magnitude of the problems those caps imposed is not clear. For example, six of the nine states that contributed more than 49 percent of all WTE project cancellations came close to fully using their caps; and more than $\$ 750$ million in solid-waste financing requests were denied in 1991 as a result of the unified volume caps. However, some states that had several cancellations did not use a high percentage of their aliowed caps.

The fundamentals of the long-term bond market are expected to be generally positive over the next decade, and, therefore, capital markets should show little strain in funding future expenditures for local environmental projects, such as WTE. The problem is whether local jurisdictions will have the financial ability and, in some cases, the political will to take on higher levels of debt burden. Large, capital-intensive WTE facilities can crowd out other local investments, and some small communities may face obstacles in accessing capital markets.

On the positive side, innovative financial instruments are increasingly available that overcome to some extent the financial obstacles imposed during the 1980s. Adjustments on the parts of capital markets and communities to new financial realities are likely to improve the financial viability of capital-intensive projects, such as WTE facilities. Although financing constraints will continue to be problematic, especially for those communities with questionable credit ratings, financial constraints are not expected to severely limit the overall viability of WTE during the 1990 s.

\subsection{CASE STUDY RESULTS}

Our aggregate analyses of socioeconomic and financial conditions do not draw strong conclusions about differences between communities that begin a WTE project and follow that project through to completion and communities that abandon a project somewhere in the planning process. Socioeconomic parameters do not differ markedly between the two groups; and while certain financial 
trends do seem to be partially responsible for the increased rate of project abandonment in the late 1980s, financial constraints do not appear to be the primary force motivating project cancellations. The major challenge faced by proponents, as well as opponents, of WTE may be obstacles that arise in the decision-making process itself.

To better understand the process by which communities make decisions about WTE and identify factors that may contribute to project cancellation, this study undertook four in-depth case studies. At two sites-Oakland County, Michigan and Broward County, Florida-a WTE project was approved, and in the case of Broward County two WTE facilities are now operational. At the two other sites-Monmouth County, New Jersey and Knox County, Tennessee-planned WTE facilities were cancelled. Questions of particular interest in the case studies included the sequence of decision events; the participation of different groups in different steps of the decision process; the degree of agreement at each decision step; the effects of mitigation and compensation at different stages of implementation; the effectiveness of different siting procedures; public attitudes about WTE technologies, costs, and environmental impacts; and any difficulties that may arise when several governmental jurisdictions are forced to cooperate or form compacts to site a facility.

Several general findings result from the case studies. In general terms, the decision to accept or reject a project does not fall neatly into simple "acceptance" or "rejection" categories. There are degrees of acceptance and rejection. At one extreme is Broward County, where WTE was clearly accepted and two facilities are now operational. Oakland County's mandate to proceed with WTE implementation is less clear. Although a public referendum narrowly approved WTE use, municipalities have failed to sign intergovernmental agreements committing their waste to the county's system. Further, the county currently has no construction and service vendor due to the recent withdrawal of Westinghouse. Monmouth and Knox Counties rejected WTE, but at different stages and in different ways. In Monmouth County, voters rejected a WTE proposal by a very small 
margin-about the same as the margin by which Oakland Country accepted their project. The Knox County project ended when Knoxville's mayor withdrew his support shortly before bond issuance.

The timing of project initiation and implementation, as well as changes occurring on a national level during the $1980 \mathrm{~s}$, affected the decision-making process at each of the study sites. For example, the Broward County project began in 1982, fully three years before the other case-study projects were initiated and before the recycling ethic swelled in the mid-to-late 1980s. As a result, one area of controversy at other sites-competition between recycling and WTE for a limited waste stream-was not an issue at Broward until late in project implementation. Also, national environmental groups, such as Greenpeace and the Sierra Club (Sierra Club 1986, 1992) adopted anti-incineration stances, and national health organizations, such as the American Lung Association (ALA/ATS Government Relations Position, 1984) expressed serious concerns about solid waste combusion in the mid-to-late 1980s. Anti-incineration activists began to campaign nationwide, visiting numerous sites and establishing networks of local activists. These activities influenced the decision-making process at the three sites initiated in 1985 and after.

Although comparisons between case studies were made largely in the context of the outcome of the decision-i.e., whether or not to proceed with the project-attention was also paid to the decision-making process itself. Examining the decision-making process does not presuppose that either WTE acceptance or rejection is the more desired outcome. It does, however, provide insights into process factors that influence the final WTE decision, even though any one factor affecting the decision-making process may not lead to consistent outcomes.

While our small sample size does not support strong conclusions about the WTE population as a whole, the following preliminary findings do stand out. First, selecting among ownership options and negotiating with vendors to provide services were arduous and some of the most time-consuming aspects of decision making at the case-study sites. However, facility ownership apparently was not 
a strong factor affecting the outcome of the decision making process.

Second, the size of the proposed facility relative to the size of the waste stream was a significant decision-making factor. Sizing decisions have implications not only for facility costs; they also have important implications for public acceptance of WTE because of resultant opportunities for waste importation and actual or perceived effects on other waste management methods, especially recycling. Study findings do suggest that the timing of WTE implementation relative to other waste reduction and recycling programs were factors affecting WTE decision making.

Third, case study comparisons indicate that there is no clear link between siting activities or site characteristics and the outcome of WTE decision making. For example, systematic site identification processes were undertaken by Broward County, where WTE was accepted, and by Knox County, where WTE was rejected. Both Oakland County and Monmouth County offered considerable financial compensation to the host communities, yet WTE was rejected at Monmouth. Further, though siting literature suggests that a technically correct, systematic, and comparative siting process is essential to siting a WTE facility, case-study siting activities suggest that a participant can be satisfied that a proposed site is technically and environmentally suitable in the absence of multi-site comparisons.

Fourth, there were clear differences between Broward and the other case-study sites in the types of interaction that occurred and the level of agreement among participants. Broward's negotiations with its member municipalities occurred against a backdrop of generally satisfactory past relations with its municipalities and a tradition of interaction with the Broward League of Cities. In contrast, for example, Knox County and Knoxville have had a troubled relationship. None of the case-study counties' member municipalities were completely supportive of the WTE project, and patterns of mistrust that resulted from unrelated matters were found to affect WTE planning. 
Fifth, having state-level support for WTE apparently influences WTE decisions. WTE planners and decision makers attempt to follow state guidelines for solid waste management whether or not the guidelines are encoded as law. As a result, state positions supporting WTE (often expressed as goals) facilitate WTE adoption at the local level. Complete or partial withdrawal of state support for WTE slows the decision-making process when permits are delayed or moratoria are enacted. Also, the public may be swayed by the positions of state governments because the public may perceive state staff to be better trained and more qualified than local government staff. Likewise, having constant and near unanimous support from county officials significantly influences the decision-making outcome.

Sixth, perception of need for waste management capacity is likely to have contributed to agreement in Broward County. Closure of the county landfill and projections of continuing population growth may have made Broward's decision makers and the public perceive a dire need for a WTE facility. At the other sites the public perceived no such urgency and urged decision makers to delay action.

Seventh, case-study respondents uniformly agreed that the public must be informed about solid waste management issues and activities early in the planning process. There were strong, though not unanimous, recommendations for improving the decision-making process by involving the public, but few concrete suggestions about how this might be accomplished. Facilitating public participation in the decision-making process will not produce uniform decisions to adopt WTE, a point acknowledged by all respondents. However, dissatisfaction with decision-making that generally excludes or makes public participation difficult, exacerbates opposition to the decision.

Eighth, the case studies uncovered evidence that state and federal regulations affecting financing and MSW management planning hastened project activities at each study site. For example, both Broward and Knox Counties hastily issued bonds to take advantage of soon-to-expire tax-exempt 
status. Monmouth County rushed to execute a power sales agreement before state reinterpretation of PURPA would significantly reduce revenues available from power sales. However, decisions about proceeding with WTE facilities at the case-study sites appear to have been unaffected by the uncertain environmental regulatory environment.

Finally, the general solid waste management experience of sites where WTE has been accepted differs from that where WTE was rejected. It may be that alone none of the contextual factors at sites where WTE was accepted-e.g., contaminated landfills, experience with waste combustion, and limited opportunities for waste exportation-are significant enough to affect WTE decisions. In concert, however, the occurrence of these factors at case-study sites where WTE has been accepted suggests that such experience positively influences acceptance of WTE.

\subsection{SUMMARY CONCLUSIONS}

Although the conclusions of this study are numerous and varied, several summary findings are particularly significant in the assessment of WTE project cancellations. First, on the basis of our aggregate socioeconomic analysis, there are marked differences between communities that initiate a WTE project and those communities that have not yet considered WTE. Socioeconomic differences do not, however, correlate with the decision to either proceed with or cancel a WTE project. Second, the study's financial analysis identifies several trends that made WTE financing more difficult in the latter $1980 \mathrm{~s}$; but that analysis does not conclude that financial barriers were the predominant reason for WTE project cancellations, nor are those financial constraints likely to be major obstacles to WTE development in the coming decade. Third, the case studies identify numerous complexities that community leaders and decision-makers must address when making a decision about WTE or most other methods to manage municipal waste. Once a WTE project has been initiated, the decision to proceed with or abandon that project appears to depend largely on the dynamics of the 
decision-making process and the interactions of concerned parties. Future research should build upon case studies conducted thus far to identify methods to assist communities in making decisions about MSW management options. 


\section{BIBLIOGRAPHY}

ALA/ATS 1984. American Lung Association/American Thoracic Society Government Relations Position. Waste Disposal or Reuse. December 7.

Blumberg, Louis and Robert Gottlieb, 1989. War on Waste: Can America Win Its Battle with Garbage? Island Press, Washington, D.C.

Buhler, Franchot, 1987. "Energy from Municipal Waste: Siting Considerations." In Energy from Solid Waste: An Option for Local Government. Kentucky Energy Cabinet, Louisville, Kentucky, pp. $45-49$.

Bullard, Robert D., 1990. Dumping in Dixie: Race, Class, and Environmental Quality. Westview Press, Boulder, Colorado.

Chertoff, Lawrence and Diane Buxbaum, 1986. "Public Perceptions and Community Relations." In William D. Robinson (ed.): The Solid Waste Handbook, John Wiley \& Sons, New York.

Commission for Racial Justice, 1987. Toxic Wastes and Race in the United States: A National Report on the Racial and Socio-Economic Characteristics of Communities with Hazardous Waste Sites. United Church of Christ, New York.

CSWS (Council for Solid Waste Solutions), 1991. "Communities with Access to PET Recycling." Data base, Washington, D.C., November.

Edwards, Melissa, 1991. "Solid Waste Incineration." Waste Management Research and Education Institute, The University of Tennessee, Knoxville, Tennessee, December 1990.

Environmental Financial Advisory Board, 1991a. Private Sector Incentives Advisory, Washington, D.C., January 30.

Environmental Financial Advisory Board, 1991b. Private Sector Participation in the Provision of Environmental Services: Barriers and Incentives. Washington, D.C., October 29.

Environmental Financial Advisory Board, 1991c. Public Sector Options to Finance Environmental Facilities. Washington, D.C., November 25.

Environmental Financial Advisory Board, 1991d. Small Community Financing Strategies for Environmental Facilities, Washington, D.C., August 9.

Federal Register, 40 CFR Parts 51, 52, and 60. Standards of Performance for New Stationary Sources and Final Emission Guidelines; Final Rules.

Federal Register, 40 CFR Part 60. Emission Guidelines: Municipal Waste Combustors.

Federal Register, 40 CFR Part 81, Air Quality Designations and Classifications; Final Rule. 
Federal Register, 40 CFR Parts 257 and 258. Solid Waste Disposal Facility Criteria; Final Rule.

Federal Reserve Bulletin, 1965-1990. Board of Governors of the Federal Reserve System, Washington, D.C.

General Accounting Office, 1983. Siting of Hazardous Waste Landfills and Their Correlation with Racial and Economic Status of Surrounding Communities. GAO/RCED-93-168, June 1.

Glenn, J., 1991. "Sorting the Mix at Materials Recovery Facilities." BioCycle, Vol. 32, No. 7, pp. 30-37.

Glenn, J. and D. Riggle, 1991a. "The State of Garbage in America." BioCycle, Vol. 32, No. 4, pp. 34-38.

Glenn J. and D. Riggle, 1991b. "The State of Garbage in America, Part I." BioCycle, Vol. 32, No. 5, pp. 30-35.

Gold, Steven D., 1991. "Changes in State Government Finances in the 1980s." National Tax Journal Vol. 44, No. 1, pp. 1-19.

Government Advisory Associates. 1982, 1984, 1986-87, 1988-89, 1991. Resource Recovery Yearbooks, New York.

Hall, B. and Mary Lee Kerr, 1991. 1991-1992 Green Index: A State-by-State Guide to the Nation's Environmental Health. Island Press, Washington, D.C.

Institute for Participatory Planning, 1981. Citizen Participation Handbook for Public Officials and Others Serving the Public (4th ed.). Laramie, Wyoming.

Jones, R.E. and Riley E. Dunlap, 1992. "The Social Bases of Environmental Concern-Have They Changed Over Time." Rural Sociology. Vol. 57, No. 1, pp. 28-47.

Kelsay, Michael, 1992. Data on Financing of Waste-to-Energy Facilities. Collected for use in his $\mathrm{Ph} . \mathrm{D}$. dissertation, University of Tennessee, Department of Economics (dissertation in progress).

Kiser, Jonathan V.L. 1992. Municipal Waste Combustion in North America: 1992 Update. Waste Age 23 (11):26-36.

Kiser, Jonathan V.L. Status of Municipal Waste Combustion in the United States: 1991 Update. Waste Age 22 (11).

Konheim Carolyn S., 1989. "Communicating with the Public About Risks." Solid Waste \& Power, Vol. 3, No. 3, pp. 36-44.

Luderer, Lynn M., 1990. Communicating with the Public about Environmental Health Risks: A Case Study of Waste-To-Energy. DOE/RR/05/106-T146. U.S. Department of Energy. 
Milbrath, Lester W., 1984. Enviomomentalists: Vanguard for a New Society. State University of New York Press, Albany.

Popp, Paul O., Norman L. Hecht, and Rick E. Melberth, 1985. Decision-Making in Local Government: The Resource Recovery Alternative. Technomic Publishing Company, Lancaster, Penn.

Sierra Club 1986. "Solid Waste Management." Sierra Club Policy. San Francisco, CA.

Sierra Club 1992. "Municipal Solid Waste Management." Sierra Club Policy. San Francisco, CA.

Syme, Geoffrey J. and Elizabeth Eaton, 1989. "Public Involvement as a Negotiation Process." Journal of Social Issues. Vol. 45, No. 1, pp. 87-107.

Terleckyj, N. E. and C. D. Coleman, 1990. Regional Economic Growth in the United States: Projections for 1991-2010. 1990 Regional Economic Projections Series, Volume III. NPA Data Services, Inc. Report Number 90-R-3. Washington, D.C.

U.S. Bureau of the Census, 1988. County and City Data Book, 1988. Washington, D.C.: U.S. Government Printing Office.

U.S. Bureau of the Census, 1991. County Government Finances: 1989-90, Series GF/90-8. U.S. Government Printing Office, Washington, D.C.

U.S. Bureau of the Census, 1992. 1990 Census of Population and Housing, Summary Tape File 1A. CD ROM.

U.S. EPA, 1989. Decision Maker's Guide to Solid Waste Management. Office of Solid Waste.

U.S. EPA, 1990a. Characterization of Municipal Solid Waste in the United States: 1990 Update. EPA/530-SW-90-042, prepred by Franklin Associates, Ltd.

U.S. EPA, 1990b. Sites for Our Solid Waste: A Guidebook for Effective Public Involvement. Office of Solid Waste.

U.S. EPA 1992, Characterization of Municipal Solid Waste in the United States: 1992 Update, prepared by Franklin Associates, Ltd., July, Final Report.

Zimmerman, Dennis, 1991. The Private Use of Tax-Exempt Bonds. The Urban Institute Press, Washington, D.C. 


\begin{tabular}{|c|c|c|c|}
\hline $\begin{array}{l}\text { Document Control } \\
\text { Page }\end{array}$ & $\begin{array}{l}\text { 1. NREL Report No. } \\
\text { NREL/TP-430-5694 }\end{array}$ & $\begin{array}{l}\text { 2. NTIS Accession No. } \\
\text { DE93018226 }\end{array}$ & 3. Recipient's Accession No. \\
\hline \multirow{2}{*}{\multicolumn{3}{|c|}{$\begin{array}{l}\text { 4. Title and Subtitie } \\
\text { Waste-To-Energy in the United States: Socioeconomic Factors and the Decision- } \\
\text { Making Process }\end{array}$}} & $\begin{array}{l}\text { 5. Publication Date } \\
\text { October } 1993\end{array}$ \\
\hline & & & 6. \\
\hline \multicolumn{3}{|c|}{$\begin{array}{l}\text { 7. Author(s) } \\
\text { T. Randall Curlee, Susan M. Schexnayder, David P. Vogt, Amy K. Wolfe, } \\
\text { Michael P. Kelsay, David L. Feldman }\end{array}$} & $\begin{array}{l}\text { 8. Performing Organization Rept. No. } \\
\text { TP-430-5694 }\end{array}$ \\
\hline \multirow{2}{*}{\multicolumn{3}{|c|}{$\begin{array}{l}\text { 9. Performing Organization Name and Address } \\
\text { National Renewable Energy Laboratory } \\
1617 \text { Cole Blvd. } \\
\text { Golden, Colorado } 80401-3393\end{array}$}} & $\begin{array}{l}\text { 10. Project/Task/Work Unit No. } \\
\text { WM31.1010 }\end{array}$ \\
\hline & & & $\begin{array}{l}\text { 11. Contract (C) or Grant (G) No. } \\
\text { (C) DA-1-1 1246-1 } \\
\text { (G) }\end{array}$ \\
\hline \multirow{2}{*}{\multicolumn{3}{|c|}{$\begin{array}{l}\text { 12. Sponsoring Organization Name and Address } \\
\text { National Renewable Energy Laboratory } \\
1617 \text { Cole Blvd. } \\
\text { Golden, CO } 80401-3393\end{array}$}} & $\begin{array}{l}\text { 13. Type of Report \& Period Covered } \\
\text { Subcontract report }\end{array}$ \\
\hline & & & 14. \\
\hline \multicolumn{4}{|c|}{$\begin{array}{l}\text { 15. Supplementary Notes } \\
\text { NREL technical monitor: Philip Shepherd, (303)231-7000, ext.7829 }\end{array}$} \\
\hline \multicolumn{4}{|c|}{$\begin{array}{l}\text { This study takes an in-depth look at the socioeconomic factors that have played a role in the decisions of communities that } \\
\text { bave considered WTE as a component of their solid waste management strategies. More specifically, a three-pronged } \\
\text { approach is adopted to investigate (1) the relationships between a municipality's decision to consider and acceptreject WTE } \\
\text { and key socioeconomic parameters, (2) the potential impacts of recent changes in financial markets on the viability of WTE, } \\
\text { and (3) the WTE decision-making process and the socioeconomic parameters that are most important in the municipality's } \\
\text { decision. The first two objectives are met by the collection and analysis of aggregate data on all U.S. WTE initiatives during } \\
\text { the } 1982 \text { to } 1990 \text { time frame. The latter objective is met by way of four in-depth case studies-two directed at communities } \\
\text { that have accepted WTE and two that bave cancelled WTE projects. }\end{array}$} \\
\hline $\begin{array}{l}\text { 17. Document Analysis } \\
\text { a. Descriptors } \\
\text { municipal wast } \\
\text { b. Identifiers/Open- } \\
\text { c. UC Categories } \\
249\end{array}$ & vaste to energy & & \\
\hline \multirow{2}{*}{\multicolumn{3}{|c|}{$\begin{array}{l}\text { 18. Availability Statement } \\
\text { National Technical Information Service } \\
\text { U.S. Department of Commerce } \\
5285 \text { Port Royal Road } \\
\text { Springfield, VA } 22161\end{array}$}} & $\begin{array}{l}\text { 19. No. of Pages } \\
159\end{array}$ \\
\hline & & & $\begin{array}{l}\text { 20. Price } \\
\text { A08 }\end{array}$ \\
\hline
\end{tabular}

Form No, 0069E (6-30-87) 